


\section{DISCLAIMER}

This report was prepared as an account of work sponsored by an agency of the United States Government. Neither the United States Government nor any agency Thereof, nor any of their employees, makes any warranty, express or implied, or assumes any legal liability or responsibility for the accuracy, completeness, or usefulness of any information, apparatus, product, or process disclosed, or represents that its use would not infringe privately owned rights. Reference herein to any specific commercial product, process, or service by trade name, trademark, manufacturer, or otherwise does not necessarily constitute or imply its endorsement, recommendation, or favoring by the United States Government or any agency thereof. The views and opinions of authors expressed herein do not necessarily state or reflect those of the United States Government or any agency thereof. 


\section{DISCLAIMER}

Portions of this document may be illegible in electronic image products. Images are produced from the best available original document. 


\section{NOTICE}

This report was prepared as an account of work sponsored by the United States Government. Neither the United States nor the United States Department of Energy, nor any of their employees, nor any of their contracturs, subcuntractors, or their employees, makes any warranty, express or implied, or assumes any legal liability or responsibility for the accuracy, completeness or usefulness of any information, apparatus, product or process disclosed, or represents that its use would not infringe privately owned rights.

This report has been reproduced directly from the best available copy.

Available from the National Technical Information Service, U.S. Department of Commerce, Springfield, Virginia 22161.

Price: Paper Copy $\$ 4.75$

Microfiche $\$ 3.00$ 


\title{
RESEARCH, DEVELOPMENT, AND DEMONSTRATION \\ FOR ENERGY CONSERVATION: PRELIMINARY IDENTIFICATION \\ OF OPPORTUNITIES IN IRON AND STEELMAKING
}

\author{
Prepared by \\ ARTHUR D. LITTLE, INC. \\ CAMBRIDGE, MASSACHUSETTS
}

DOE CONTRACT NO. EC-77-C-03-1692

\section{DIVISION OF INDUSTRIAL ENERGY CONSERVATION DEPARTMENT OF ENERGY WASHINGTON, D.C.}

JANUARY, 1978 


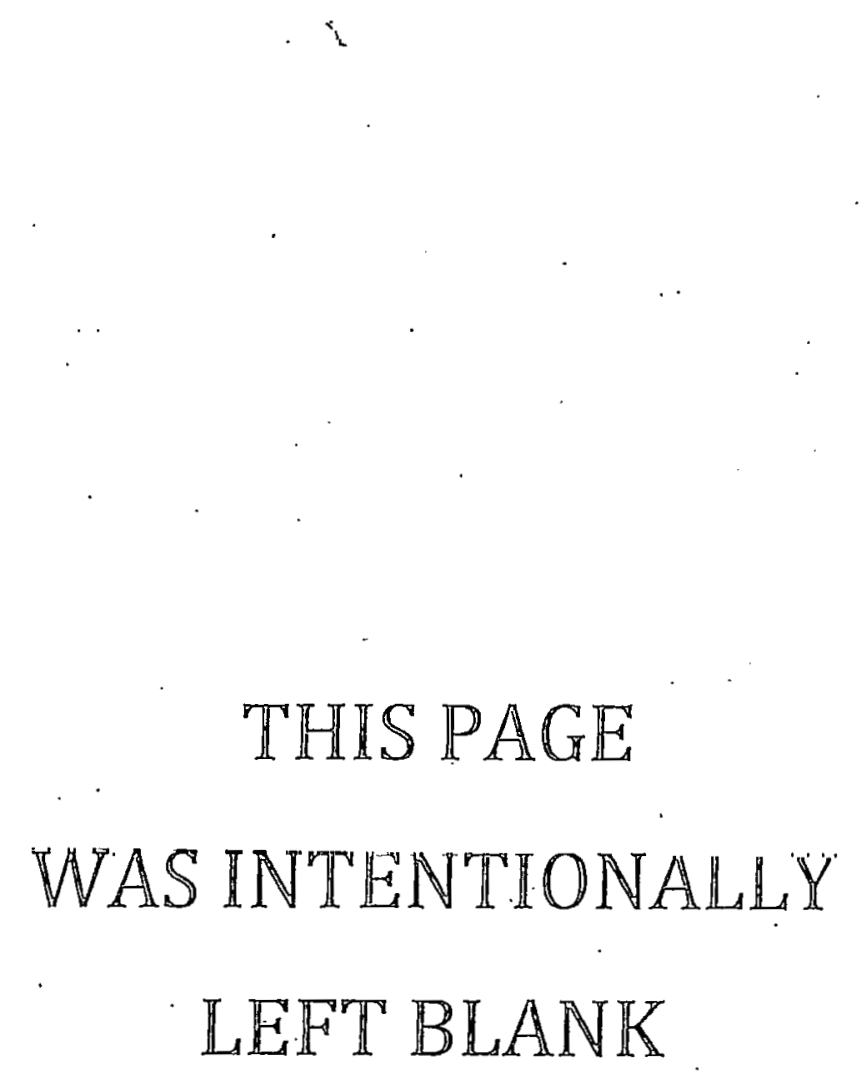




\section{TABLE OF CONTENTS}

I. SUMMARY

$$
\begin{array}{r}
\text { Page } \\
\text { I - } 1
\end{array}
$$

A. Objectives I-1

B. Findings I-1

II. BACKGROUND II 1

A. Industry Characteristics II-1.

B. Energy Use in the Iron and Steel Industry II-2

C. Industry Trend and the Role of Scrap II-8

III. APPROACH III-1
A. Scope
I I -1
B. Cost Benefit Methodology.
II -3
C. Energy Value of Scrap
I I I -3

IV. OVERVIEW AND GENERIC ENERGY CONSERVATION OPPORTUNITIES

$$
\begin{aligned}
& I V-1 \\
& I V-1 \\
& I V-2 \\
& I V-4
\end{aligned}
$$

A. Overview

B. Energy Balance within a steel Plant

V. MINING, MILLING, BENEFICIATION, AND AGGLOMERATION

$$
\begin{aligned}
& v-1 \\
& v-1 \\
& v-1 \\
& v-4 \\
& v-5 \\
& v-9
\end{aligned}
$$$$
\text { A. The U.S. Iron Ore Industry }
$$$$
\text { B. Iron Ore Mining }
$$$$
\text { r. Milling }
$$$$
\text { D, Crushing and Grinding }
$$

E. Agglomeration 
TABLE OF CONTENTS (Cont'd.)

VI. COKEMAKING

$$
\begin{aligned}
& \text { Page } \\
& V I-1 \\
& V I-1 \\
& V I-3 \\
& V I-4 \\
& V I-7 \\
& V I-8 \\
& V I I-1 \\
& V I I-1 \\
& V I I-18 \\
& V I I-27 \\
& V I I-31
\end{aligned}
$$

A. Background VI-1

B. Coal Preheating VI-3

C. Dry Coke Quenching VI-4

D. Coal Car. Thawing VI-7

E. Formea coke VI-8

VIİ. IRON AND STEEIMAKING VII-1
A. Blast Furnace
B. Basic Oxygen Furnace
C. Scrap-Based Processes
D. Direct Reduction

VIII. STEELCASTING - - INGOTS, BILLETS, BLOOMS AND SLABS

VIII -1
A. Conventional Technology
VIII -1
B. Continuous Casting
$V I I I-1$

IX. STEELFORMING

I $X-1$

A. Soaking Pits and Reheat Furnaces

I $X-1$

B. Heat Treating Furnaces

I X -19

C. Role of Government Funding of $R, D \& D$

$I X-23$

X. OTHER ENERGY CONSERVATION OPPORTUNTTIES

$\dot{x}-1$
A. Better sensors, Instrumentation, and controls
$x-1$
B. Improved Burners
$x-1$ 
TABLE OF CONTENTS (COnt.d.)

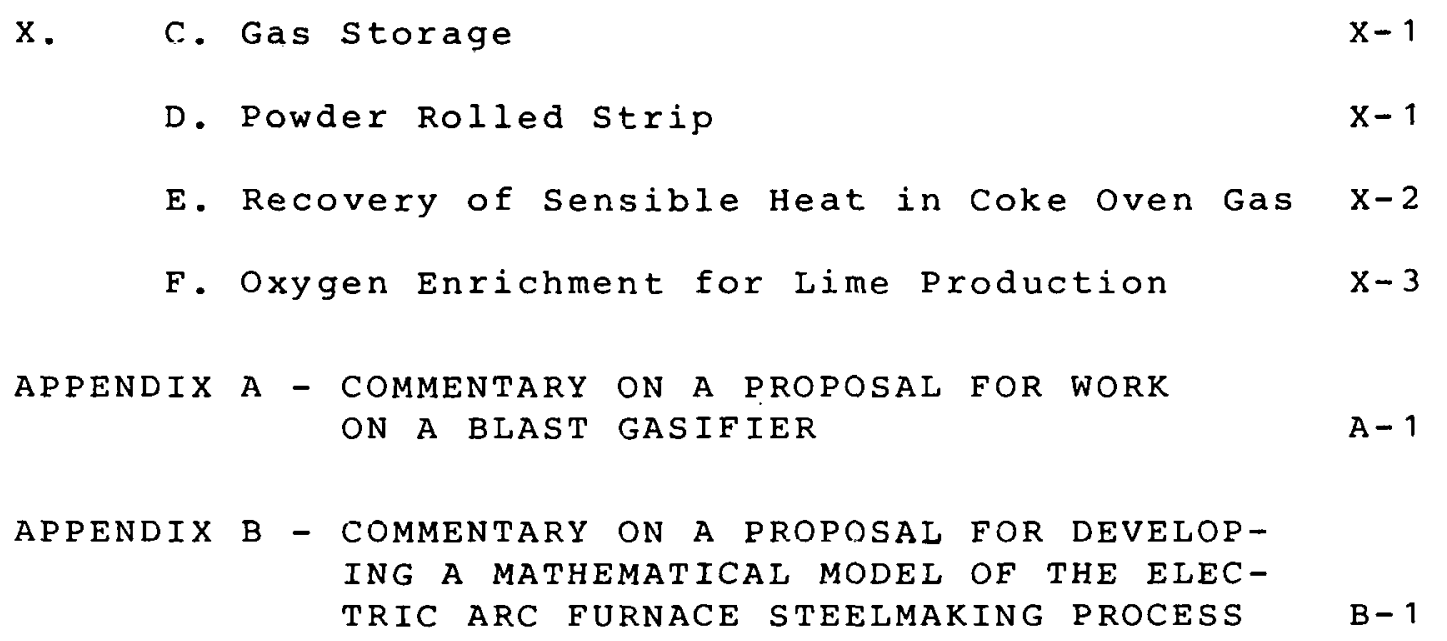




\section{THIS PAGE}

\section{WAS INTENTIONALLY LEFT BLANK}




\section{LIST OF TABLES}

\begin{tabular}{|c|c|c|}
\hline Table No. & Title & Page \\
\hline$I-1$ & $\begin{array}{l}\text { Major Energy Conservation opportunities } \\
\text { for Engineering Development in Iron and } \\
\text { steelmaking }\end{array}$ & $I-3$ \\
\hline$I-2$ & $\begin{array}{l}\text { Examples of other Energy Conservation } \\
\text { opportunities in the Iron and steel } \\
\text { Industry }\end{array}$ & $I-5$ \\
\hline$I-3$ & $\begin{array}{l}\text { Other Major Energy Conservation opportuni- } \\
\text { ties Useful to the Iron and steel Industry }\end{array}$ & $y \quad I-6$ \\
\hline I I - 1 & $\begin{array}{l}\text { National Energy Consumption in the steel } \\
\text { Industry - - By Fuel Type }\end{array}$ & I I - 10 \\
\hline I I I - 1 & $\begin{array}{l}\text { Scrap Use and Energy Equivalent - EAF } \\
\text { Versus BOF }\end{array}$ & I I I - 5 \\
\hline IV -1 & $\begin{array}{l}\text { Consumption of Energy by the U.S. Steel } \\
\text { Industry }\end{array}$ & IV -1 \\
\hline I V -2 & $\begin{array}{l}\text { Utilization of Fuels by the U.S. Steel } \\
\text { Industry by consuming sector, } 1976\end{array}$ & I V - 3 \\
\hline$V-1$ & $\begin{array}{l}\text { U.S. Iron Ore Mine Production and Total } \\
\text { Shipments in } 1976\end{array}$ & $v-2$ \\
\hline$v-2$ & Major Producers of Iron ore in 1976 & $V-3$ \\
\hline$v-3$ & U.S. Pelletizing Plants & $v-11$ \\
\hline$V I I-1$ & $\begin{array}{l}\text { Origin and Quantity of Recoverable Mater- } \\
\text { ials from Flue Dusts and Mill Scales in } \\
\text { the U.S. Iron and steel Industry, } 1972\end{array}$ & $V I I-5$ \\
\hline$V I I-2$ & $\begin{array}{l}\text { Potential Energy Recovery from Expansion } \\
\text { Turbines }\end{array}$ & $V I I-12$ \\
\hline VI I - 3 & $\begin{array}{l}\text { Cost structure in New Complete-Combustion } \\
\text { system }\end{array}$ & $V I I-22$ \\
\hline VII -4 & $\begin{array}{l}\text { Cost structure in New suppressed- } \\
\text { Combustion system }\end{array}$ & $V I I-23$ \\
\hline$V I I-5$ & $\begin{array}{l}\text { Retrofit to shop with Existing suppressed- } \\
\text { Combustion Hood system }\end{array}$ & $V I I-25$ \\
\hline$V I I-6$ & $\begin{array}{l}\text { Energy Requirements of the Conventional } \\
\text { and Direct Reduction steelmaking Routes }\end{array}$ & VII -33 \\
\hline
\end{tabular}


Table No.

Title

Page

IX-1 Estimated Capacities of U.S. Steel Industry Soaking $P$ its and Reheating Furnaces IX-3

IX-2 Heating Temperatures and Energy Consumption in Soaking Pits, Reheating Furnaces, and Annealing Furnaces

I $x$

Energy Efficiency of Soaking Pits and Reheat Furnaces in the U.S. Steel Industry IX-5

$I X-4$

Energy Consumption in Reheat and Annealing Furnaces in the United States, 1976

$I X-5$

$\mathrm{IX}-5$

Estimated Capacities of U.S. Heat Treating Furnaces

IX -20

Ix-6 Annealing Temperatures and Energy Consumption

IX -7

Summary of Energy Savings, Probability of Success, Retrofitting Potential, and Time Required for Commercialization of Concept 
Geographical Distribution of the Iron and steel Industry

Process Unit Interrelationships

$I I-5$

$I I-3$

Estimated U.S. Level-1 Energy Consumption by Major Process Units in 1976

Energy Consumption for U.S. Steel Products in 1976

Energy Recovered by Air Preheating, Expressed as Relative Savings of No. 6 Fuel oil

$\mathrm{IV}-5$

V-1

Typical Milling of Taconite ore

$\mathrm{V}-7$

$\mathrm{V}-2$

Grate-kiln Pelletizing Plant

$V-12$

$V I-1$

Dry Coke Quenching systems

$\mathrm{VI}-5$

$V I-2$

FMC Formcoke Process

$V I-9$

$\mathrm{VI}-3$

Consol-BNR Formed Coke Process

$V I-10$

$V I-4$

BFL Formed Coke Process

$\mathrm{VI}-11$

VII -1

Amanda coal Injection - - Low-Pressure Air system Plus Coal Pulverizing/Collecting

VI I - 2

VII -2

Amanda Pressurized Coal Injection System

VII - 3

VII -3

Fvaporative cooling system

VII - 10

VII -4

Blast Furnace Gas Cleaning system with Energy Recovery Turbine

Schematic of BOF Off-Gas Recovery system

$I X=1$

Stages at. which soaking pits, Reheat Furnaces, and Annealing Furnaces are Used in a Steel Mill

I X -2

I X -2

Energy Recovered by Air Preheating, Expressed as Relative Savings of No. 6 Fuel oil 


\section{SUMMARY}

\section{A. OBJECTIVES}

The Federal Government has initiated, expanded, and is accelerating a cost-shared program with the iron and steel irdustry to develop innovative, cost-effective programs for new energysaving technologies. If successful, such technologies would significantly reduce the industry's dependence or all forms of energy, particularly on natural gas and liquid fuels. The purpose of this document is to identify opportunities for research and development in the iron and steel industry, giving due consideration to the many barriers that impede the implementation of new technology. These technology sectors also reflect the following three fundamental criteria that DOE has formulated to guide the selection of projects for consideration in this program:

- The project must have the potential to save energy. While emphasis here is on saving natural gas and liquid fuels, reducing the consumption of metallurgical coal and coke is also considered important.

- The project must be considered cost-effective when fully developed.

- When fully developed, the project must be considered reliable and have no negative effect on capacity.

Concepts that we have considered for commercial development have been selected because of their significant potential for conserving energy and/or critical fuel forms and on the assumption that they would involve:

- Preparation of proposals by or in conjunction with companies associated with the steel industry, to ensure the practicality of the concept in a steelmaking environment;

- Cost sharing with companies associated with the steel industry; and

- Demonstration of technology that would provide an option for the iron and steel industry to be less dependent on natural gas and distillate fuels.

In addition, the program is aimed at stabilizing employment and increasing U.S. strategic security.

\section{B. FINDINGS}

Using metallurgical coals for cokemaking and steam coal for electric power generation, it is feasible to build energy-efficient integrated iron and steel facilities. Since the 1950's and 1960's, however, natural gas and liquid fuels have been available at low cost and have furnished about a fourth of the iron and steel industry's energy needs; the remaining energy is provided by coal and purchased electric power. There are no readily implementable solutions for converting existing integrated steel plants from natural gas or liquid fuels wholly to coal.

Technical development efforts undertaken by industry are generally directed toward resolving problems of immediate urgency in current production, process engineering impiovements for 
cost reduction, or market-oriented process and product development. Since many energy-saving concepts in the iron and steel industry appear to be economically marginal at present, efforts at developing them have not received primary emphasis. Moreover, unless it is mandated by current legislation, industry representatives question whether energy costs will increase faster than capital costs if the price of natural gas and fuel oils remains at $\$ 2.00$ to $\$ 2.50$ per million Btu in 1978. To make major expenditures on the assumption that these fuel costs will significantly outpace inflation is, in industry's mind, a risk that it is unprepared to take.

Accordingly, we believe that few programs with large energy-conserving potential will be undertaken and pursued to completion within the near term without some form of government incentives. However, the iron and steelmaking industry does have the resources and facilities to conduct many of these programs, given the stimulation of direct program support and indirect incentives for implementation. Should technically sound and economically viable concepts bc supported in part by government funding, the time frame for their commercial implementation would prohahly he suhstantially shortened.

In general, the iron and steel industry is seeking process technology that has been successfully demonstrated under U. S. conditions, in order to minimize the technical and economic risk. Once an energy-saving technology has been shown to be practicable, we believe il will be of considerable interest to the industry, especially when a new facility is built or an obsolete facility is replaced.

Table 1-1 lists some general concepts and related specific examples of technologies which we believe have the greatest potential for energy conservation in the next decade. Approximate costs of commercial demonstration and a rough indication of the total funds needed for demonstrating the technologies are also shown. Of the concepts listed, the greatest energy-saving impact would be achieved by the following:

- Improved reheating furnaces, which today are generally dependent upon gaseous and liquid fuels.

- Improvements to the blast furnace process. Even small incremental gains here could have large overall energy savings because of the tremendous amount of energy consumed nationally by blast furnaces. Although these furnaces are-already being run at quite high efficiencies, there are potential improvements. The difficulty is that many experimental tests cannot be justified by an individual steel plant, because they might jeopardize production.

- Development of a low-cost, economical, clean fuel gas generator or burner based upon coal. Such a device could have a variety of applications: underfiring of coke uvens, use in rehcating ovens, infection into the blast lurnace, etc.

- Greater use of scrap, to the extent that it is available.

- Development of techniques for inspecting and identifying flaws and surface imperfections on hot slabs, blooms, or billets in order to permit spot hot-scarfing.

- Increasing yields in the steelmaking process. This would save energy by eliminating remelting of scrap that is primarily generated in the steelcasting and steelforming processes. 
TABLE I-1

MAJOR ENERGY CONSERVATION OPPORTUNITIES FOR ENGINEERING DEVELOPMENT IN IRON AND STEELMAKING

Sector

Examples of Energy-
Conserving Technology
Minimum Total Funding

to Demonstrate a New

Technology

(s Millions)

Reheating, Including Annealing

Monobeam furnace (B)

Furnace using direct coal

firing rather than gas

$$
\text { or oil (A) }
$$

Improved forge furnace

efficiencies (C)

waste heat recovery in

annealing (C)

Coal injection (A)

Reducing gas injection to

stack (A)

$$
15-25
$$

$15-50$

$1-20$

Dry quenching

(A)

$5-25$ (?)

$15-25$
Better heat recuperation (B)

External desulfurization (A) $5-10$

Form coke (A)

Co collection from BOF for scrap preheating (A)

More Scrap Use in Steelmaking, Including Preheating Technologies Coal-based Gasifier/ Burner Electric arc furnace scrap preheat (B)

Blast gasifier (A)

New coal burner (A)

Yield Improvement:

Conserving slab Heat Hot inspection and spot scarfing (A)

Casting and Rolling Continuous casting of preforms like beam blanks (B)

$20-60$

$1-40(?)$

$50-100$
Comments

Funding For Broader Demon-

stration

(s Millions)

(a)

(a)

Engineering problems need to be resolved

$$
\text { (a) }
$$

Demonstration needed on

a continucus basis

Potentially interesting if economic coal gasifier developed U.S. demonstration of foreign technology needed

Medium Btu by-product gas process desirable

Good engineering

concept needed

Good engineering

concept needed

$$
\text { (a) }
$$

Sulfur and ash

removal needed.

from hot gas stream

1 - 10 (?) Research and development

required

semi-finished steel formin

technology requires conceptual development and demonstration. (slab, bloom, and billet casting need economic incentives

for implementation.)

(A) Potential for national energy conservation of $50-500 \times 10_{12}^{12} \mathrm{Btu} / \mathrm{yr}$.

(B) Potential for national energy conservation of $5-50 \times 10_{12}^{12} \mathrm{Btu} / \mathrm{yr}$.

(C) Potential for national energy conservation of $0.5-5 \times 10^{12} \mathrm{Btu} / \mathrm{yr}$.

(a) Reasonable to moderate extrapolation of currently available technology 
Table I-2 shows examples of other energy conservation opportunities in the iron and steel industry which we place in a lower priority category, either because a potential for rapid technical progress is not foreseen or because the potential energy conservation impact is not deemed to be as important. (In the direct reduction of iron ore, for example, the major effect, using currently developed technology, is the potential conservation of metallurgical coal reserves at the cost of using more Btu's of steam coal or subituminous coal.)

Finally, Table I-3 shows other major areas for potential energy conservation in the iron and steel industry. These are of a more general nature and are applicable to other industries as well, such as improvements in high-temperature materials and cogeneration.

All of these concepts for energy conservation generally incorporate a wide variety of specific opportunities, of which only representative samples have been uncovered in the course of this study. Nevertheless, we believe that the energy-conserving technologies discussed in this report represent in general the type of programs and eingineering prujects that industry may propose for development on a cost-sharing basis.

In addition to the above technological sectors, considerable thought should be given to the implementation of energy-conserving technology after its commercial demonstration. This effort will have to overcome three general barriers to the implementation of energy-conserving (and other) technologies:

- Capital availability problems, which force the steel industry to consider funding only high-priority or regulation-mandated projects unrelated to energy considerations;

- Concerns about regulatory issues ranging from compliance with the Clean Air Act, amendments to the Federal Water Pollution Control Act, or New Source Performance Standards to antitrust actions of the Federal Trade Commission, actions of state public utility commissions, etc.; and

- Management-labor interaction in the introduction of new technology, including labor training and concerns aboul occupational safety and health.

As an example of some of these barriers, the most visible technique for incrcasing steel mill yiclds and improving energy efficiencies is continuous casting. While this is a proven technology and has been accepted by the steel industry, $85-90 \%$ of casting is still done in the conventional way. The reasons for the relatively slow penetration of this new energy-conserving technology are insufficient capital availability and the low return on investment partially resulting from relatively long depreciation periods (typically $14-16$ years).

Since such energy-conserving technology is only slowly being incorporated today, we believe that considerable thought should be given to discussion with steelmakers on incentives for implementing energy-conserving technology once it is developed. 
TABLE I-2

EXAMPLES OF OTHER ENERGY CONSERVATION

OPPORTUNITIES IN THE IRON AND STEEL INDUSTRY

\begin{tabular}{|c|c|c|c|}
\hline Sector & $\begin{array}{l}\text { Example of } \\
\text { Concepts }\end{array}$ & $\begin{array}{l}\text { ergy } \\
\text { ervation } \\
\text { ential }\end{array}$ & Comments \\
\hline Agglomeration & $\begin{array}{l}\text { Conversion from } \\
\text { natural gas or } \\
\text { fuel oil to } \\
\text { coal in pellet- } \\
\text { izing plants }\end{array}$ & B & Technology established \\
\hline $\begin{array}{l}\text { Grinding of } \\
\text { Iron ore }\end{array}$ & $\begin{array}{l}\text { Improvement in } \\
\text { particle class- } \\
\text { ification }\end{array}$ & B & $\begin{array}{l}\text { Small improvements } \\
\text { over time }\end{array}$ \\
\hline $\begin{array}{l}\text { Electric Arc } \\
\text { Furnace }\end{array}$ & Modeling & B & $\begin{array}{l}\text { Small improvements } \\
\text { over time }\end{array}$ \\
\hline $\begin{array}{l}\text { Basle osyyein } \\
\text { Furnace }\end{array}$ & $\begin{array}{l}\text { Utilization nf } \\
\text { BOF off-gases } \\
\text { other than for } \\
\text { scrap preheating }\end{array}$ & B & $\begin{array}{l}\text { Co gas collection } \\
\text { technology estab- } \\
\text { lished, but an } \\
\text { economic system for } \\
\text { use of co is still } \\
\text { to be devised }\end{array}$ \\
\hline $\begin{array}{l}\text { Flue Dusts and } \\
\text { Sludges }\end{array}$ & $\begin{array}{l}\text { Recovery of metal- } \\
\text { lic and carbon } \\
\text { values }\end{array}$ & B & $\begin{array}{l}\text { An important problem } \\
\text { relating to waste } \\
\text { disposal }\end{array}$ \\
\hline Ladle Preheating & $\begin{array}{l}\text { More efficient } \\
\text { ladle preheater }\end{array}$ & B & $\begin{array}{l}\text { Logistical and engi- } \\
\text { neering problem }\end{array}$ \\
\hline $\begin{array}{l}\text { Difeet Reduc- } \\
\text { tion }\end{array}$ & $\begin{array}{l}\text { Steam coal or lig- } \\
\text { nite based pro- } \\
\text { cess }\end{array}$ & A & $\begin{array}{l}\text { Conserves metallux- } \\
\text { gical coal; process } \\
\text { development expected } \\
\text { to be capital-inten- } \\
\text { sive }\end{array}$ \\
\hline $\begin{array}{l}\text { Lime Manufac- } \\
\text { ture }\end{array}$ & $\begin{array}{l}\text { Oxygen use in lime } \\
\text { kilns; fluid bed } \\
\text { process }\end{array}$ & B & $\begin{array}{l}\text { Most applications would } \\
\text { be outside of steel } \\
\text { industry }\end{array}$ \\
\hline $\begin{array}{l}\text { A : Potential for } \\
\text { B: Potential for } \\
\text { C:Potential for }\end{array}$ & $\begin{array}{l}\text { national energy cor } \\
\text { national energy cor } \\
\text { national energy cor }\end{array}$ & $\begin{array}{l}\text { ervation } \\
\text { ervation } \\
\text { ervation }\end{array}$ & $\begin{array}{lrlll}\text { of } & 50-500 & \mathrm{x} & 1012 & \mathrm{Btu} / \mathrm{yx} \\
\text { of } & 5-50 & \mathrm{x} & 1012 & \mathrm{Btu} / \mathrm{yr} \\
\text { of } & 0.5-5 & \mathrm{x} & 1012 & \mathrm{Btu} / \mathrm{yr}\end{array}$ \\
\hline
\end{tabular}

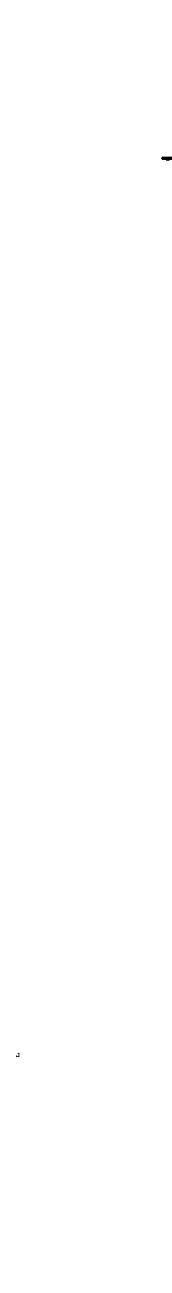

Example of Conservation 
TABLE I -3

OTHER MAJOR ENERGY CONSERVATION

OPPORTUNITIES USEFUL TO THE IRON AND STEEL INDUSTRY

\section{sector}

Improvements in High-Temperature Materials

Improvements in Plant Energy Management

Improvements in Temperature sensing, Burner Design, and Control of Combustion

Cogeneration

Regional Energy Management
Major Application

Rerupexators, regcncrators,
skids for reheating
furnaces
Computer control of energy
management and production
scheduling
Reheating furnaces
Use of low-temperature heat
Highly industrialized areas 


\section{BACKGROUND}

\section{A. INDUSTRY CHARACTERISTICS}

\section{Energy Efficiency}

Present-day U.S. steel facilities were built largely at a time when fuels were plentiful and available at low cost. Energy was used as efficiently as could be economically justified by relative capital costs, productivity, etc. Now industry must adopt more energy-efficient production technologies, which is easier to do in newer facilities. The industry has made a significant effort to modernize its aged plants, but there are major hindrances - difficulties in retrofitting existing facilities, limited capital availability, high cost of borrowed capital, and necessary expenditures for pollution abatement.

\section{Plant Categories}

In 1976, the usable iron ore production in the United States, including a small amount from pyrite roasting, amounted to 76.7 million long tons and was produced from 222.8 million long tons of mined ore. About $85 \%$ of the total crude iron ore produced in this country came from the Lake Superior district. Over $95 \%$ of all ore was concentrated before shipment, and $81 \%$ of all ore was agglomeraled at or ncar tho mine sites hefnre shipment. Captive mines owned and/or operated by the large integrated iron and steel companies furnish $85 \%$ of the ore used by the domestic iron and steel industry.

Raw-steel producing plants may be categorized into two broad groups - integrated and non-integrated. Integrated plants normally start with iron ore and coking coal, from which hot metal (molten pig iron) is produced in blast furnaces. The resulting hot metal, along with scrap, is then charged into steelmaking furnaces to produce molten steel, which is subsequently cast and fabricated into finished steel products. More recently, a small number of plants have incorporated technology for the direct reduction of iron ore, which is then made into steel by electric arc furnaces.

Non-integrated plants use scrap steel, pig iron or, in some cases, purchased sponge iron made by direct reduction furnaces as raw materials. Charges of these materials are melted and refined in electric arc steelmaking furnaces. A special group of small non-integrated plarits, having a capacity of less than 200,000 tons and producing only bar mill products, rebars, and merchant bars, are classified as mini-mills.

A third category of plants consists of mills which purchase semi-finished steel intermediates, such as slabs, blooms, or billets, produced by integrated or semi-integrated producers for finish rolling and/or additional fabrication to final products. Many such plants are satellite finishing operations for the raw-steel producers.

Steel producers are further classified by the type of steel produced: carbon, alloy, and stainless steel. Cárbon steel is the predominant grade of steel shipped, accounting for over $85 \%$ of the total U.S. steel production. 


\section{Facility Distribution}

The geographical distribution of the major iron and steel facilities is shown in Figure II-1. The six states bordering the Great Lakes - New York, Pennsylvania, Ohio, Indiana, Illinois, and Michigan - have historically accounted for over $75 \%$ of total U.S. steel output. Within these states are $81 \%$ of the integrated plants and $69 \%$ of the semi-integrated and specialty steel plants. This industry concentration is induced primarily by the favorable accessibility of raw material sources, transportation arteries, and major steel-consuming markets.

Metallurgical-grade coal produced in West Virginia, Pennsylvania, Kentucky, and Alabama supplies about $80 \%$ of the industry requirements. Some steel companies with integrated steel plants operate their own mines and coal processing facilities.

\section{B. ENERGY USE IN THE IRON AND STEEL INDUSTRY}

Energy requirements for the manufacture of various steel products may be calculated on a variety of bases, including;

- Direct energy usc of fuels, electricity, steam, etc.

- Direct energy use as above plus energy requirements for the manufacture of materials involved in the steelmaking, such as lime or refractories used in a basic oxygen furnace.

In energy accounting terminology, the first method is called a level 1 analysis and the second a level 2 analysis. In this study, we have focused our efforts on the level 1 energy analysis.

The level 1 energy use in the iron and steel industry can be examined from three different viewpoints, namely: 1) by process unit, 2) by finished product, and 3) by type of fuel used.

\section{By Process Unit}

The flow of material and the functions of the unit processes in the iron and steelmaking and steelforming sequences of an integrated plant are depicted in Figure II-2.

Iron ore mined in open pits or in underground operations may be shipped directly to the iron maker or "beneficiated" at the mine site to produce a high iron oxide content in concentrates, sinter, or pellets. This step may be carried out in a number of ways, including dry magnetic separation, wet magnetic separation, electrostatic separation, flotation, and specific gravity separation. Since the resulting concentrates are quite fine in particle size, it is usually necessary to agglomerate them into larger sizes by pelletizing or sintering to prevent entrainment of the iron values in the off-gases leaving the blast furnace.

Limestone and coal are the other major raw materials used in the iron-making operation. The coal is converted to coke in large, externally heated coke ovens, which drive off volatile materials contained in the coal and create a solid product (coke) that can withstand the high temperatures and tremendous crushing pressures found in a blast furnace. 


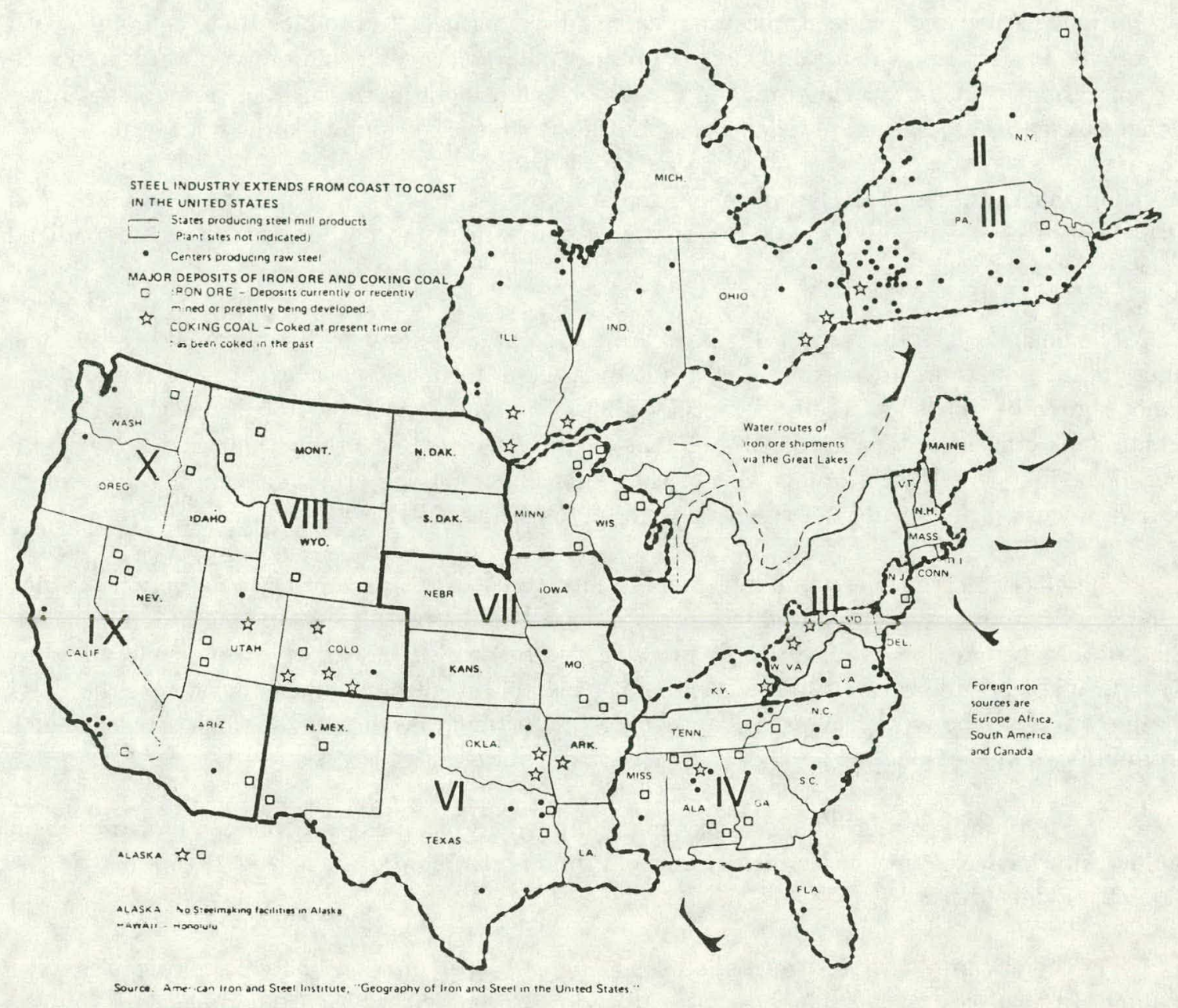

FIGURE II-1 GEOGRAPHICAL DISTRIBUTION OF THE IRON AND STEEL INDUSTRY 
The blast furnace continues to be the major iron-making process. Coke, limestone, and ironbearing raw materials are fed in at the top of the blast furnace shaft. Preheated air is forced into the bottom of the shaft, through tuyeres, to react with coke and generate heat and carbon monoxide, producing a temperature higher than $3000^{\circ} \mathrm{F}$. The iron oxide is thus reduced by the hot carbon and carbon monoxide. Limestone, calcined by the heat to produce lime, combines with the gangue materials in the ore and coke to produce a liquid slag. The molten iron, saturated with carbon (about $4 \%$ ), is tapped from the furnace bottom along with the slag. Part of the blast furnace off-gases are burned in regenerative air heaters (stoves) to provide the hot air blast.

The hot liquid metal is transferred in ladles or refractory-lined cars to a basic oxygen furnace or other steelmaking operation, where carbon, silicon, and other impurities are oxidized from the metal phase.

The basic oxygen furnace (BOF) has become the predominant method for making raw steel since its introduction in the early 1950's. In this type of furnace, blast furnace hot metal is the major source of iron and usually comprises about $70-80 \%$ of the total iron-bearing charge, the remainder being scrap. In $1976,62 \%$ of the total U.S. raw-steel production was by the BOF method. I'his growth was largely due to the replacement of the economically marginal openhearth process, which could not effectively compete with the BOF process.

The electric furnace steelmaking process commonly uses scrap for the production of steel. Sponge iron produced by direct reduction is also found to be practical for up to $50 \%$ of the charge. Electric arc furnaces may be used to produce the full range of carbon steels, medium-alloy structural steels and specialty alloys, stainless steels, tool steels, and super-alloys. Like the BOF, the electric furnace is expected to play a more important role in steelmaking as open-hearth production is phased out.

After refining, molten steel is commonly tapped into ladles and then poured into ingot molds. Alternatively, the energy-consuming continuous casting process is used to produce billets, blooms, or slabs directly.

'I'he ingots are stripped from their molds and placed in fuel-heated soaking pits. The soaking pit ensures a uniform ingot temperature for subsequent rolling to produce slabs, billets, or blooms, which are normally stored before further processing to finished steel products. The final products may be structural shapes, rails, bars, wire, pipe, sheet, or strip. Flat products are often galvanized, tin-plated, aluminum-coated, or painted as an integral part of the steelmaker's operation.

Figure II-3 presents an estimate of the 1976 energy consumption, broken down by process unit, in the U.S. iron and steel industry. Blast furnaces are by far the largest energy users; they account for about $40 \%$ of the total energy used in the industry. Heating and annealing furnaces use approximately $15 \%$ of the total consumption. Coke ovens, steelmaking furnaces, and casting/breakdown operations use roughly $10 \%$ each. The remainder is used in all other process units.

To meet the pollution control requirements for 1983 by implementing the "best available technology economically achievable" (BATEA), the energy needed has been estimated at about $141 \times 10^{12}$ Btu. $^{1}$

1. "Steel and the Environment - A Cost Impact Analysis," prepared for the American Iron and Steel institute by Arthur D. Little, Inc., May 1975. 


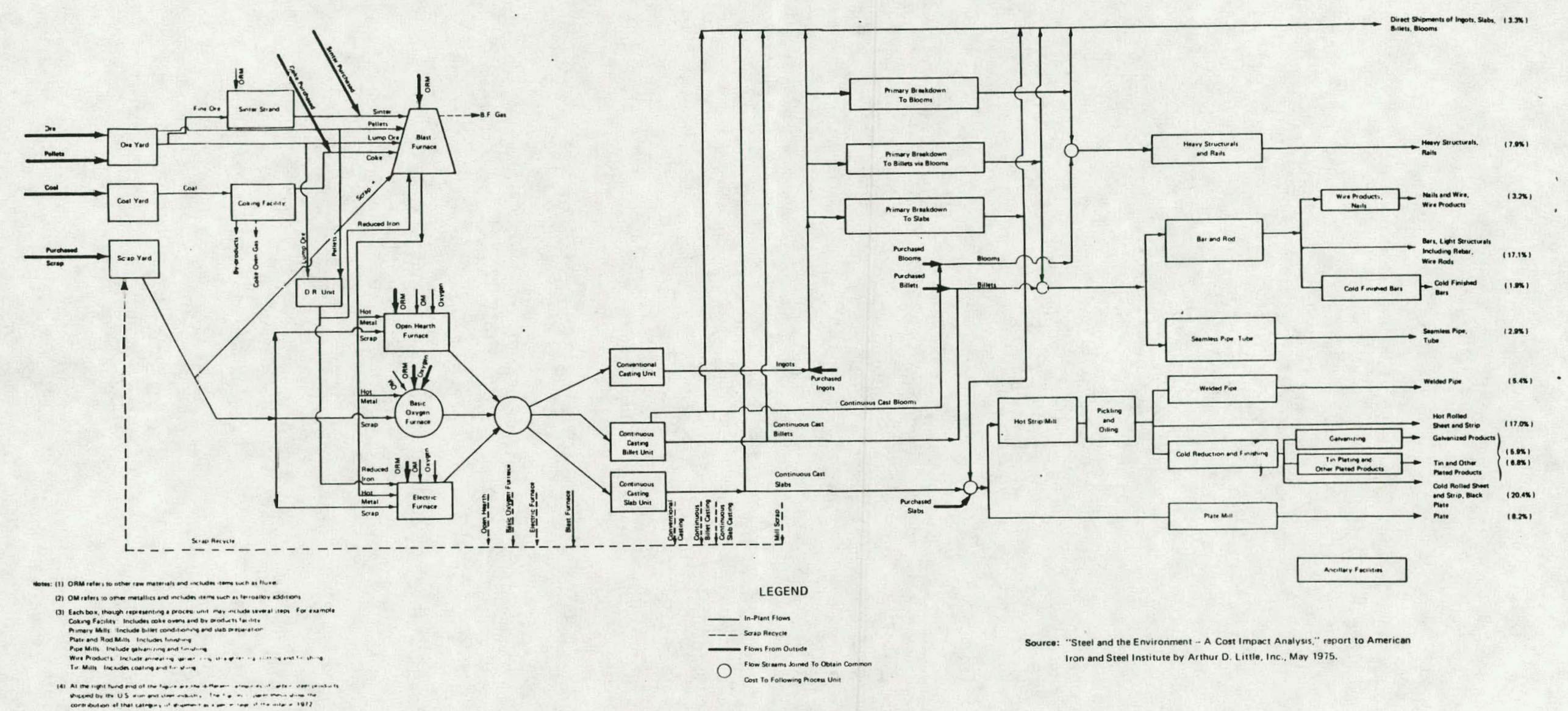

FIGURE II-3 PROCESS UNIT INTERRELATIONSHIPS 
THIS PAGE

\section{WAS INTENTIONALLY LEFT BLANK}




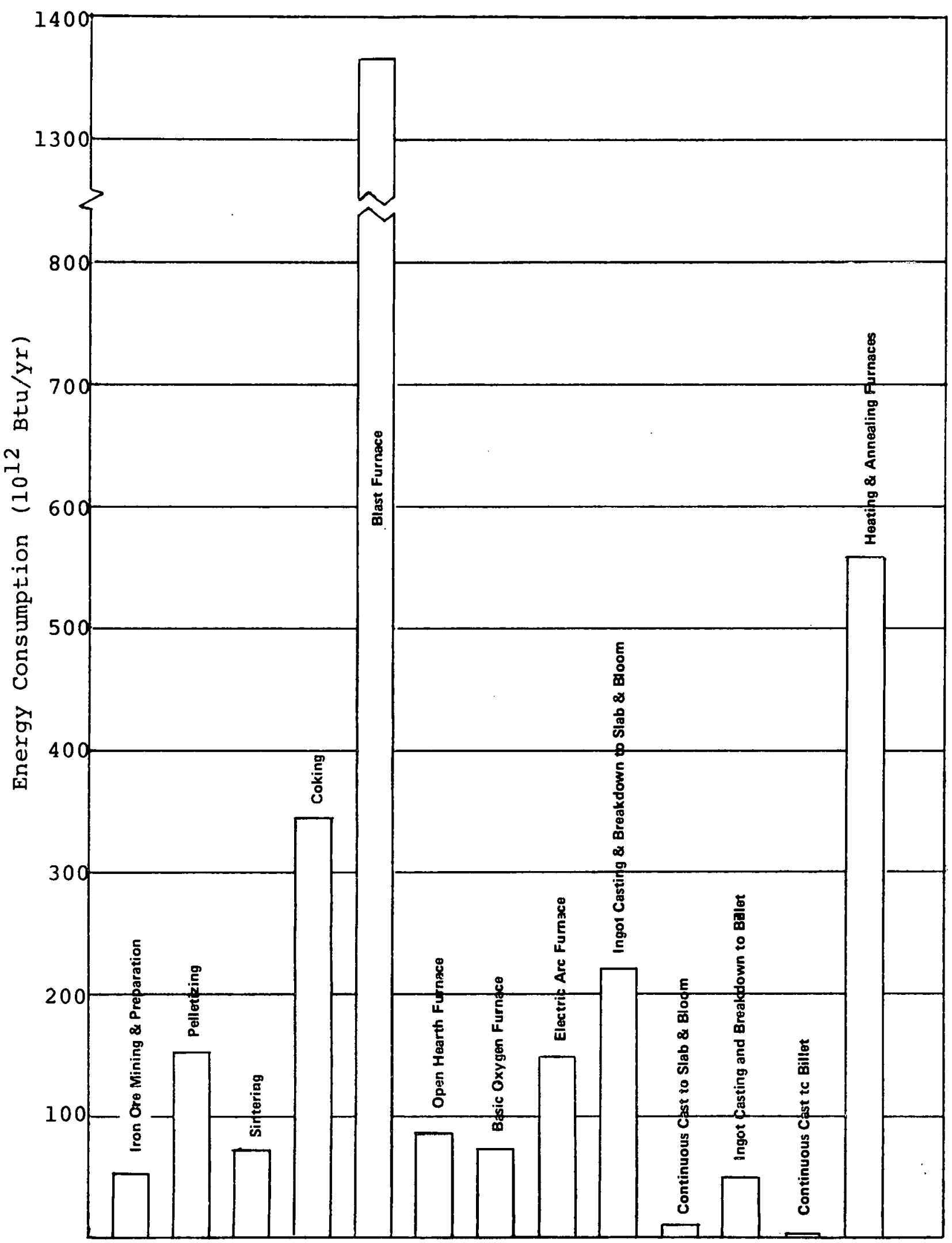

FIGURE II-3 ESTIMATED U.S. LEVEL-1 ENERGG CONSUMPTION BY MAJOR PROCESS UNITS IN $1976^{\circ}$ 


\section{By Product Line}

Processes involved in producing finished steel products require different combinations of chemistry, pressure, and temperature to achieve desired properties for the end use. Figure II-4 shows the distribution of energy consumption for major U.S. steel product lines using 1976 statistics published by American Iron and Steel Institute.

\section{By Fuel Type}

The national energy consumption by fuel type for the steel industry, calculated from AISI published statistics, is shown in Table II-1. Fuels directly derived from coal supply about $64 \%$ of the total energy used. Natural gas and petroleum-based fuels supply $23 \%$, and purchased electricity contributes the remaining $13 \%$.

\section{INDUSTRY TREND AND THE ROLE OF SCRAP}

While the obsolescent open-hearth can theoretically run on $100 \%$ scrap charges, operating practice today generally relies on a charge consisting of blast furnace hot metal and scrap in about a 50-50 ratio. The predominant oxygen processes being used or considered in the steel industry are the Basic Oxygen Process (BOP) and the Q-BOP. Both rely on a hot metal/scrap ratio of about 3 or 4 to 1 . Oxygen process technology is most commonly used in large integrated mills that produce a variety of products ranging from heavy structurals and rails, plates, hot- or cold-rolled strips and sheets, and plated products to nails and wire products. Since the average yield from rolled steel to these finished products is in the order of $70 \%$ to $75 \%$, an integrated mill produces a large amount of "home" scrap; this scrap supplies most of that needed (as a coolant) in the oxygen furnaces, so an integrated mill relying upon oxygen furnace technology generally has little need for outside purchases of scrap.

Therefore, the major users of purchased scrap today are open-hearth shops and electric arc furnaces. About $75 \%$ of the ferrous charge in an EAF is in the form of purchased scrap. Since $\mathrm{OH}$ and EAF production totaled 23.5 and 24.6 million tons in 1976, respectively, about 30.2 million tons of purchased scrap were consumed by the U.S. steel industry. In this same period, 9 million tons of scrap iron and steel were exported to other countries.

We expect the decrease in open-hearth production to continue. Either electric furnaces or oxygen processes will replace this capacity. Thus, we believe that the blast furnace-oxygen process and the electric furnace are likely to be the predominant steelmaking routes for at least the next two decades. 


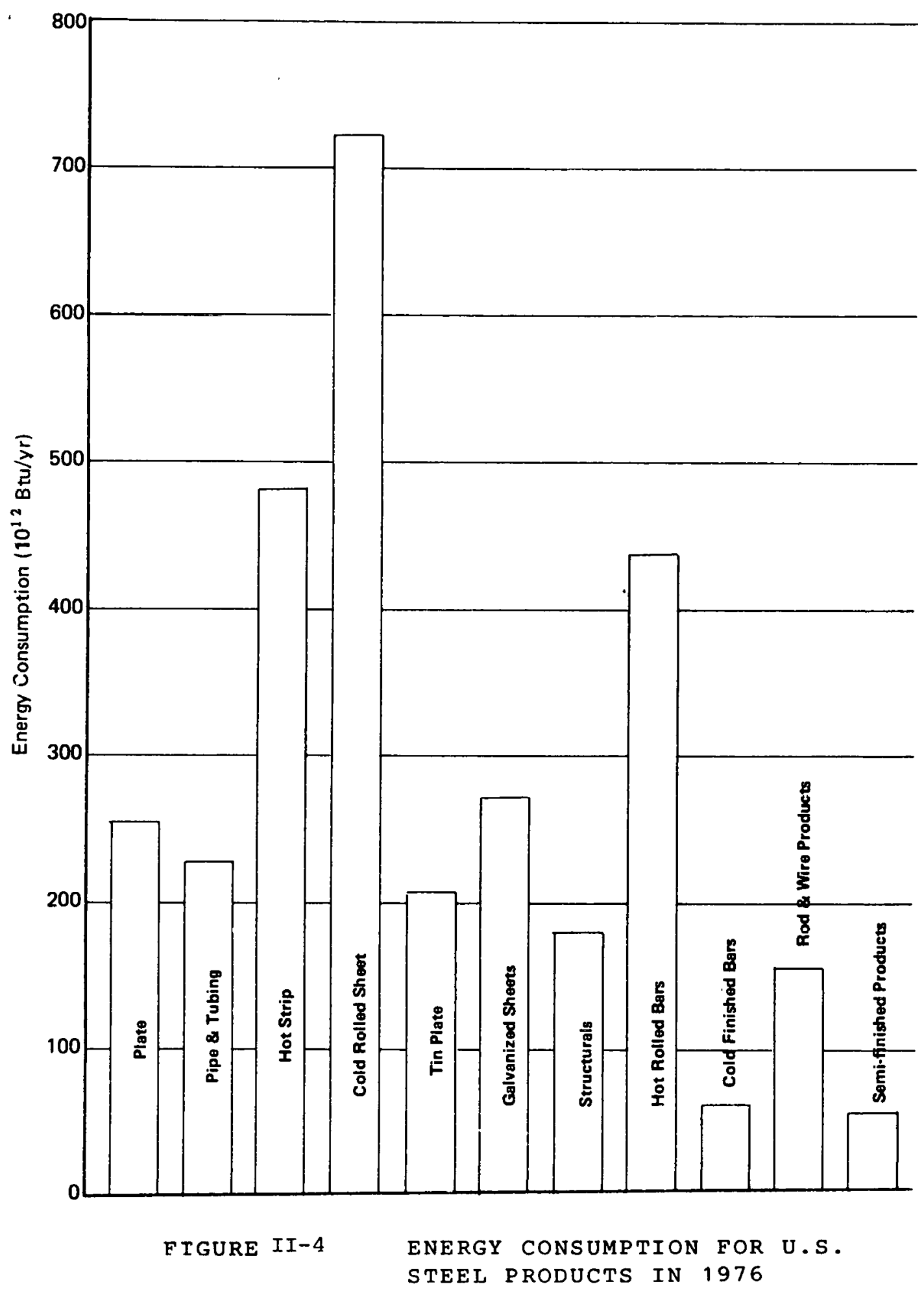


TABLE II-1

NATIONAL ENERGY CONSUMPTION IN THE STEEL INDUSTRY BY FUEL TYPE

Fuel Type

Fuel Oil

Tar \& Pitch .

Liquid Petroleum Gas

Natural Gas

Coke Oven Gas

Blast Furnace Gas

Coke

Steam Coal

Purchased Electricity

Total Energy
Quantity, $10^{12}$ Btu

224.0

39.3

3.6

595.0

435.0

414.0

1303,0

75.0

465.0

3553.9
Percent of Total

6.30

1.11

.10

16.74

12.24

11.65

36.67

2.11

13.08

100.00

Source: AISI Annual Statistics, 1976. 


\section{APPROACH}

\section{A. SCOPE}

Within the context of this study, energy conservation could take either of two forms:

- Energy (Btu) savings, in which processes or process modifications result in lower consumption of energy while turning out the same or a similar final product.

- Conservation of critical fuel forms, specifically natural gas, liquid fuels, and, to a smaller extent, metallurgical coke. Conservation of these fuels typically would mean use of steam coal as a substitute, which might actually consume more Btu's of energy than if the more critical fuels were used. It is recognized that such substitution runs counter to some previous programs that attempted to achieve an overull Btu energy reduction in the industry.

In undertaking this particular study, we examined three general types of energy conservation opportunities:

- Conceptual opportunities within each of the process units for making steel. 'This included the identification of major energy conservation opportunities presented by waste or byproduct streams containing energy values that are not now recovered.

- Identification of new technologies that could conceivably replace present-day technologies, such as dry quenching of coke instead of conventional wet quenching, and the direct reduction of iron ore with an electric arc furnace rather than the conventional coke oven/blast furnace/basic oxygen furnace (or open-hearth) route.

- Identification of general opportunities for energy conservation within a steel mill or a steel mill complex, such as better management of energy by fuel form depending upon production demands, the use of coal-fired fuel generators, computer control, etc.

Our approach relied largely upon the following:

- Field visits to major steel companies,

- A meeting with the American Iron and Steel Institute, which was represented by seven major steel companies, and

- Previous studies done in the field of energy conservation in the iron and steel iindustry, such as:

- "Energy Conservation in the Steel Industry," by American Iron and Steel Institute, 26 May 1976;

- "Evaluation of the Theoretical Potential for Energy Conservation in Seven Basic Industries," prepared for FEA by Battelle Columbus Laboratories, 11 July 1975; 
- "Rècommendations for Future Government-Sponsored Research and Development in the Paper and Steel Industries," prepared for ERDA by Thermo Electron Corp., August 1976;

- "Energy Use Patterns in Metallurgical and Non-Metallic Processing, Phase 8: Opportunities to Improve Energy Efficiency" (NTIS PB-261 152) prepared for the Bureau of Mines by Battelle Columbus Laboratories, Ohio,17 September 75 ;

- "Potential for Energy Conservation in Nine Selected Industries," prepared for FEA by Gordian Associates;

- "Environmental Considerations of Selected Energy-Conserving Manufacturing Process Options" (EPA-600-7 - 76-034), prepared for EPA by Arthur D. Little, Inc., December 1976;

- "Steel and the Environment - A Cost Impact Analysis," prepared for the AISI by Arthur D. Little, Inc., May 1975;

- "Risk/Rate of Return Tradeoff Analysis: A Case for Federal Support" (draft) prepared for ERDA by Energy and Environmental Analysis, Inc., 30 August 1976.

After identifying the major conceptual opportunities for energy conservation, we reviewed specific proposals that have been considered or utilized for achieving energy recovery within the conceptual framework. For example, the recovery of carbon monoxide off-gases from basic oxygen furnaces is a conceptual way of conserving energy. One of the ideas advanced for recovering this energy value is the conventional approach of combusting the $\mathrm{CO}$ with excess air and recovering the sensible heat in the off-gases by generating steam; however, such steam is unusable if it cannot be economically transported to the steam-consuming sectors of the plant. Alternatively, the gases emitted from the BOF vessel could be collected directly, and the resulting fuel values could be stored in a gas holder for appropriate use in the steel plant. Also, after the off-gases are collected, the $\mathrm{CO}$ could be used for scrap preheating or generating the necessary energy to make oxygen. Some of these and other ideas have been piloted or tested to measure the actual Btu savings from this very generalized concept of collecting $\mathrm{CO}$ gäses.

Because this program was to focus on a time frame of under ten years, and because it takes many years in the iron and steel industry to develop a concept to a practical, fully engineered and demonstrated process, it was our judgment that major portions of any idea worthy of consid. eration today must already have been piloted or tested on a large scale.

Our secondary and less important focus was on the longer term ideas that might go beyond ten years for development and engineering and thus might be worthy of support for long-term encrgy conservation bencfito.

Our objective was to identify those concepts that would have a major impact on energy conservation if applied to the whole of the U.S. steel industry. Clearly, if an idea is to be given widespread application, adequate returns on investment must be demonstrated while the development program is under way. 'I'hus, to the extent that information was available, we show potential energy savings using current values for energy of about $\$ 2.00$ per million Btu, and then discuss the impact of higher fuel costs ( $\$ 4.50$ per million Btu) with all other costs unchanged. 
The scope of this assignment ranged from iron ore coking and lime manufacture through the steelforming operations. Coating operations were not included, though they clearly have energy conservation potential. Coal mining was also not considered to be within the scope of this assignment.

\section{B. COST BENEFIT METHODOLOGY}

In most cases we assessed only one part of the overall process of producing steel from ore. Presumably, the new programs to be suggested would (if successful) replace an existing process; hence, to assess energy savings and cost effectiveness, one must compare an existing process with the new process, both of which will produce a similar product. Energy savings are calculated by subtracting the energy consumed by the new process from that consumed by the existing process. Clearly, a similar approach can be used with costs.

Many methods have been developed to determine returns on investment, including:

- Simple payback period (pre-tax)

- Payback period after corporate taxes on income

- Simple rate of return

- Internal (discounted cash flow) rate of return

Effective corporate taxes vary widely from company to company and can thus affect any after-tax calculations. Moreover, in the initial phases of screening energy conservation opportunities, details on estimated costs are often lacking, and the time period for implementation (necessary for calculating the internal rate of return) is largely unknown. Thus, where information was available, we relied on a simple pre-tax payback period in our calculations to indicate the relative attractiveness of the various technologies, recognizing that more detailed calculations may be desirable for evaluating specific projects.

\section{ENERGY VALUE OF SCRAP}

About 98 million tons of scrap was collected in 1972; 7.7 million tons was exported, and the rest was consumed in the U.S. steel industry. Iron and steel scrap is classified into three broad categories:

- Home scrap is scrap generated in the iron and steelmaking process. It accounts for about one half of all scrap. Most of it is recycled and used within a steel plant.

- Prompt industrial scrap is scrap generated in fabrication and manufacturing operations. It accounts for about a quarter of all scrap. Most is row recycled to steel plants.

- Old or obsolete scrap, which accounts for the remaining one quarter of all scrap, is composed of materials scrapped at the end of their economic lives. This type of scrap arises from all parts of the economy and ranges from junk automobiles and machinery to parts of demolished buildings, old household appliances, etc. Obsolete scrap is largely recycled in electric arc furnaces. 
The electric arc furnace can make steel from $100 \%$ scrap, but the BOF is limited to a much smaller proportion; the remainder of its ferrous charge comes from iron ore. Since the mining and agglomeration of ore pellets requires large amounts of energy, direct energy use in the EAF route to steel is much less than by the coke oven/blast furnace/ BOF route (Table III-1). For each ton of scrap used, the energy consumption is 16 million Btu less by the first route than by the second, based on converting electric energy at 10,500 Btu per $k$.Wh.

The diagram accompanying Table III-1 compares typical material balances for these two steelmaking processes. Note that the EAF uses 1.0 ton of purchased scrap - about twenty times as much as does the BOF - in making the same amount ( 0.83 ton) of steel. If we assume that the demand for steel is constant, an increase in EAF production will cause a cutback in BOF production by an equal amount; from the standpoint of purchased scrap, each additional ton going into the EAF will cause a 0.067-ton reduction in scrap purchases for the BOF and yield an energy saving of $16 \times 10^{6} /(1.0-.067)=17.15 \times 10^{6}$ Btu.

In this analysis we have neglected open-hearth steel production, considering it an obsolescent technology. Since there are no plans to install new open-hearth shops, we believe that in setting a data base for new or replacement steelmaking capacity in the United States, the only alternatives to be considered for the next decade are the electric arc furnace and oxygen processes such as the BOF or Q-BOP.

Clearly, the same analysis could be used for determining the energy saving for incremental steel capacity by various routes, or assessing the energy savings attributable to a higher proportion of scrap utilization in the BOP. Recognizing that the available supply imposes a limit to scrap utilization, and that the energy saved depends on how the scrap is recycled, we have attributed an energy saving to the U.S. economy of 17 million Btu per ton of incremental scrap consumed. 
TABLE III-1

SCRAP USE AND ENERGY EQUIVALENT -- EAF VERSUS BOF

Purchased Scrap Used (tons) $\quad \frac{\text { EAF }}{1} \quad \frac{\text { BOF }}{0.067} \frac{\begin{array}{c}\text { Net } \\ \text { Difference }\end{array}}{0.933}$

Energy Used per Ton of scrap

(milion Btu)

$7.93 \quad 23.93 \quad 16.0$

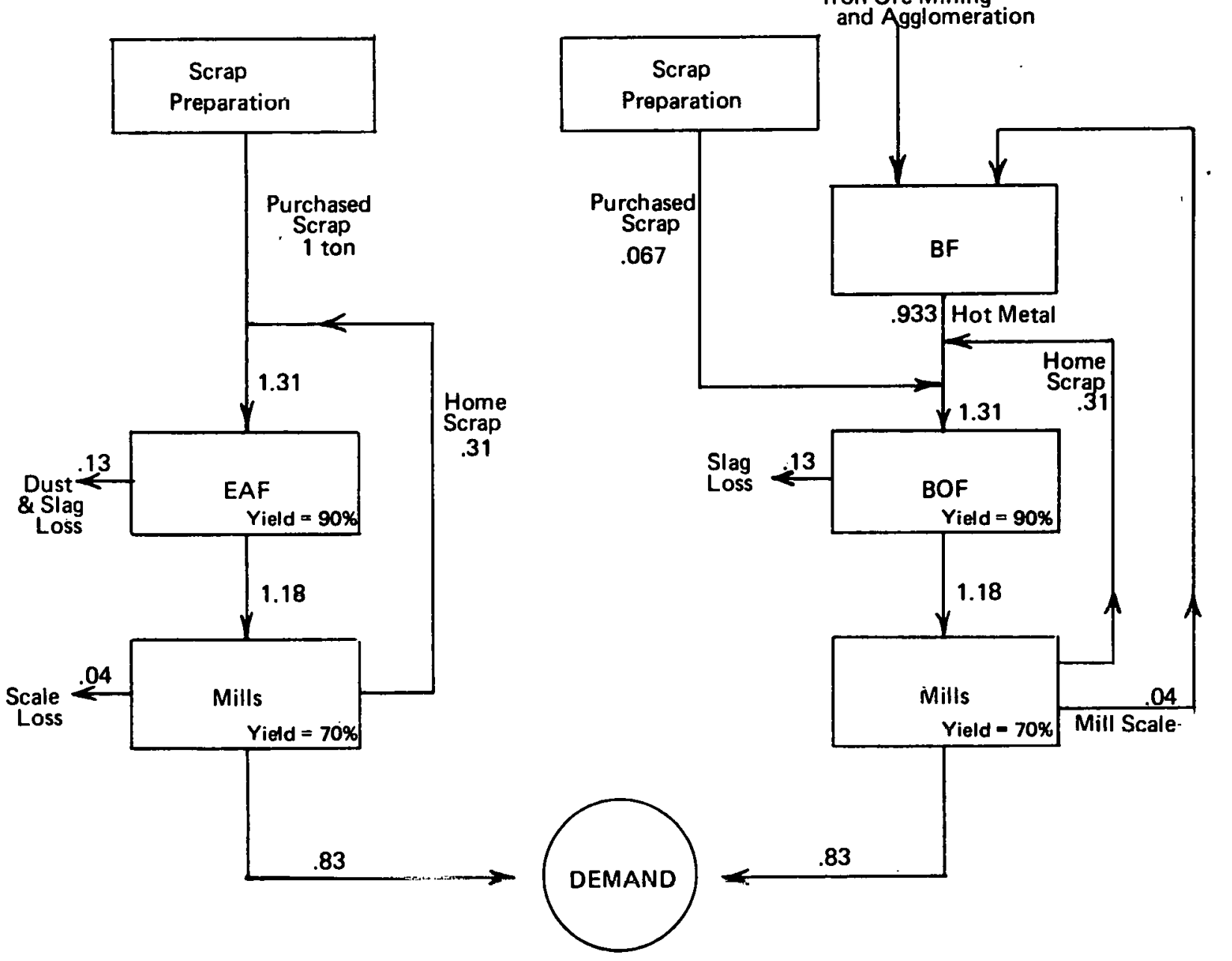

Source: Arthur D. Little, Inc. estimates 


\section{OVERVIEW AND GENERIC ENERGY CONSERVATION OPPORTUNITIES}

\section{A. OVERVIEW}

The pattern of energy consumed by the U.S. steel industry in 1976 is summarized in Table IV-1. The sources are classified into four types:

- Critical fuels, consisting of fuel oil (6.3\% of total energy consumption), LPG $(0.1 \%)$, and natural gas $(16.7 \%)$

- Energy derived from metallurgical coal, consisting of the energy in coke (36.7\% of total energy consumption) and in coal by-products - coke oven gas $(12.2 \%)$, blast furnace gas (11.7\%), and tar and pitch (1.1\%);

- Energy derived from steam coal (2.1\%), which is used for on-site production of steam and generation of electric power;

- Purchased electricity.

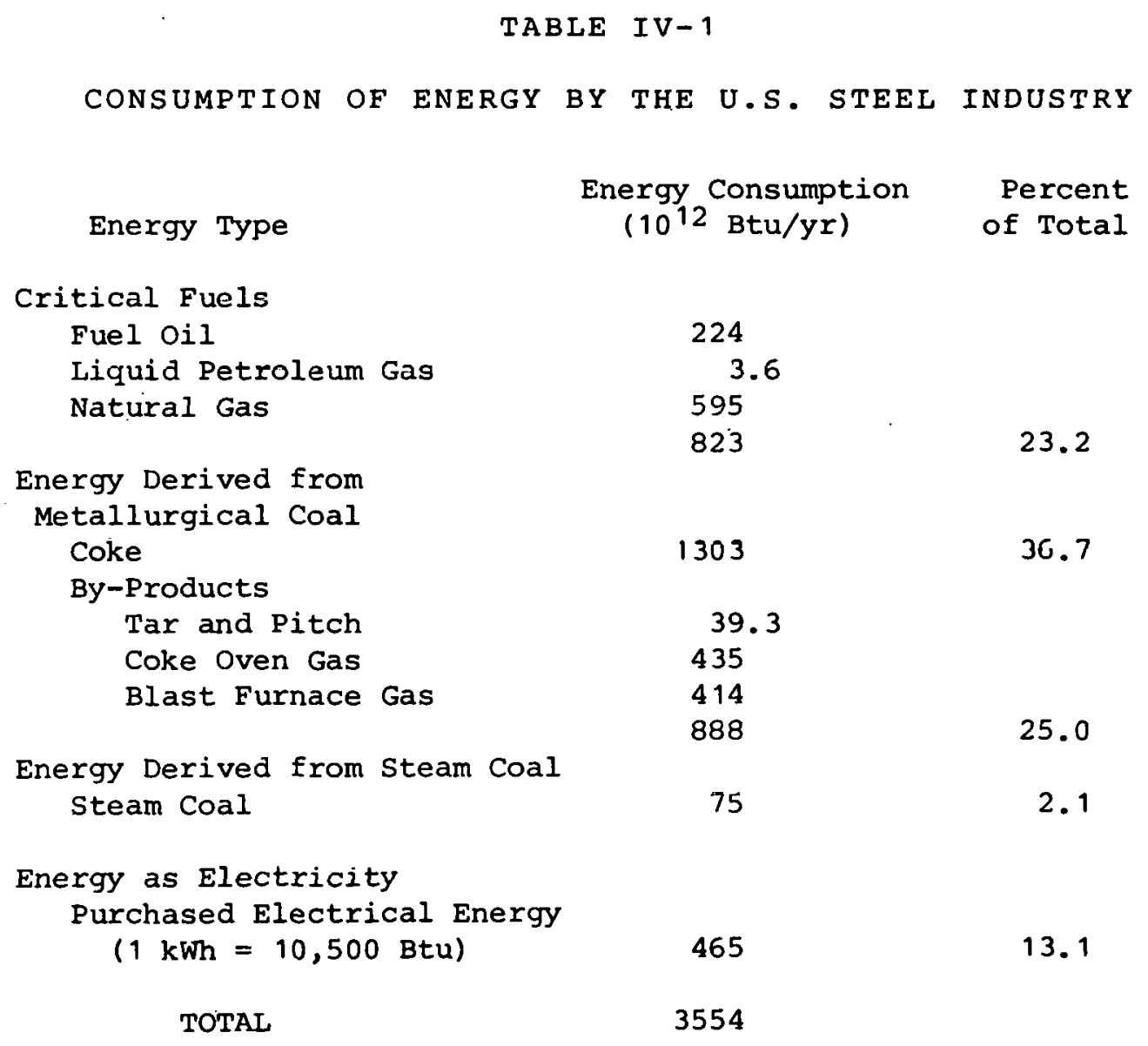

Source: Annual Statistical Report for 1976, AISI 
It is clear from the table that almost two thirds of the energy consumed by the industry is derived from metallurgical and steam coal. The critical fuels - specifically, natural gas and liquid fuels - provide a little less than a quarter of the energy requirements. The remaining $13 \%$ is purchased electrical energy generated by the utility industry from other fuels. Table IV-2 shows how much of these fuels (excluding purchased electricity) was used by each sector of the industry.

\section{B. ENERGY BALANCE WITHIN A STEEL PLANT}

The sources of energy used by a steel plant vary with the type of plant. Only integrated mills, for example, generate fuels in-plant. These fuels (coke oven gas and blast furnace gas) are derived from the metallurgical coal used by the mill.

Coke oven gas has a heat content of 550 Btu per SCF, and the volume that is available depends on the amount of coke that is made in the coke ovens. It is used for underfiring coke ovens and in sinter plants, soaking pits, and steel reheating furnaces at the rolling mills. It can be used alone or in combination with fuel oil and/or natural gas.

The amount of blast furnace gas available depends on the coke consumed by the blast furnaces. Its heat value is only $85 \mathrm{Btu}$ per SCF, and it is used for preheating the air blast in blast furnace stoves, steam generation in boilers, and, to a limited extent, soaking pits and annealing furnaces. It can also be used for underfiring coke ovens, but most plants heavily enrich it with coke oven gas for this purpose.

Although it is predominantly coal-based, the steel industry makes use of by-product fuels and waste heat recovery to some degree, and its facilities are generally designed with alternative fuel capabilities. However, one potential by-product fuel - the carbon monoxide in the off-gases from basic oxygen furnaces - is little used (see Chapter VII). To supplement the fuel gases generated on site, integrated steel plants must presently purchase natural gas, liquid fuels, and steam coal. Coal and blast furnace gas are the principal fuels used to produce steam for the electrical generators.

Some operations such as soaking pits, reheat furnaces, heat treating, and coating lines have no practical alternative to using oil or gas as fuels. Natural gas and oil have also been used to increase the productivity of blast furnaces, open hearths, and basic oxygen furnaces. In most. applications the flexibility with respect to fuel alternatives is presently between natural gas and oil.

Semi-integrated plants, including mini-mills, are based on electric arc furnace steelmaking by scrap remelting and refining, and their principal energy requirement is purchased electrical energy. Such plants also consume natural gas and liquid fuels, as do non-integrated plants. There. are a few plants that only make raw steel (through ingot casting). At such plants there is likely to be some by-product fuel available for export. 


\section{TABLE IV -2}

UTILIZATICN OF FUELS BY THE U.S. STEEL INDUSTRY

BY CONSUMING SECTOR, 1976

$\left(10^{12}\right.$ Btu per year)

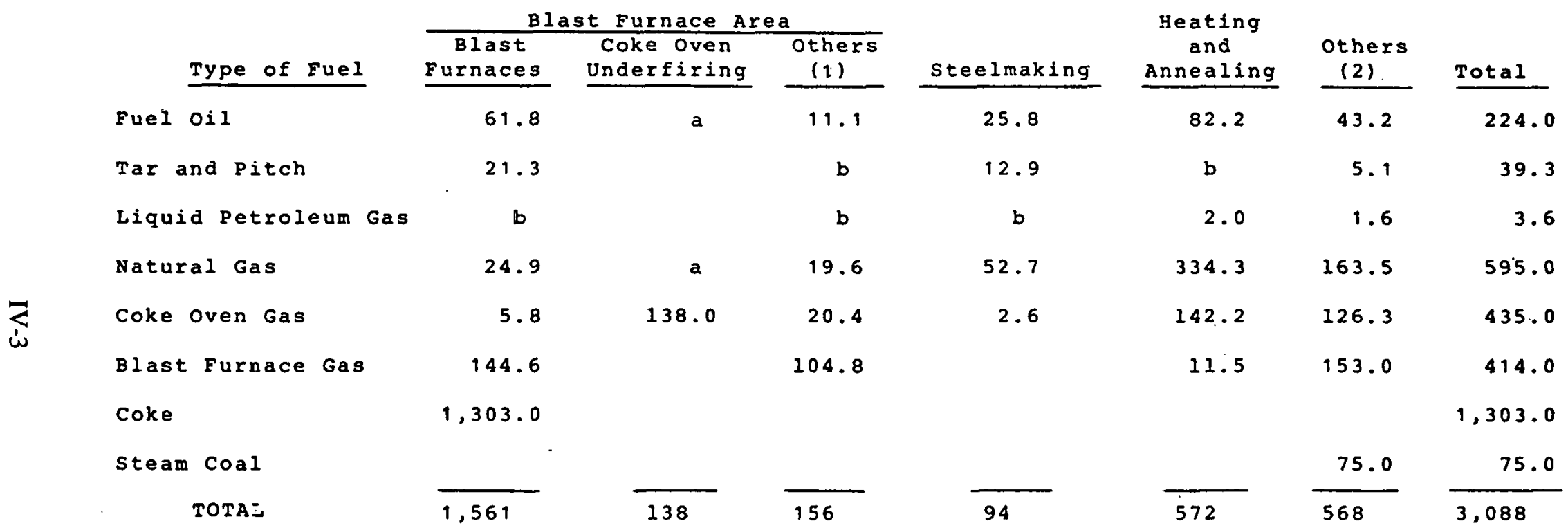

ancluded in others (1)

bincluded in others (2)

Source: annual statistical Report for 1976; AISI 


\section{GENERIC ENERGY CONSERVATION OPPORTUNITIES}

\section{Energy Management by Use of Computer Models}

The development of energy-balancing computer models would be a useful conservation measure. These would determine the availability of various fuels within an integrated steel plant and allocate them to appropriate consuming units on the basis of priorities set both for the fuels and the consuming units. One of the main objectives would be to maximize the use of in-plant generated fuels, so that the amount of purchased fuels would be minimized. Such models exist, but some research is needed to extend the state of the art. The use of these models in real-time systems could be advantageous: a monitoring system would determine the demand for fuels and their availability, and the model could then be utilized to match supply and demand.

When the problems of plant energy models had been overcome, the principle could be extended to regional energy management.

\section{Development of Better High-Temperature Materials}

Research and development is warranted in the following areas:

(a) High-temperature refractories are needed for the development of processes (e.g., oxygen enrichment) that produce higher flame or process temperatures.

(b) Better materials of construction are needed for waste heat recovery devices. For example, ceramic recuperators are limited in most cases to air preheat temperatures in the range of $400-600^{\circ} \mathrm{F}$ because of mortar cracks, plugging, and subsequent leakage problems. Metallic recuperators have few problems with leakage, but they must be protected from overheating by diluting the waste gas with cold air; this restricts air preheat temperatures to $500-800^{\circ} \mathrm{F}$. It is also necessary to protect the heat exchange surfaces from fouling, which also limits air preheat temperatures.

\section{Better Design of Burner/Recuperator Systems}

When recovered waste heat is used to preheat combustion air, the amount of fuel saved over the no-recovery condition can be related to the average air preheat temperature. The amount of fuel saved for a specific fuel type is a function of average preheat temperature, the amount of excess air used, and the waste gas temperature at the exit of the furnace. Figure IV-1 shows the relation between fuel savings and air preheat temperature for heavy fuel oil fired with $10 \%$ excess air. (On new burners we understand that the excess air may be as low as $1 \%$.)

The potential waste heat recovery is primarily dependent on process temperature. The exit gases from steel heating furnaces are around $2000^{\circ} \mathrm{F}$; this offers a potential for $50-60 \%$ relative fuel savings, but restrictions on the operation of the recovery device-and burner system reduce recovery levels well below the maximum potential. For large burners, such as those used on soaking pits, the maximum air preheat temperature is about $1200^{\circ} \mathrm{F}$. For processes requiring smaller burners, such as those used on continuous reheat furnaces, the maximum air preheat temperature is $1000^{\circ} \mathrm{F}$. 


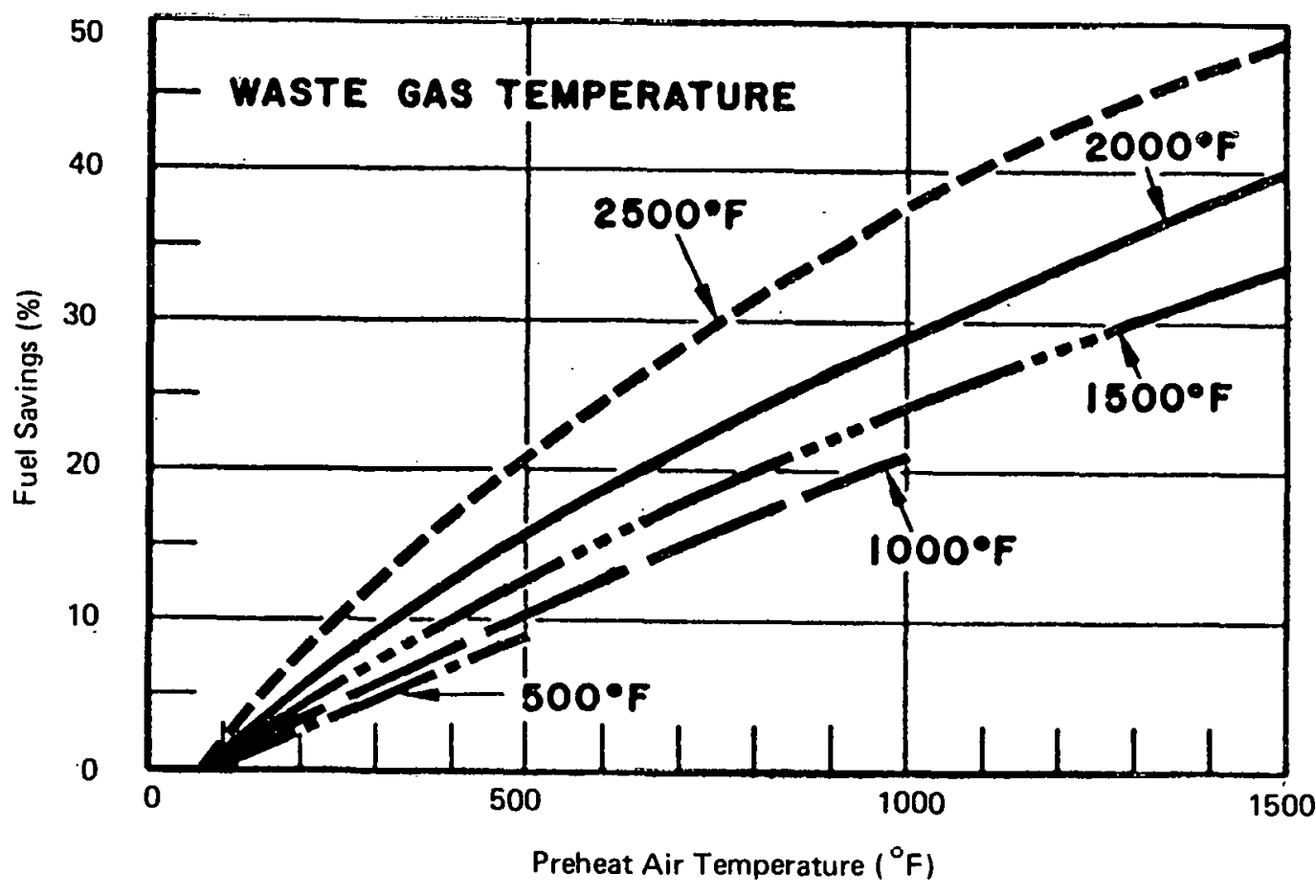

Source: "Energy Conservation in the Steel Industry," AISI, 1976, p. 141.

FIGURE IV-1 ENERGY RECOVERED BY AIR PREHEATING, EXPRESSED AS RELATIVE SAVINGS OF NO. 6 FUEL OIL

It is seen from Figure IV-1 that if the furnace waste gas is at $2000^{\circ} \mathrm{F}$, an increase in the preheat temperature from $1000^{\circ} \mathrm{F}$ to $1500^{\circ} \mathrm{F}$ could permit about a $10 \%$ fuel saving. If applied on a national basis to reheating furnaces in the iron and steel industry, approximately 0.05 quad could be saved.

There is thus a need to develop burner/recuperator systems that can handle high temperatures. Additional potential energy savings could be realized if better temperature and gas composition sensors were used to activate control systems coupled to the burners, as discussed more fully in Chapter $\mathrm{X}$.

Hot gases from the firing zone can, of course, also be used to preheat the incoming feedstock. This is common practice in new reheat furnaces, but it cannot be economically retrofitted on existing furnaces.

\section{Other General Ideas}

(a) Scrap utilization should be increased in blast furnace and steelmaking operations. For each ton of scrap utilized, there is an energy saving of 17 million Btu. In 1976, 8.2 million tons of scrap was exported; this represented an energy export of 0.14 quad. (See Chapter VII.) 
(b) Energy derived from metallurgical coal represents $60.6 \%$ of the total energy consumed by the U.S. steel industry. However, low-sulfur metallurgical coal reserves are limited' and it would be desirable to conserve them as much as possible.

One strategy is to extend these reserves by developing external desulfurization of hot metal (discussed in Chapter VII), so that higher sulfur coals can be used. The preheating of coal charged to coke ovens allows for lower-rank coal to be used to make furnace-quality coke.

Another strategy is to find substitutes for metallurgical coke, such as Formcoke, which would utilize steam coal. This is discussed further in Chapter VI.

(c) Gasification schemes and burners should be developed to permit the use of steam coal as a fuel in applications that now use oil or gas as a fuel. An economic high-temperature desulfurization process is needed, because present-day commercial coal gasification processes such as Lurgi, Kuppers-Tulzek, U-Gus, und the WD/GI gasifier require that the gases be cooled to $200^{\circ} \mathrm{F}$ before being treated for sulfur removal. (The blast gasifier effectively removes sulfur from hot gases, but the fuel gas produced is at a relatively low temperature.) In addition, development of an adequate and economical coal burner applicable to reheat furnaces could potentially replace the 0.5 quad of natural gas and fuel oil used in these furnaces.

1. Some concern has recently been reported about the methodology generally used to estimate when reserves will become depleted. One of the objects of this concern is the likelihood of continuing exports of metallurgical coal. 


\section{MINING, MILLING, BENEFICIATION, AND AGGLOMERATION}

\section{A. THE U.S. IRON ORE INDUSTRY}

In 1976, the usable iron ore production in the United States, including byproduct ore (sinter from pyrite roasting), amounted to 76.7 million long tons and was produced from 222.8 million long tons of mined ore. About $81 \%$ of this production was in the form of pellets.

About $95 \%$ of the ore produced goes to iron blast furnaces; the remainder goes to steel furnaces. Eighty five percent of the ore used by the domestic iron and steel industry is furnished from captive mines owned and/or operated by the large, integrated iron and steel companies.

The heart of the iron ore industry in the United States is the Great Lakes iron mining district in Minnesota and Michigan. Small but significant production also comes from New York, Pennsylvania, Alabama, Missouri, Texas, Wyoming, Utah, Georgia, Wisconsin, and California. Table V-1 shows the statistics on production by region and locations. The Lake Superior district produces $85 \%$ of the total crude ore.

The U.S. crude ore production in 1976 came from 31 companies operating 60 mines, 44 concentrating plants, and 20 pelletizing plants. Of the 60 mines, 54 were open-pit and 6 underground. Open pits accounted for $95 \%$ of the total ore output. Over $95 \%$ of all ore was concentrated before shipment, and $81 \%$ was agglomerated at or near the mine sites before shipment.

There are approximately 20,000 employees in the iron ore mining/milling industry. The major producing companies are listed in Table V-2.

After they are mined, iron ores are "beneficiated" to produce a burden that can withstand the high crushing forces in the blast furnace. Beneficiation includes such processes as crushing, grinding, screening, concentrating, classifying, pelletizing, and sintering. These processes are combined in various ways to suit the type of ore used.

\section{B. IRON ORE MINING}

\section{Introduction}

As indicated above, practically all iron ore is mined by open-pit methods in large surface mines. In this process, both the ore and overburden are drilled, blasted, loaded, and hauled. Overburden or waste rock is separated and placed in waste piles or occasionally in mined-out portions of the pits. The ore is then hauled to the milling plants, most commonly by truck. (One pit moves ore by rail; two others use trucks to the primary crusher and rail the remaining distance to the processing plant.)

\section{Energy Usage - Mining}

In open-pit mining, most of the energy is provided by diesel fuel in the large mobile equipment, gasoline in the smaller vehicle fleet, electricity in the large shovels and the larger drills, and explosives. Other items consumed are grease and lubricants, drill bits, and (on mobile equipment) tires; the latter represent a major cost. 
TABLE $V-1$

U.S. IRON ORE MINE PRODUCTION AND TOTAL SHIPMENTS IN 1976

(thousands of long tons)

Crude ore

\begin{tabular}{|c|c|c|c|c|}
\hline $\begin{array}{l}\text { Great } \\
\text { Lakes }\end{array}$ & $\begin{array}{c}\text { North- } \\
\text { eastern }\end{array}$ & Southerna & Western & $\begin{array}{l}\text { Total } \\
\text { U.S. }\end{array}$ \\
\hline 94,627 . & 5,507 & 7,639 & 15,036 & 222,808 \\
\hline
\end{tabular}

Run of Mine

$83=$

91

1,012

1,186

coarse

3,975

b

b

1,173

5,521

Fines

5,530

1,120

113

887

7,649

Pellets

55,340

b

$\mathrm{b}$

3,475

62,155

Sinter

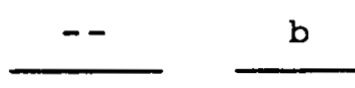

b

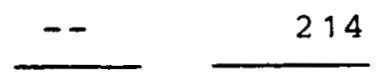

Total shipment

$64,928 \quad 2,099$

3,152

$6,547 \quad 76,726$

a. Includes by-product ore

b. Shipments not shown to avoid use of individual company data

Source: "1976 Data Book," American Iroń Ore Association, Cleveland.

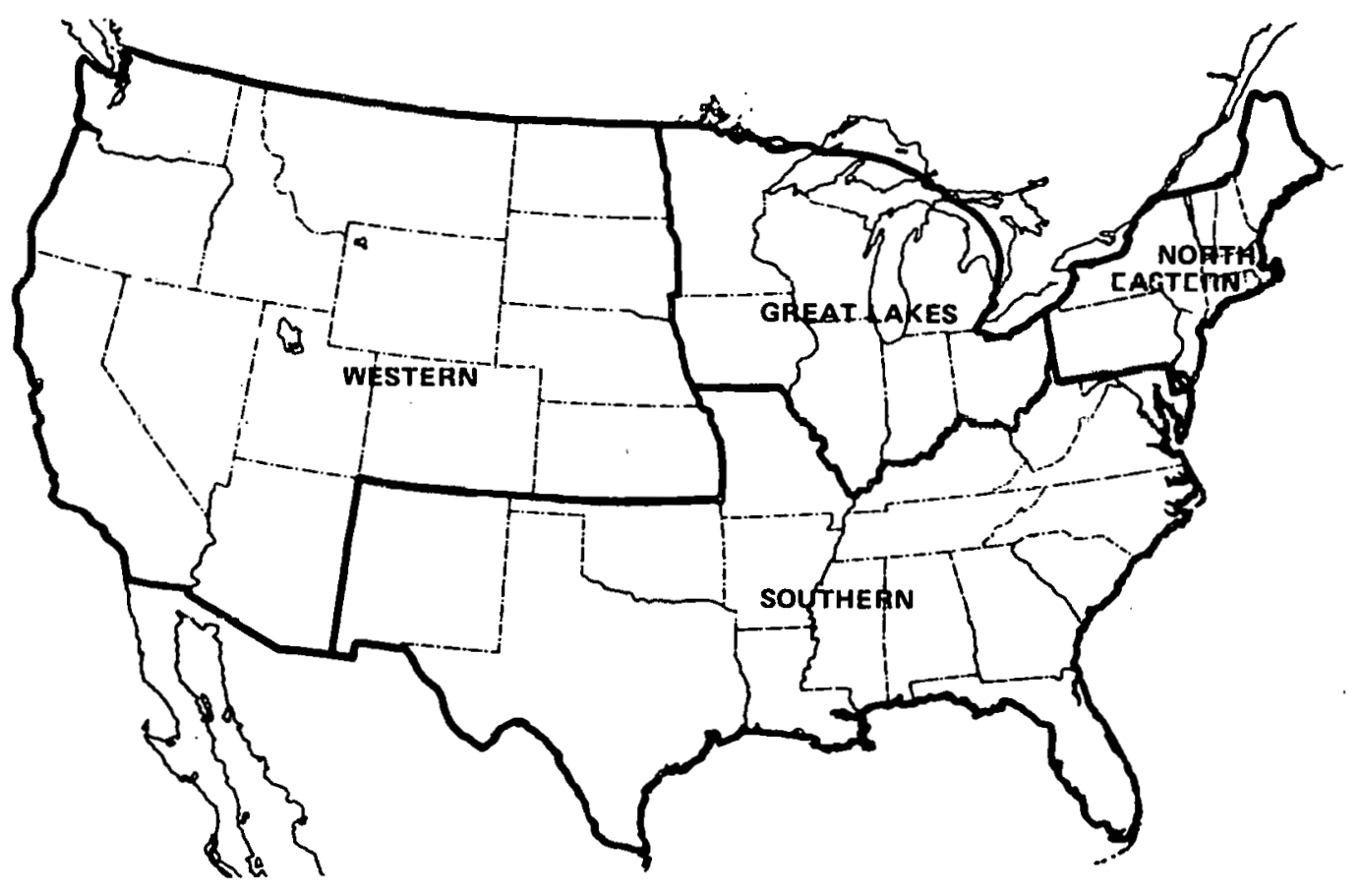




$$
\begin{aligned}
& \text { TABLE V-2 } \\
& \text { MAJOR PRODUCERS OF IRON ORE IN } 1976^{\mathrm{a}} \\
& \text { (includes ore, concentrate, and pellets) }
\end{aligned}
$$

COMP ANY

Cleveland Cliffs

Hanna Mining Co.

Inland steel

Jones and Laughlin

Kaiser Steel

Meramec Mining Co.

oglebay Norton

Pickands Mather

Reserve Mining

U.S. Steel

Colorado Fuel and Iron

Bethlehem Mines

Pittsburgh Pacific
PRODUCTION

(milion long tons)

14.8

7.7

1.0

2.8

3.0

1.3

2.0

10.3

9.7

18.5

1.4

1.0

0.5

"Major" defined as those producing over $1 / 2$ million long tons of products per year. 
In this analysis we are considering only direct fuel use. The estimated consumption in 1976, when 223 million tons of ore and 178 million tons of waste were mined, is as follows:

$\frac{\text { Fuel Consumption }}{\text { Total }}$ MMBtu/ton ore

$\begin{array}{lrl}\text { Electric Power } & 180 \times 10^{6} \mathrm{kWh} & 0.009 \\ \text { Diesel Fuel } & 80 \times 10^{6} \mathrm{gal} / \text { year } & 0.050 \\ \text { Gasoline } & 20 \times 10^{6} \text { gal/year } 0.011\end{array}$

Total

0.070

\section{Potential Energy Savings}

There does not appear to be any promising technology or changes coming that could materially affect the encrgy consumption in the iron ore mining industry. Mining equipment is being gradually improved, and there is a continuing trend to larger and more efficient drilling, loading, and hauling equipment; these improvements should help to reduce the energy consumed per unit of production, but their effect will be small and marginal over the coming years.

\section{MILLING}

The milling of taconite ore typically includes numerous crushing, grinding, and separation steps. The energy consumed in this process is approximately as follows:

$$
\begin{aligned}
& \text { Energy Consumption } \\
& \text { (kwh/ton cruae ore) }
\end{aligned}
$$

Crushing and Grinding

17.0

Concentrating

1.5

Tailings Disposal

1.2

Water Supply

1.5

Total

21.2

The total power used in milling the 222.8 million tons of ure processed in 1976 is, therefore, about 0.5 quad ( 0.223 million Btu/ton ore x 222.8 million tons ore/yr).

Potential energy savings are in crushing and grinding, as discussed in detail in the following section. 


\section{CRUSHING AND GRINDING}

\section{Introduction}

Iron ores and most other metallic ores occur in nature as mixtures of valuable metalcontaining minerals and gangue (waste minerals). The common iron ores are intimate mixtures of iron oxides (hematite and magnetite) in gangue such as quartz and iron-bearing silicates.

Therefore, to separate valuable minerals and concentrate them, the ore must be crushed and ground to the size at which the valuable particles are liberated. This requires large amounts of energy, particularly for the harder ores like the taconites. Size reduction is a very inefficient operation in terms of a comparison between the energy input and the resulting increase in surface energy of the material being ground. Energy is consumed both in breaking down the material itself and in the machinery doing the breaking. The following table (from Ref. 1) summarizes the major ways energy is used in crushing and grinding before it appears as heat:

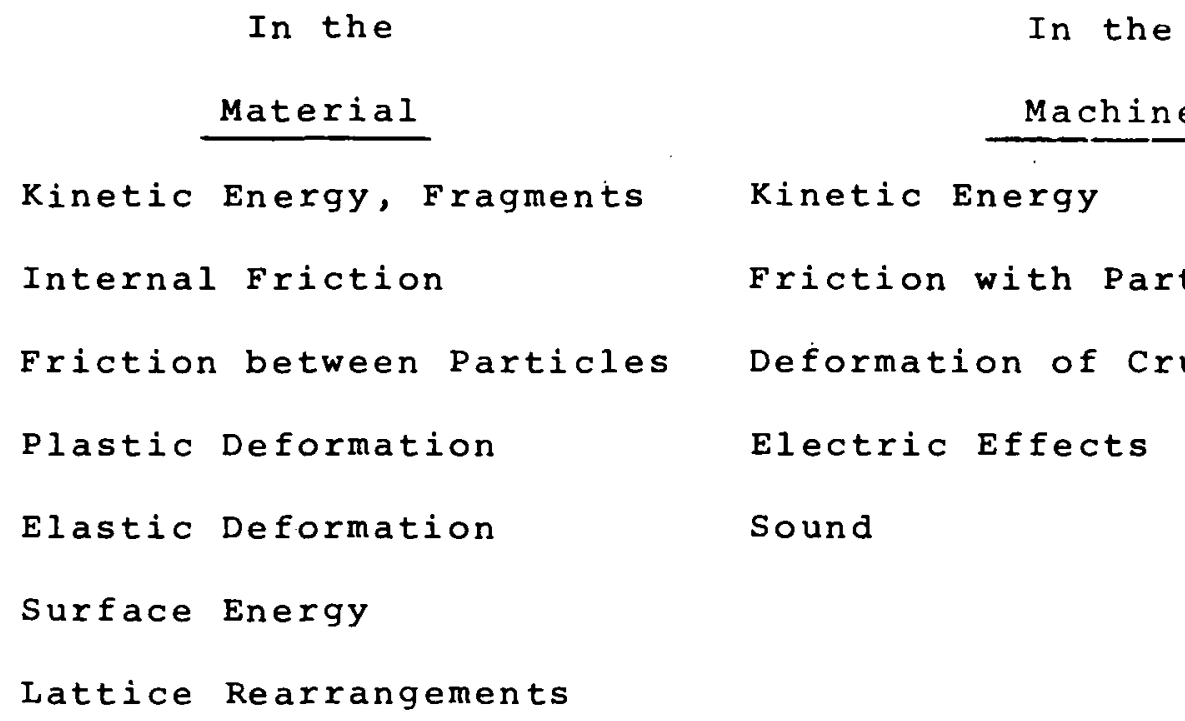

There are a number of ways to estimate and report energy consumption in crushing and grinding. The one in common use is Bond's Third Theory of Comminution (Ref. 2), which calculates the amount of power to reduce material by the following equation:

$$
\begin{aligned}
\mathrm{W} & =\frac{10 \mathrm{Wi}}{\sqrt{\mathrm{P}_{\mathbf{8 0}}}}-\frac{10 \mathrm{Wi}}{\sqrt{\mathrm{F}_{\mathbf{8 0}}}} \\
\mathrm{W} & =\text { power in } \mathrm{kWh} / \text { short ton ore } \\
\mathrm{Wi} & =\text { Bond's work index } \\
\mathrm{P}_{\mathbf{8 0}} & =\text { size in microns which } 80 \% \text { of product passes } \\
\mathrm{F}_{\mathbf{8 0}} & =\text { size in microns which } 80 \% \text { of feed passes }
\end{aligned}
$$


In considering energy consumption in the crushing and grinding of any ore, one must include the entire process; this is because there are intimate relationships between the crushing and grinding itself, the sizing equipment used, the movement of materials between machines, and the size of grind required and its relationship to the recovery or concentration process used.

In crushing and grinding no fossil fuel is used, only electric power. The other major input in crushing and grinding - which can be considered as a secondary energy input - is the steel worn off the liner, mantle, balls, and rods. This varies with the hardness of the ore and method of grinding, but for hard and abrasive ores like the taconites, it amounts to about $4 \mathrm{lb} /$ ton of ore processed. On softer ores it can be as low as $1 \mathrm{lb} /$ ton of ore. This secondary type of energy input is not considered in this study.

\section{Energy Use}

It is evident that the mujor energy-consuming process in U.S. iron ore production is the making of pellets from the fine-grained magnetic and non-magnetic taconites in the MichiganMinnesota area. The taconites are very hard ores and require crushing and fine grinding to liberate the hematite or magnetite particles for separation.

A wide variety of crushing, grinding, and separation processes are used with these ores. A typical operation may involve primary crushing in gyratory crushers near the mines, secondary and tertiary crushing at the mills in cone crushers, and fine grinding in rod mills and ball mills. The flowsheet shown in Figure V-1, which applies to a magnetic taconite, shows the relationship of the fine grinding mills to the other equipment in the separation process. The crushing and grinding consists of the following:

- Primary crushing, run-of-mine ore: $5 \mathrm{ft}$. crushed to 6 in.

- Secondary and tertiary crushing: 6 in. to $3 / 4$ in.

- Rod mill: $1 / 4$ in. to $1 / 4$ in.

- Primary ball mill: $1 / 4$ in. to $40 \%-270$ mesh

- Secondary ball mill: $40 \%-270$ mesh to $90 \%-270$ mesh

Using the Bond equation and work index for taconite (14.87), we can estimate the energy used in crushing and grinding this material as follows:

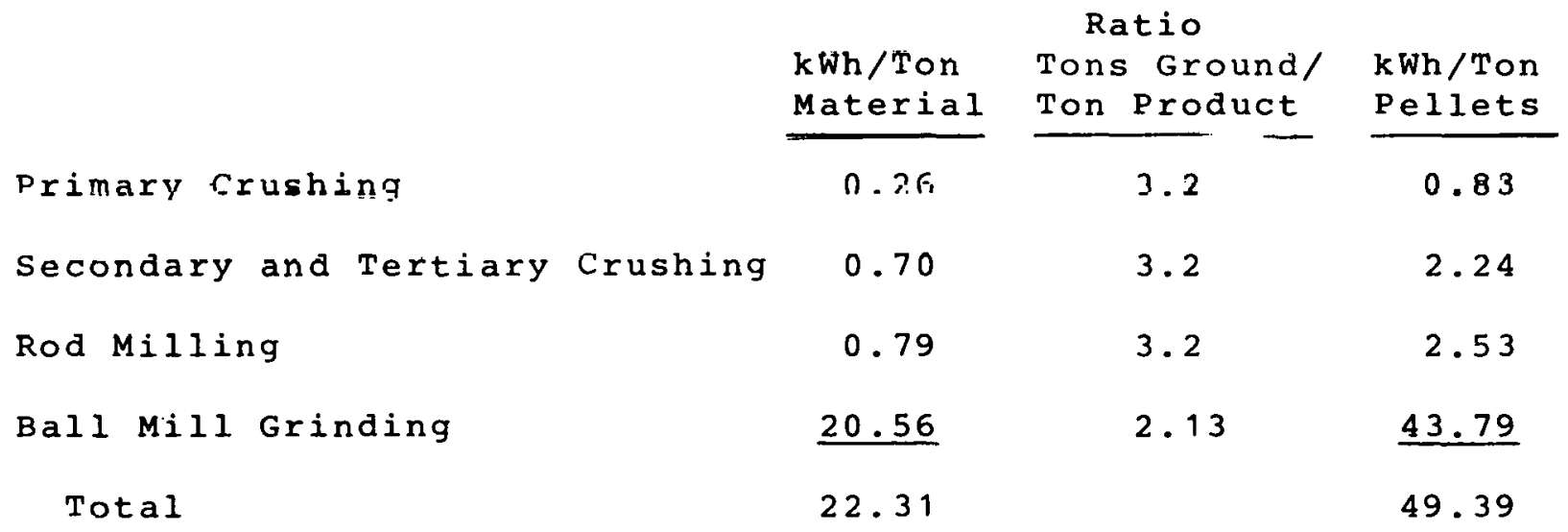




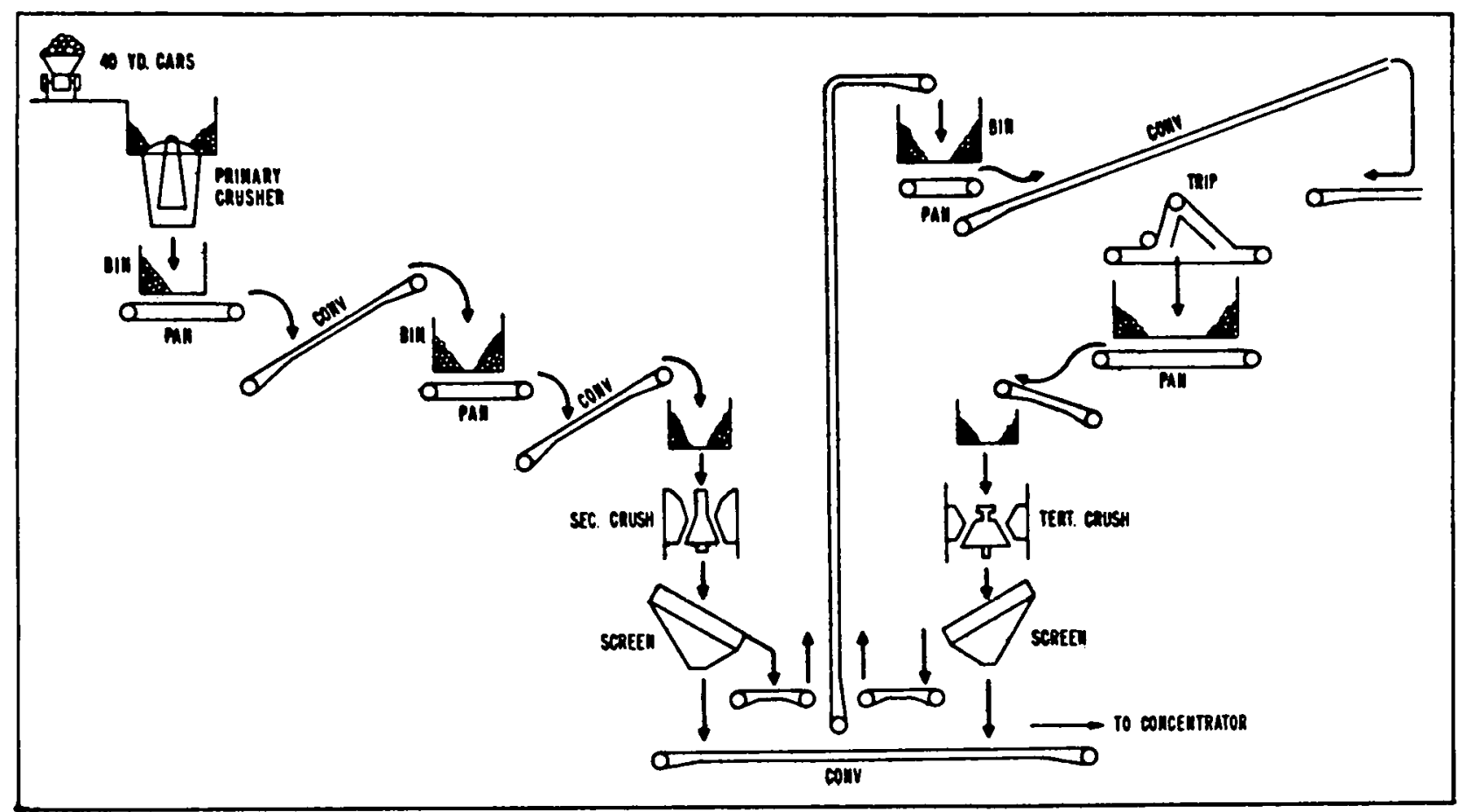

a. Crushing Plant

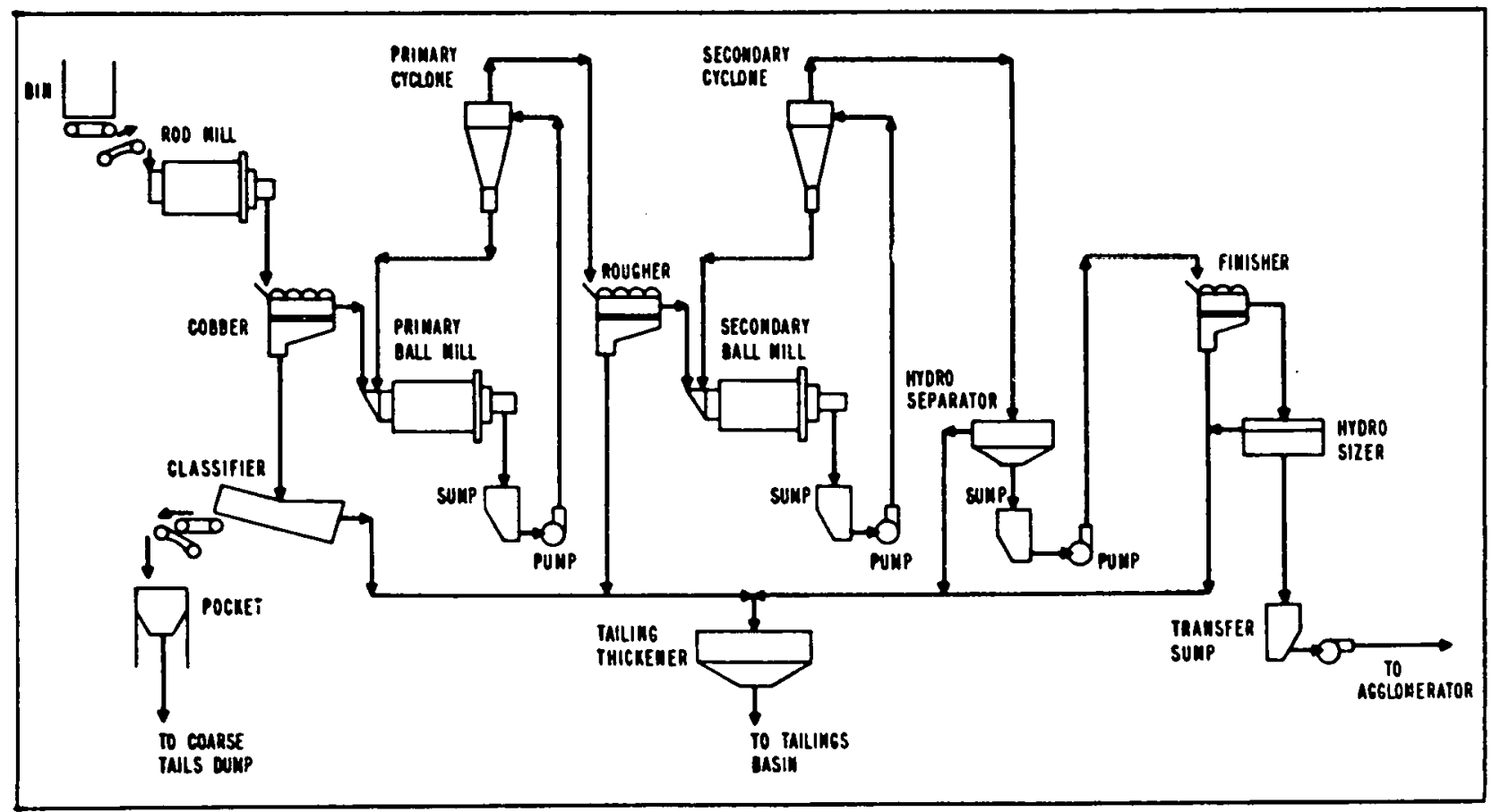

b. Concentrator Section

Source: "North American Iron Ore," Engineering \& Mining Journal, Nov. 1974, pp. 108-9.

FIGURE V-1 TYPICAL MILLING OF TACONITE ORE 
The $49.4 \mathrm{kWh}$ of crushing and grinding energy needed to produce a ton of finished pellets is equivalent to $15.4 \mathrm{kWh} /$ ton ore. Thus, the 62 million tons of pellets produced in 1976 required approximately 3,062 million $\mathrm{kWh}$. The actual crushing and grinding power reported to be consumed at a plant similar to that shown in Figure V-1 was $17.0 \mathrm{kWh} /$ ton of ore; the difference is probably due to inefficiencies in feeding, changes in ore character, and imperfect sizing in screens and cyclones.

The remainder of the iron ore industry, that is, direct shipping ore production and the production of fine and coarse concentrates, also requires crushing and grinding energy. These activities involve the processing of about 24 million long tons of ore, which consumes about 192 million $\mathrm{kWh}$ of electrical energy.

Therefore, for the total U.S. iron ore processing industry, about 3,254 million $\mathrm{kWh}$ is used per year in crushing and grinding.

\section{Potential for Energy Savings}

Much work has been done on energy use and consumption in the grinding portion of the ovcrall crushing-grinding flowshect, since that is by far the largest energy-consuming step. Less attention has been directed toward energy used in crushing and how it is related to the grinding energy.

A recent paper (Ref. 3) has pointed out important relationships between the crushing equipment and its sizing devices (screens) and that energy can be saved by their proper application. For the most effective utilization of energy, the crushing equipment and its screens and the grinding equipment and its sizing devices (cyclones) must be considered as a single system.

There is no way to estimate exactly how much energy might be saved by the total industry if all crushing and grinding systems were perfectly designed and operated in an optimum mode. However, several authorities believe that on the order of $20 \%$ is possible. This would probably require the development and application of automatic control systems.

We see little likelihood of a revolutionary development in crushing and grinding that will make possible order-of-magnitude savings in energy use. More probably, small and gradual improvements and energy savings will be made as more effective machinery is developed and utilized. The following would help in this endeavor:

- Application of automatic control to the total crushing, sizing, and grinding flowsheet. This requires modeling of the total system and selection of strategies for control, kinds of parameters to measure, instruments to use, etc. It also requires study of the characteristics of crushing and grinding, classification and sizing, and transport.

- Improvement of sizing devices (screens and hydraulic cyclunes) to make a closer and more perfect size separation at the desired point. The major impact would be from improvements in the sizing ability of hydraulic cyclones.

- The use of grinding aids. These might reduce energy usage slightly. 
- Improvements in grinding media to reduce metal wear and consumption. These would include the use of inhibitors to reduce ball and rod corrosion.

\section{E. AGGLOMERATION}

When concentrates are produced from iron ores, they must be prepared for feeding to the blast furnace by either sintering or pelletizing in order to prevent the iron-bearing material from being carried out of the blast furnace by the upflowing gas stream. In general, the coarser concentrates can be sintered and the finer ones pelletized. Four principal processes are used for agglomerating iron ores and concentrates: sintering, nodulizing, briquetting, and pelletizing. Each of these is described below.

\section{Sintering}

In the grate sintering process, concentrates are mixed with pulverized coal or coke breeze and with recycle sinter fines. This mixture, with some moisture, is placed on the moving grate. The top surface is then ignited, and the burning zone progresses downward through the bed. When it reaches the bottom, the reaction is complete, and the sinter is cooled and discharged.

In this process, the necessary fuel is provided by the coal or coke added. The requirements vary from 1.3 to 1.9 million Btu per short ton of sinter.

It is not likely that any substantial energy savings can be made in the sintering process.

\section{Nodulizing}

In the nodulizing process, iron ore concentrates are mixed with limestone and fed to a rotary kiln fired with pulverized coal. For each ton of nodules, about 82 pounds of limestone is added, about 1.9 million Blu of fuel (coal) is consumed, and about $12 \mathrm{kWh}$ of power is used by the fans, kiln, etc.

This process is not extensively utilized in the United States and does not represent any great opportunity to save energy.

\section{Briquetting}

Briquetting is probably the oldest method for agglomerating iron ores and has the advantage of saving the energy used in sintering or pelletizing. Binders such as cement, sulfite liquor, and iron sulfate solution have been used, but the resulting briquettes are not strong enough for blast furnace use.

Cold briquetting has been tried with iron ore fines and 1.0-1.5\% portland cement, but these briquettes cannot be stockpiled because they disintegrate when wet.

Hot briquetting processes have been tried but are not widely used. 


\section{Pelletizing}

\section{a. Introduction}

Pelletizing consists of forming balls from a mixture of the fine concentrate and binder at room temperature and then hardening them by heat treatment.

Balling involves dewatering of the fine concentrate (70-90\% -325 mesh) to $9-11 \%$ moisture, thorough mixing with about 14 pounds of bentonite per ton of concentrate as the principal binder, and the forming. of green balls in drums or discs. For heat treating the green balls, four types of equipment are used - shaft furnaces, Dravo-Lurgi traveling grates, the Allis Chalmers gratekiln system, and the McKee circular grate. Details of all these processes are available in the literalure. Table V-3, a list of U.S. pelletizing planto, ohowe that there were three shaft plants, seven straight (traveling) grate plants, ten grate-kiln plants, and no circular grate systems in operation in 1976.

Figure V-2 is a pictorial diagram of a typical grate-kiln plant.

\section{b. Energy Use in Pelletizing}

Pelletizing plants use a hydrocarbon fuel for induration and a substantial amount of electric power, principally for fans to circulate and control the gases.

Fuel consumption amounts to about 500,000 Btu per ton of pellets when indurating magnetite and about $1,000,000$ Btu per ton when indurating hematite. Power consumption is on the order of $25 \mathrm{kWh}$ per ton of pellets.

The total fuel consumption in the U.S. pelletizing industry is estimated as follows (for 1976):

$$
\begin{array}{lrl}
\text { Magnetite: } & 47.4 \times 10^{6} \times 500,000 & =23.7 \times 10^{12} \mathrm{Btu} / \mathrm{yr} \\
\text { Hematite: } & 9.9 \times 10^{6} \times 1,000,000=9.9 \times 10^{12} \mathrm{Btu} / \mathrm{yr} \\
4.9 \times 10^{8} \times 750,000 & =3.7 \times 10^{12} \mathrm{Btu} / \mathrm{yr} \\
& \text { Total }=37.3 \times 10^{12} \mathrm{Btu} / \mathrm{yr}
\end{array}
$$

Total power consumption is on the order of $1.6 \times 10^{9} \mathrm{kWh}$ per year.

Fuel oil and natural gas are used as the fuels in pelletizing; however, dwindling supplies and rising prices have led to the consideration of alternate fuels, principally the direct use of coal or gas mare frnm ronal.

The use of low- and intermediate-Btu gas from coal for pelletizing has been assessed in some detail in a Bureau of Mines study (Ref. 4). The latter concluded that low- or intermediate-Btu gas produced by gasification of coal in a Wellman-Galusher or Koppers-Totzek gasifier, external to the indurator, could be successfully used in shaft furnaces, traveling grate, and grate/kiln systems. For the iron ore industry in Minnesota and Michigan, low-sulfur Western coals would be preferred, to avoid the problem of sulfur dioxide emissions. 
TABLE $\quad V-3$

U.S. PELLETIZING PLANTS

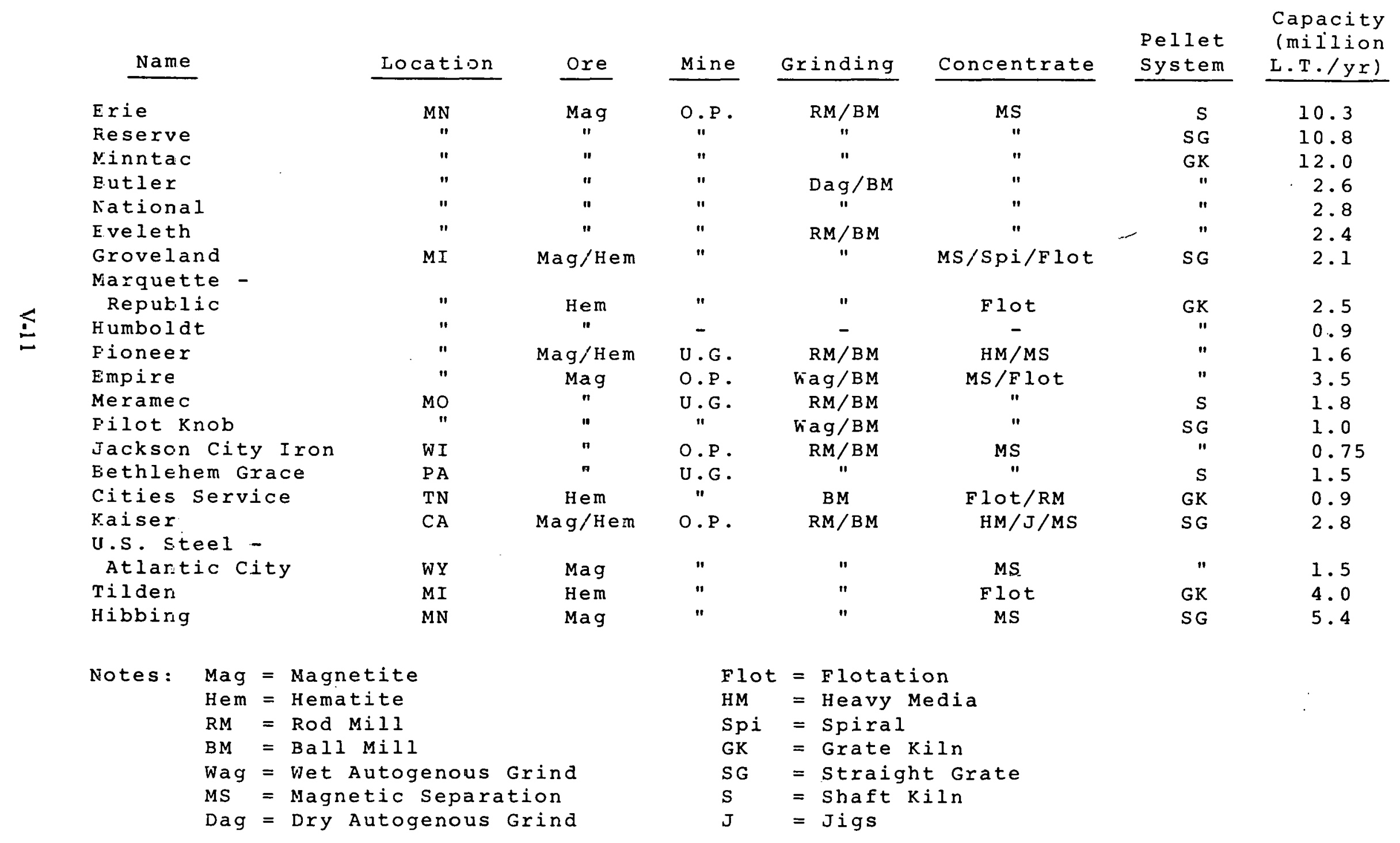




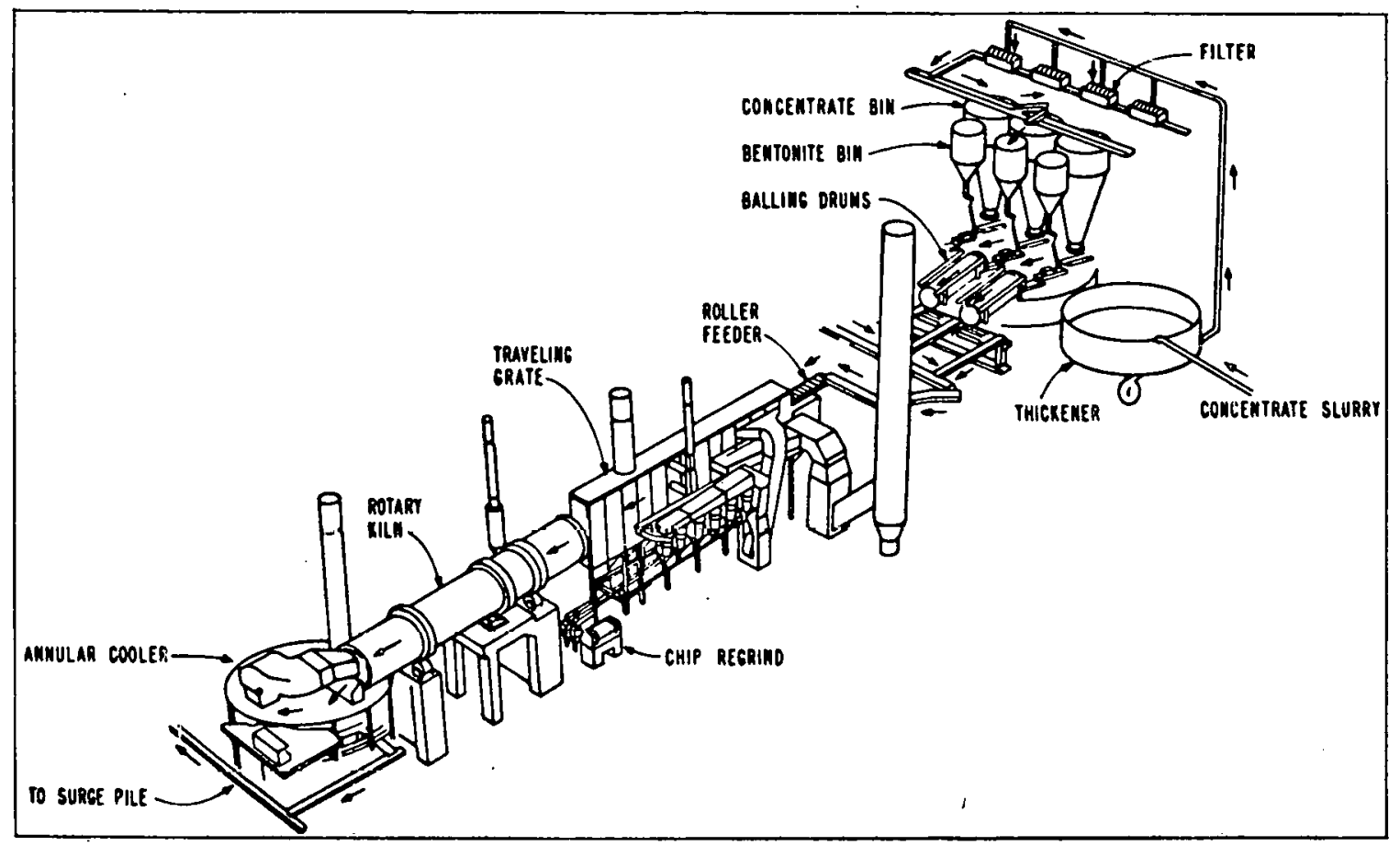

Source: "North American Iron Ore." Engineering \& Mining Journal, Nov. 1974, p. 109.

$$
\text { FIGURE V-2 GRATE-KILN PELLETIZING PLANT }
$$

For an on-site plant (i.e., one located at the mining, processing, and agglomeration facilities) producing 2.5 million long tons of pellets per year, the investment in the gasification plant was estimated at $\$ 11$ million. Necessary modifications to the pellet plants themselves would cost from $\$ 143,000$ to $\$ 1,650,000$, depending on the gas used and the type of indurating plant. The study concluded that with coal gasification yielding equivalent natural gas costs of $\$ 3,00$ per million Btu, coal gasification would be a viable alternative source of fuel for pelletizing in the future.

The other possibility is direct firing of pulverized coal in the indurating furnace. Allis Chalmers, who supplies the grate-kiln systems, has intensively investigated the direct firing of coal in its system; it has concluded that coal is similar to oil and natural gas with regard to heat transfer and temperature profiles in the kiln, that ash build-up in the process equipment can be ameliorated by the proper selection of coal and optimization of the process control, that there is no contamination of the product or atmospheric pollution, and that there is no effect on sizing or energy utilization of the induration process equipment. The best coal to use is, in general, that with the lowest ash content. Coals must be tested to assess their applicability. Starting a coalfired plant requires a small amount of either natural gas or oil.

Dravo has also conducted research and developed methods of direct coal firing for its traveling grate system. Its concept calls for combustion chambers on both sides of the grate and gun-t.ype suspension burners.

The shaft furnace is probably the most difficult system to adapt to direct coal firing because of the multiplicity of combustion chambers and passages. 


\section{c. Energy Savings with Coal Firing}

The following developments in coal firing of pellet plants had taken place as reported by trade journals in the second quarter of 1977 :

- Erie Mining Co. plans to build a $\$ 39$ million coal gasification plant at Hoyt Lakes, Minnesota, for its 27-shaft furnace plant with ERDA (now DOE) support.

- Inland Steel announced that its Minorca plant plans to burn Western coals in external combustion chambers starting in 1978.

The above has been accomplished by the industry and its equipment suppliers with help from Government agencies. Progress since the second quarter of 1977 has not been monitored. However, it appears that the technology is being pursued and that the iron ore industry is seriously considering the retrofit of its pelletizing plants to the use of coal. Should the above projects be successful, we believe this trend will continue as natural gas becomes more scarce and expensive.

If all pelletizing plants convẹtted to çoal, there would be a conversion of $37.3 \times 10^{12} \mathrm{Btu} / \mathrm{yr}$ from natural gas and fuel oil to coal. If the technology is technically and economically demonstrated, we would expect that probably $50 \%$ of the plants would convert in the near future, so the savings would be about $20 \times 10^{12} \mathrm{Btu} / \mathrm{yr}$.

\section{d. Other Potential Energy Savings Developments}

New energy-conserving developments in pelletizing that should be considered are (1) the incorporation of coal fines in the pellets before firing and (2) cold bonding processes, which require no fuel for induration.

(1) Coal in Pellets. This practice consists of adding coke breeze or some other solid redustant, such as anthracite fines in the mixture of concentrate, bentonite, and water so that it is incorporated in the green balls, which are then fired. This, of course, reduces the amount of external fuel (oil or gas) required, and the heat is liberated more efficiently inside the pellet.

Experimental work at Hoogovens in The Netherlands showed that 1.0-1.5 of coke breeze by weight increased the productivity of a pelletizing strand and decreased external fuel requirements. More than $1.5 \%$ resulted in poor pellet quality; about $1 \%$ by weight appeared to be the optimum amount.

With the $1 \%$ coke breeze addition, a saving of about $1 \% \%$ in external fuel requirements was achieved. 
We know of one pelletizing operation in Africa where $0.7 \%$ by weight of anthracite fines (70: carbon; calorific value $11,200 \mathrm{Btu} / \mathrm{lb}$ ) is added in the pellet. This saves seven liters of fuel oil $(272,000 \mathrm{Btu})$ per long ton of pellets.

Addition of anthracite to the pellet also gives better energy utilization. For example, in the case above, the energy content of the anthracite added was $176,000 \mathrm{Btu}$ per long ton of pellets, while the energy content of the oil saved was 272,000 Btu per long ton of pellets.

We do not see any effort in the United States to apply this technology; however, with the need for more effective energy utilization, we believe it is interesting and should be encouraged, particularly for pelletizing the hematites. If all U.S. hematite pelletizing plants adopted this practice, $2.7 \times 10^{12} \mathrm{Btu}$ of oil and natural gas energy would be converted to coal annually.

This practice might be encouraged if DOE were to sponsor a study to assess the potential in grealer detáil.

(2) Cold Bonding. In cold bonding processes, pellets, briquettes, etc., are made at ambient temperatures. Unlike the presently used high-temperature induration, no fuel is required.

Numerous patents have been granted for the cold bonding of iron ore fines and similar materials. Binders used include tar, petroleum residue, cement, lime, magnesia, molasses, wax, glue, soap solution, starch, dextrin, paper pulp, sulfite liquor, sodium silicate, sodium and potassium hydroxide, carbonates, chlorides and sulfates, borates, bentonite, clay, diatomaceous earth, ferric chloride, marine plants, peat, colemanite, and some plastics. However, only the following have been applied on a large scale for iron ore fines and steel plant wastes:

- Carbonate bond process: Mix iron ore concentrate, water, hydrated lime, and coal fines. Pelletize and dry, carbonate with $\mathrm{CO}_{2}$, and screen. Pellets were produced by this process on a pilot-plant scale, but not commercially. Iron grade was only $55 \%$. The pellets had low tensile strength.

- Grancold process: Mix iron ore concentrate, water, and portland cement. Pelletize, screen, harden, and screen again. Developed in Sweden, where commercial plant is now operating. Hardening takes 3-6 days, and full hardness is reached in 30 days while pellets are in storage. Makes good pellets.

- Chor process: Process similar to Grancold, but hardening is accelerated by steam curing. Pilot-plant tested in Michigan. No commercial application.

- MTU cold bond process: Mix iron ore concentrate, water, lime, silica, and coal fines (optional). Pellelize, dry, steam auloclave, and dry. Developed at Michigan Tech. $92-94 \%$ of iron ore fines $(65.7 \% \mathrm{Fe})$ are mixed with $5-7 \mathrm{wt} \%$ of $\mathrm{CaO}$ and $1 \%$ $\mathrm{SiO}$, Final product is a good pellet with $68 \% \mathrm{Fe}$. If $15 \%$ coal is added, iron oxides are completely reduced to metallic iron in the blast fumace. Pilot plant has been in operation in California since 1976. Autoclaving time is 1-2 hours at. 300 psig.

- Cobo process: Developed in Sweden and similar to the MTU process. Lime and silica can be used or, alternatively, slag and portland cement. The first commercial 
plant was built in Sweden to pelletize chromite fines. Autoclaving takes place at $200^{\circ} \mathrm{C}$ compared with $1250-1400^{\circ} \mathrm{C}$ for conventional processes; hence, there is an appreciable energy saving.

In the MTU and Cobo processes, drying a ton of green balls requires about 3 liters of oil $(119,000 \mathrm{Btu})$; steam autoclaving takes another $35,000 \mathrm{Btu}$ per ton of pellets. Hence, the total fuel energy input for these processes is approximately 154,000 Btu per ton of finished pellets.

In high-temperature indurating processes, we calculate that an average of $600,000 \mathrm{Btu}$ is used per ton of pellets. Hence, if one went to a cold induration process of the MTU or Cobo type, an energy saving of 446,000 Btu per ton of pellets would be expected.

In a typical mixture used in the MTU process, about $6 \mathrm{wt} \% \mathrm{CaO}$ is added. The energy to produce this is about 100,000 Btu per ton of pellets. Thus, the net saving by using cold bonding would be approximately 346,000 Btu per ton of pellets. If the total industry were to do this, some $21.5 \times 10^{12}$ Btu would be saved per year.

The above energy-conserving concepts are critical only from the viewpoint of saving natural gas or liquid fuels, and only if some severe impediments develop in converting present-day pelletizing plants to coal firing.

There appears to be little interest in cold bonding in the United States; however, pilot plant work on the MTU concept is being done in California and the Cobo process is operating in Europe. The results of these and perhaps other developments should be assessed before DOE sponsors work in the area.

\section{CHAPTER V}

\section{REFERENCES}

1. Orr, C., .Jr., Parliculate Technology, Macmillan, New York, 1966.

2. Bond, F. C., "Crushing and Grinding Calculations," Allis Chalmers, 1961.

3. Flavel, M. D., "Scientific Methods to Design Crushing and Screening Plants," Annual Meeting of AIME, 1977.

4. McKee, A. G. \& Co., "Study of Low and Intermediate Gas from Coal for Iron Ore Pelletizing," reported in Engineering and Mining Journal, July 1977. 


\section{COKEMAKING}

\section{A. BACKGROUND}

\section{Conventional Technology}

Approximately 1.46 tons of metallurgical coal are consumed in the production of each ton of metallurgical coke. This coal is a specially selected blend with particular characteristics of sulfur content, volatile content, and caking properties. It is usually delivered to steel plants in rail cars; in winter, the coal often freezes in the cars and is thawed by holding the hopper cars in thaw sheds - sections of track with wind screens on either side and coke oven gas-fired "hotdog"-type burners lying between the rails.

A portion of the coal delivered to the site is put into storage, and the remainder is transferred to a conveyorized coal preparation system, typically by a tracking stacker/reclaimer. Coal reclaimed from or bypassing the piles passes through a bar grizzly station equipped with a tramp metal magnet to remove any large or ferrous foreign material. The coal is then screened, and the oversized material is crushed to $-1 / 2$ inch. The crushed coal is typically metered from storage bins by weigh belt feeders to obtain the desired coking coal blend in the feed to the coke ovens. Oil may be mixed with these blended coals to control bulk density. The resulting coking coal blend is stored in stocking bins above the coke ovens.

The coke oven battery is a refractory structure consisting of many slot ovens, each typically 50 feet long, 20 feet high and only $16-1 / 2$ inches wide. Gas spaces between the slot ovens form combustion and flue gas chambers in which coke oven gas or enriched blast furnace gas burn to heat ("underfire") the ovens to nearly $1000^{\circ} \mathrm{C}$. Hot combustion products pass into brick checkerwork regenerators beneath the ovens on a cyclic basis; alternately, combustion air is blown through the hot regenerators to preheat it prior to combustion. The coking coal blend is charged through three or four charging ports in the roof of each slot oven by a special coal-charging machine, called a lurry car, which runs on rails alung the roof of the battery.

During coking, the coal is baked in the oven for 16 to 18 hours, reaching temperatures as high as $1100^{\circ} \mathrm{C}$. Since air is excluded from the slot ovens, the coal does not burn but is transformed to hard, porous coke. Volatile gases and liquids are driven off from the coal during coking and are evacuated from the oven by steam aspirators. The gases are collected in muins that run the length of the battery and are conveyed to the byproduct plant, where valuable tars and oils are recovered and noxious gases (such as $\mathrm{H}_{2} \mathrm{~S}$ ) are removed. Some of the gas is returned from the byproduct plant to the coke oven battery for underfiring; the remainder is used as fuel in other parts of the steel plant.

On one side of the battery are special pushing machines which move on rails the length of the battery. These machines serve two purposes: they push levelling bars through the ovens, just beneath the roof, to level the charge of coal in each oven, and they push the coke out of the ovens. When the coal in an oven is fully coked, the pusher machine lines up with the door, opens the door, and uses a ram to expel the coke through an open door on the other, or coke, side of the oven. On the opposite side of the battery are coke-side door machines, which open the doors on that side and may tow portable coke guides which enclose the coke as it exits from the oven to reduce air polloution. 
When the coke is discharged from the oven through the coke guide, it is collected in a hot coke transfer car. This car conveys the hot cuke into a quenching station or tower, where it is cooled by overhead water sprays. Once quenched by these sprays, the coke is discharged onto a coke wharf, where further cooling takes place and where hot spots can be detected and extinguished. The cool coke is then screened into blast furnace coke $(+3 / 4-i n c h)$ and smaller buckwheat coke and coke breeze.

The raw coke oven gas withdrawn through the slot oven ascension pipes is rich in valuable tars and oils and contains noxious gases such as $\mathrm{NH}_{3}, \mathrm{H}_{2} \mathrm{~S}$, and $\mathrm{HCN}$. Traditionally, this gas is quenched to $100^{\circ}-200^{\circ} \mathrm{C}$ by flushing liquor (primarily water) sprays in the coke oven gas mains. The gas is further cooled by indirect heat exchange in the primary coolers located in the byproduct plant. Tars and naphthalene are recovered by condensation. Much of the ammonia is recovered by absorption in the flushing liquor; the remainder may be recuvered by various absorption processes. Light oil (consisting primarily of benzene, toluene, and xylene) is typically recovered by absorption in a petroleum vil. A number of prucesses are available for desulfurization of the coke gas. The light oil is generally sold to petroleum refiners or chemical companies; the tar and naphthalene recovered may be either sold or burned on site as boiler or blast furnace fuels.

In 1976, approximately 53.2 million tons of coke were consumed in the United States, almost all of which (51.6 million tons) was consumed by blast furnaces. This represents approximately 0.61 ton of coke for each ton of steel produced by domestic blast furnaces. Production of this coke consumed 76.1 million tons of metallurgical coal. Each ton of metallurgical coke produced yields 13,000-19,000 SCF of coke oven gas containing 450-550 Btu/SCF. Much of this gas is returned to underfirc the oven; in 1976, $185 \times 10^{12}$ Btu of gaseous fuel (COG, BFG, and natural gas) was consumed in underfiring coke ovens. Total energy consumption in coke ovens, including steam and electricity consumed by the ovens themselves, by the roal preparation system, and by the byproduct plants represented approximately $264 \times 10^{12} \mathrm{Btu}$ in 1976, excluding the fuel value of the metallurgical coal.

\section{Possible Energy-Conserving Changes in Cokemaking}

The total thermal energy consumed in cokemaking could be reduced by the use of at least four possible process changes: dry quenching of coke, preheating of coking coal, recovery of sensible heat from coke oven gas, ${ }^{1}$ and more efficient thawing of coal cars. Consumption of oil, natural gas, and metallurgical coal would therefore be reduced by any of the above processes. In addition, coal preheating would allow coke producers to draw from an expanded range of coals, thus effectively increasing the domestic metallurgical coal base. The metallurgical coal base could be more radically increased by converting from the conventional cokemaking technolngy to some of the more advanced formed-coke processes.

Consumption of critical fuels by the steel industry might also be reduced by changing the pattern of fuel use within the steel plants; for example, more blast furnace gas might be used to underfire coke ovens, thus releasing more coke oven gas, which could replace natural gas elsewhere in the plant. Another energy-conserving change would be to leave the light oil in the coke oven gas and burn it within the steel plant rather than selling it as a chemical feedstock. (The chemical value of light oil has generally been higher than its fuel value, but this may not be true in the future.)

1. As we are not aware of any commercial application of this concept, it is discussed in Chapter $X$. 


\section{B. COAL PREHEATING}

\section{Description}

If the blended coal is dried and preheated prior to charging in the coke ovens, a stronger coke will result than if wet coal is charged directly. A typical coal preheating operation involves further crushing of the coal to $-1 / 8$ inch. Coke oven gas, blast furnace gas, or natural gas is burned to supply a high-velocity, inert gas stream that will entrain, heat, and dry the coal as it is conveyed in a series of risers and cyclones. The preheated coal, at approximately $200^{\circ}-250^{\circ} \mathrm{C}$ and $1 \%$ moisture, is collected from the gas stream by cyclones and electrostatic precipitators and is conveyed to hot coal charging bins. From these bins it travels to the ovens by a stream-fluidized pipeline, enclosed chain conveyor, or modified larry car.

By whatever method it is charged, preheatcd coal flows more evenly into the ovens, thus eliminating the need for leveling of the coke oven charge. The preheated coal also cokes faster and more evenly, thus reducing the residence required in the oven from 16-18 hours to approximately 12 hours. This effectively increases productivity of a given coke oven battery by $30-35 \%$ over that of conventional wet coal charging. Additionally, coal preheating and the accompanying enclosed charging system is likely to reduce emissions from the cokemaking operations by eliminating many of the possible avenues of gas leakage.

\section{Energy Conservation Potential}

Published estimates of the possible savings in gas consumption due to preheating of the coke oven charge range from zero to $17.4 \%$. Coaltek, the major vendor of the systems, estimates a $10 \%$ reduction in the gas required for the preheater and underfiring of the coke ovens. While it is true that additional steam and electrical energy are required to operate the preheater, it appears that the reduction in gas consumption more than compensates for these relatively small increases in energy consumption.

The increased thermal efficiency of coal preheating as compared with the conventional practice results from more effective heat transfer and higher throughput density; the stack temperature from a coal preheater is typically only $200^{\circ}-250^{\circ} \mathrm{C}$, instead of the $300^{\circ}-350^{\circ} \mathrm{C}$ typical at the stack of a conventional coke oven battery. If a reasonable energy conservation potential of $10 \%$ is assumed, the application of coal preheating nationally would result in a reduction of $18.5 \times 10^{12} \mathrm{Btu}$ for underfiring of coke ovens. The reduction in thermal energy required will release more coke oven gas or blast furnace gas for use elsewhere within the steel plant, thus reducing consumption of natural gas or fuel oil.

\section{Present Status of Development}

Many coal preheating systems are currently operating, both here and abroad. Most of those operating domestically are associated with the Coaltek pipelining system. The first such installation was at Allied Chemical's Ironton, Ohio plant in late 1970. Other Coaltek facilities are located at Iones \& Laughlin's Aliquippa Works, Alabama Byproducts Corporation, Inland Steel's Indiana Harbor, and Allied Chemical in Detroit. These and other non-Coaltek units have demonstrated the reliability and efficiency of coal preheaters. The improved coke quality resulting from 
coal preheating has been proved. Major improvements associated with coal preheating generally involve the reliability of the specific method of hot coal charging and, therefore, are not directly related to energy conservation.

The latest information available indicates that the capital cost of coal preheating associated with a smaller coke oven battery is roughly equivalent to the capital cost of a conventional larger coke oven battery of equal capacity. Economic benefits accrue from permitting the use of lowergrade coking cuals.

\section{Discussion}

The operational and production benefits of coal preheating have been adequately demonstrated by industry to date. New plants are being planned by the U.S. sletl industry, and we can. expect further implementation of this technology without government encouragement. Very little could be done to improve the thermal efficiency of the preheaters now commercially available; thcrefore, no R\&D efforts involving preheating appear to require the attention of DOE.

\section{DRY COKE QUENCHING}

\section{Description}

In conventional cokemaking, the sensible heat of the incandescent coke leaving the oven is wasted as the coke is quenched by water sprays in a wet quench tower. The objective of dry coke quenching is to recover this considerable sensible heat by transferring it to a hot inert gas, which can then be used to heat steam, compressed air, or some other working medium for power recovery, steam generation, coal preheating, or othcr applications.

Two dry coke quenching systems are available: the Soviet system, now being promoted in this country by the Patent Management Company; and the Sulzer Process, now exclusively licensed in North America by the Pennsylvania Engineering Company from $\Lambda$ merican WaagnerBiro Company, Inc. The two systems are quite similar, as illustrated in Figurc VI-1; the most significant difference is the addition of a pre-chamber in the Soviet system which allows an equalization of coke temperature and flow rate into the coke cooling chamber. The resulting equalization in heat extraction is accomplished differently in the Sulzer Process by incorporation of a recirculating gas bypass, which allows a portion of the cooled gas from the heat exchanger to bypass the coke cooling chamber and mix with the hot gas returning to the heat exchanger.

Referring to Figure VI-1, dry cooling is accomplished by collecting the hot coke from the ovens in hot coke hoppers. These hoppers are conveyed by rail to the dry coke quenching facility and lifted to the top of the hot coke bunker, where they are discharged. Pollutant emissions at this Grdisfer point are minmized by careful control of the local pressure during hot coke loading. The coke drops into the cooling bunker at $1000^{\circ}-1100^{\circ} \mathrm{C}$. As cool $\left(200^{\circ} \mathrm{C}\right)$ inert gas flows upward through the hot coke, it picks up heat and leaves the cooling bunker at $650^{\circ}-800^{\circ} \mathrm{C}$. An impacttype coarse particle scparator removes large coke particles from the hot inert gas in the Sulzer system; a dropout chamber performs a similar function in the Suviei system. From the coarse particle separator, the hot gas passes through a heat exchanger system, where its heat is usually transferred to water, generating high-pressure steam. When it leaves the heat exchange section, the inert gas has cooled to $150^{\circ}-200^{\circ} \mathrm{C}$. Fine coke particles are removed in a cyclone before the gas is returned by a blower to the cooling bunker. 

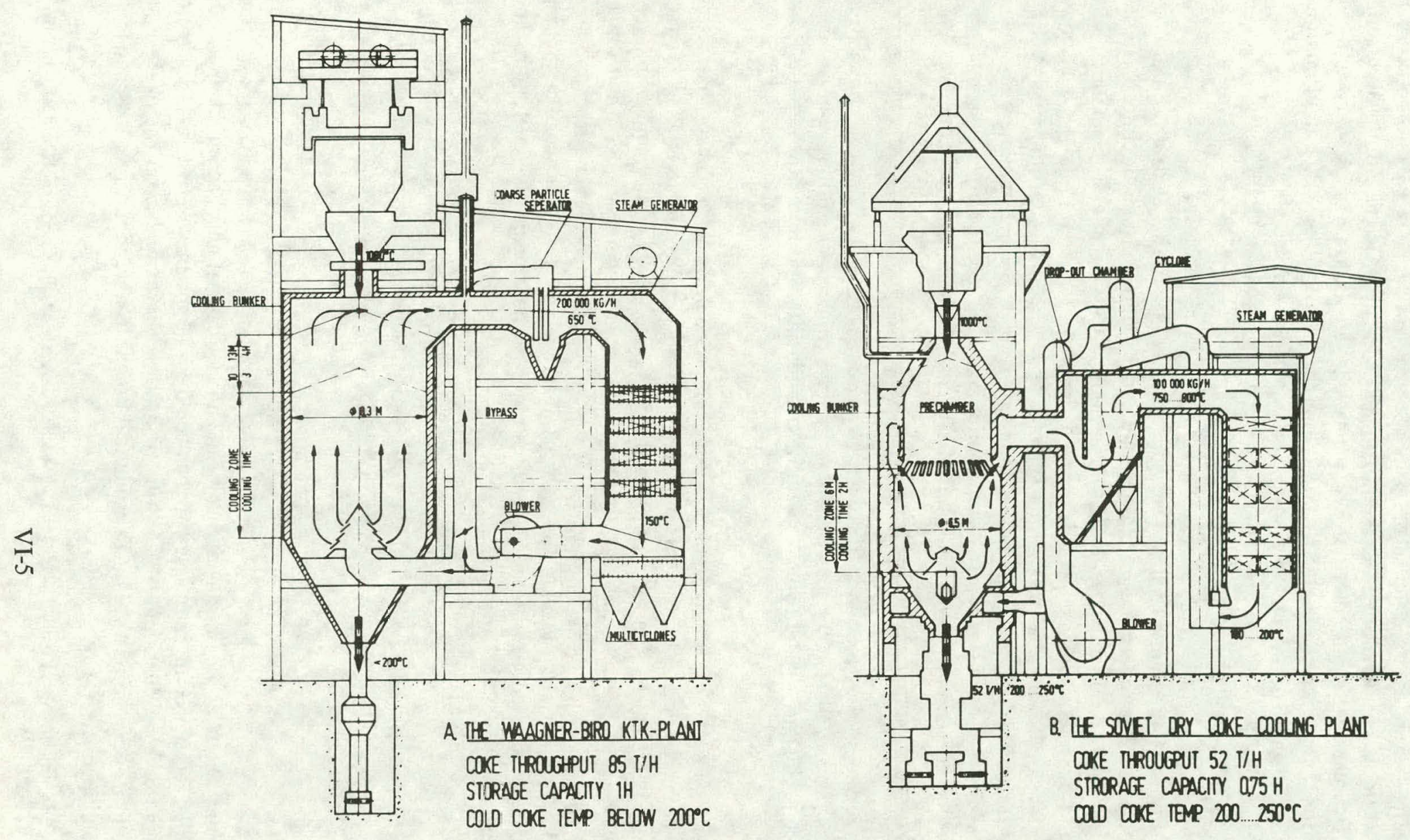

Source: R. Kemmetmueller, "Economics of Dry Coke Cooling," American Waagner-Biro Co., Inc., 1976. 


\section{Energy Conservation Potential}

Estimates of the thermal energy recoverable in dry coke quenching systems vary from 1.1 to 1.3 million Btu per ton of coke, depending on the coke temperature and the design temperature of the gas leaving the heat exchanger section. If we use a reasonable average of 1.2 million Btu per ton and assume that dry coke quenching is applied to all coking facilities in the United States, we find that $64 \times 10^{12} \mathrm{Btu}$ per year could potentially be recovered. This thermal energy recovery will require some additional consumption of electric power, but the latter will be vanishingly small in comparison with the thermal energy retrieved.

\section{Present Status of Development}

Hundreds of dry coke quenching facilities were installed earlier in this century, but almost all were abandoned when cheap supplies of energy made their operation uneconomical. One of these early facilities has been operated at Ford Motor Company's Dagenheim, England, plant since the 1930's, and a similar operation is still in use at Homecourt, France. The Soviet Union has been actively developing dry coke quenching systems since the 1960 's and now has over 50 installations in operation; such facilities are now mandatory in the U.S.S.R. for all new coke oven batteries, as well as for rebuilt batteries, if space permits. Variations of the Soviet designs have been licensed and constructed by the Japanese, but no dry coke quenching systems have yet been installed in North America.

On the basis of the above experience, the energy recovery potential of dry coke quenching can be accepted as proven. The major questions that remain concern the influence of dry coke quenching on coke yield and blast furnace operations, potential environmental benefits, and reliability.

The capital cost of a new 2 million ton per year dry coke quenching facility is approximately $\$ 20$ million. This is much more than the cost of a conventional wet quenching facility of equal capacily. Huwever, if constructed as a part of a new cokemaking nperation including cual preparation, coke ovens, and cuke handling equipment, the cost would represent less than $10 \%$ of the total capital investment. A recent economic analysis by American Waagner-Biro Company, Inc. has projected a 3 - to 5 -year payback rate for the capital investment in a dry coke quenching facility; this analysis was based on firm cost estimates made for ten prospective customers, and on an energy value as steam of $\$ 3.75$ per million Btu.

In contrast, a study by $\mathrm{AISI}^{2}$ showed a pretax payback period of about 18 years. The major differences between the two studies were that (1) AISI's estimated investment per annual ton was $\$ 20.54$, while Waagner-Biro estimated $\$ 10.00$, and (2) the AISI study valued steam at about half the cost used by Waagner-Biro

\section{Discussion}

In recent years, the U.S. steel industry has been short of capital and has maintained that dry coke quenching facilities could not be justified on the basis of potential return on investment. In addition, it has not been confident of the limited information available on the operational reliability and benefits of the process. This attitude will probably remain until dry coke quenching is demonstrated in this country.

2. "Energy Conservation in the Steel Industry," 84th General Meeting of American Iron and Steel Institute, May 1976. 
The potential environmental benefits seem almost certain. However, the Environmental Protection Agency has had difficulty mandating this technology in new installations, because it has not been adequately demonstrated; the major operational experience has been in the Soviet Union, and the information available from that country has not been adequate to convince U.S. producers.

The energy conservation potential of dry coke quenching is a certainty. Both theoretical analyses and actual operating experience have indicated recovery potentials in the same range. The first step in demonstrating this conservation potential will be a new engineering study of a dry coke quenching facility adapted to a particular site; such a study has been proposed to the Department of Energy by National Steel Corporation. The next step would be the construction of an actual facility to quench 1-2 million tons per year. The required capital investment for such a facility would be in the range of $\$ 10-20$ million. Once this plant is constructed and operational, blast furnace testing of the resulting coke and environmental monitoring of the process operations will determine the validity of other claimed benefits.

This demonstration phase of dry coke quenching technology could be accomplished within five years. Since a large number of domestic coke ovens will have to be replaced in the coming decade, significant penetration of the industry by this new technology could be expected within 10 to 15 years.

\section{COAL CAR THAWING}

\section{Description}

The present practice of thawing coal in rail cars as delivered to steel plants in the winter is to haul the hopper cars into an uncovered shed with open coke oven gas burners placed along the center of the rail track. To the casual observer, this seems an extravagant waste of thermal energy, since most of the fuel value is probably lost by convection through the open shed instead of being transferred to the frozen coal. It seems obvious that energy could be conserved by the use of more enclosed, insulated structures.

\section{Energy Conservation Potential}

Reasonable estimation of the energy conservation potential of better thawing techniques is next to impossible. However, it is probably between 0.01 and $0.1 \times 10^{12} \mathrm{Btu}$ per year. Thus, although this is an obviously inefficient operation, the energy conservation implications of process improvement are quite small in comparison with other fuel-consuming activities within the steel plant.

\section{Present State of Development}

As far as we know, no work is currently being done to improve the efficiency of coal car thawing. 'I'here is evidently no private interest in developing a new technology.

\section{Discussion}

This is an infrequently used operation, and the economic benefits realizable from efficiency improvements are quite small. However, any improvement in efficiency of this operation would release a small additional quantity of natural gas or coke oven gas for consumption elsewhere. 


\section{E. FORMED COKE}

\section{Description}

The formed coke process is the most direct approach to reducing the steel industry's consumption of metallurgical coal. Although numerous variations of the process have been developed around the world, all have in common the substitution to varying degrees of cheaper, non-coking coals for conventional metallurgical coal. This substitution is accomplished by more sophisticated chemical processing of the coals and mechanical forming of the coke product. In general, formed coke processes may be either continuous or batch continuous, but all are totally enclosed. As such, they hold the potential for more effective pollution control than can be achieved with conventional coke oven batteries.

Two formed coke processes have been developed in the United States to demonstration scale: the FMC Formcoke process and the Consol-BNR process. Of these two, the FMC process (Figure VI-2) is the most advanced formed coke process in the world. Coal of any type is flashdried, if necessary, and ground to less than $2.5 \mathrm{~mm}$. It is then heated by partial combustion to successively higher temperatures in three fluidized beds operating at $160^{\circ} \mathrm{C}, 485^{\circ} \mathrm{C}$, and $850^{\circ} \mathrm{C}$, respectively. Volatile materials are collected by a tar condenser; a low-Btu (100-200Btu/SCF) fuel gas is produced. The calcinate is cooled to about $100^{\circ} \mathrm{C}$ in another fluidized system before being blended with air-blown pitch produced from the tar. The process is self-sufficient in pitch if the feed coal contains more than $35 \%$ volatiles. The mix is briquetted in a double-roll press, and the briquettes are cured in oxygen-free air in a moving-grate oven. The cured briquettes are finally coked at elevated temperature in a shaft coker, similar to the Lurgi Spulgas oven.

The Consol-BNR process has been developed by a consortium composed of Consolidation Coal Company, Bethlehem Steel, National Steel, and Republic Steel. Only the barest process description has been revealed for this closely guarded project. In essence, preheated, crushed coking coal is mixed with recycled coke fines, finely divided char made in a fluidized bed, and perhaps pitch. This blend of products is hot-pelletized in a rotary kiln at $450^{\circ} \mathrm{C}$. The pellets are then coked in a continuous shaft furnace of the Lurgi Spulgas design. The process is outlined schematically in Figure VI-3.

Perhaps the most advanced foreign process is the BFL process (Figure VI-4) developed by Bergbau Forschung GmbH and Lurgi Mineralotechnik GmbH (West Germany). A charmaking coal of any rank is ground to $-10 \mathrm{~mm}$, flash-dried to less than $2 \%$ moisture, and then fed to a carbonizer of the Lurgi Ruhrgas (LR) type. In the carbonizer, the dry coal is mixed with 5-10 parts of hot $\left(750^{\circ} \mathrm{C}\right)$ recycled char, passes through a devolatilization chamber, and is finally calcined in a vertical-shaft flash calciner, reaching a maximum temperature of about $750^{\circ} \mathrm{C}$. (Alternatively, carbonization may occur in a fluidized bed; Lurgi claims higher product density with the LR carbonizer.) Off-gas from the LR carbonizer has a heating value of 500-600 $\mathrm{Btu} / \mathrm{SCF}$; some tar and oil is recovered with this gas. A binding coal with more pronounced caking qualities is also ground and dried, and then mixed with the char (and some tar) for briquetting in a double-roll press. Normally, the briquettes are then heat-cured at $550^{\circ}-600^{\circ} \mathrm{C}$ for one to three hours to reduce volatiles to $5 \%$ and to improve strength and abrasiun resistance. Briquettes are finally cooled in a water bath and stored with $2-3 \%$ moisture content. Lurgi claims these "green" briquettes can be used directly in a blast furnace. Alternatively, to produce fully coked briquettes, Lurgi suggests the use of a BBF sand-shaft carbonizer. 


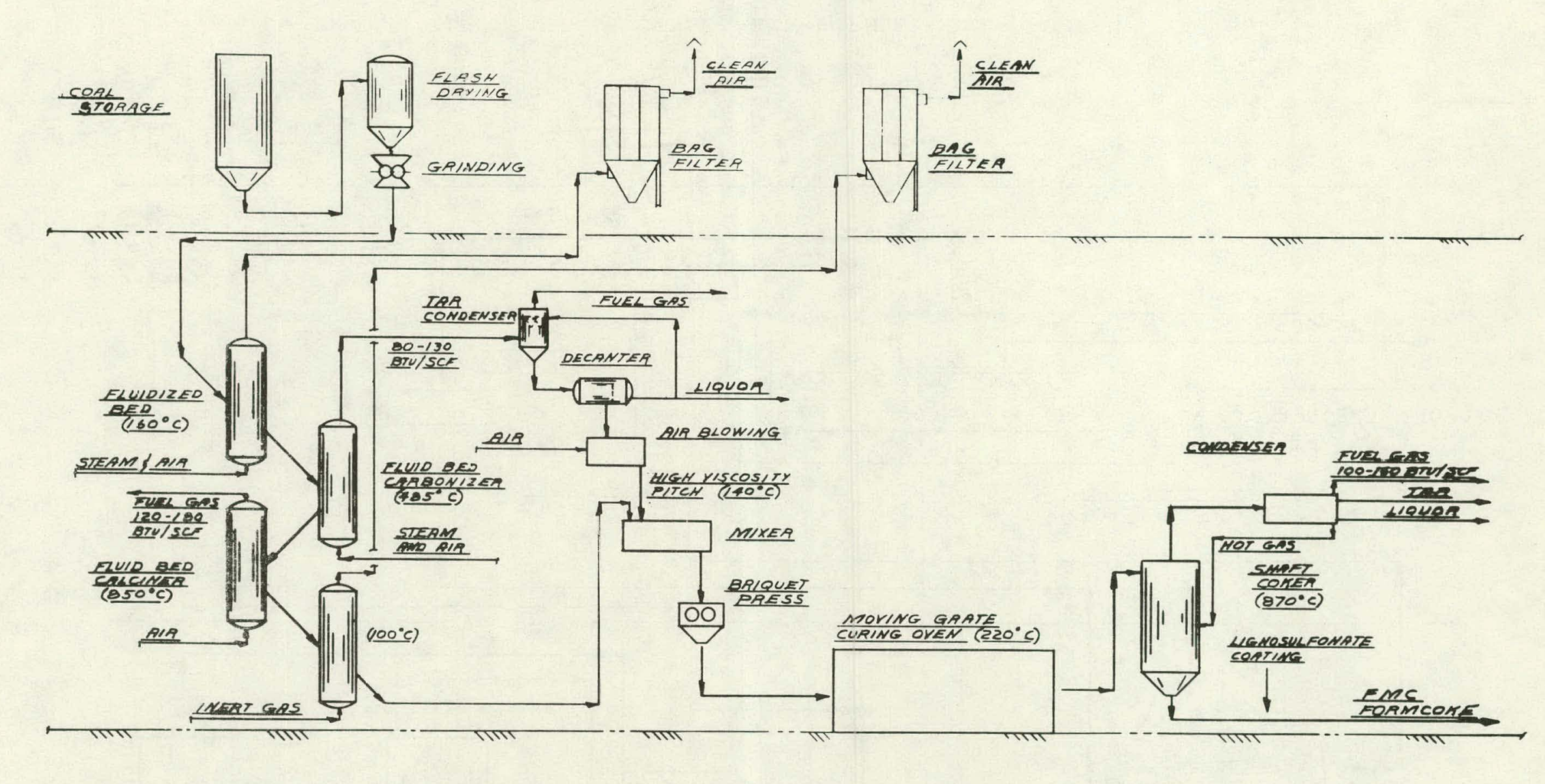




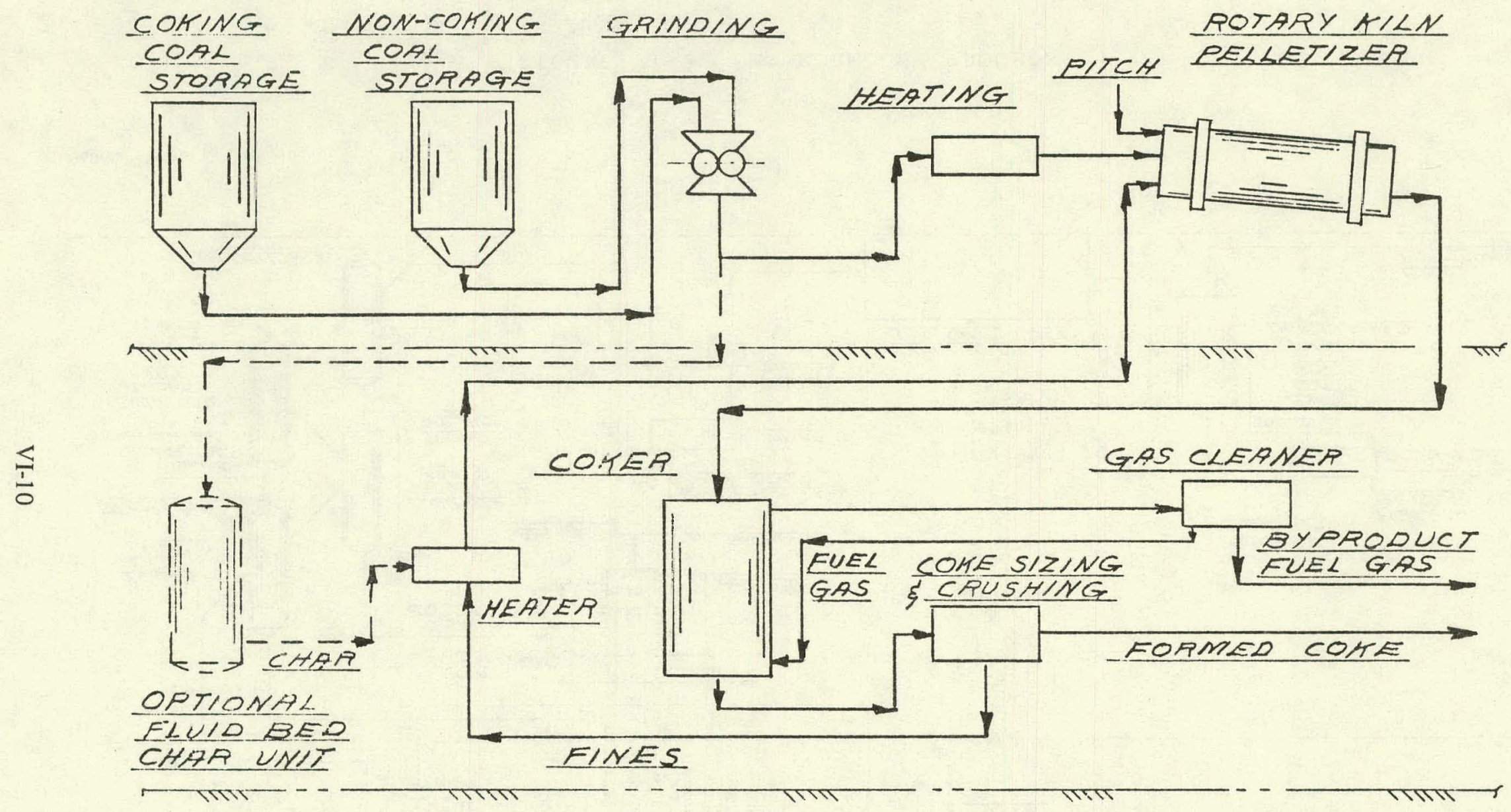

Source: Arthur D. Li:zle, Inc. 


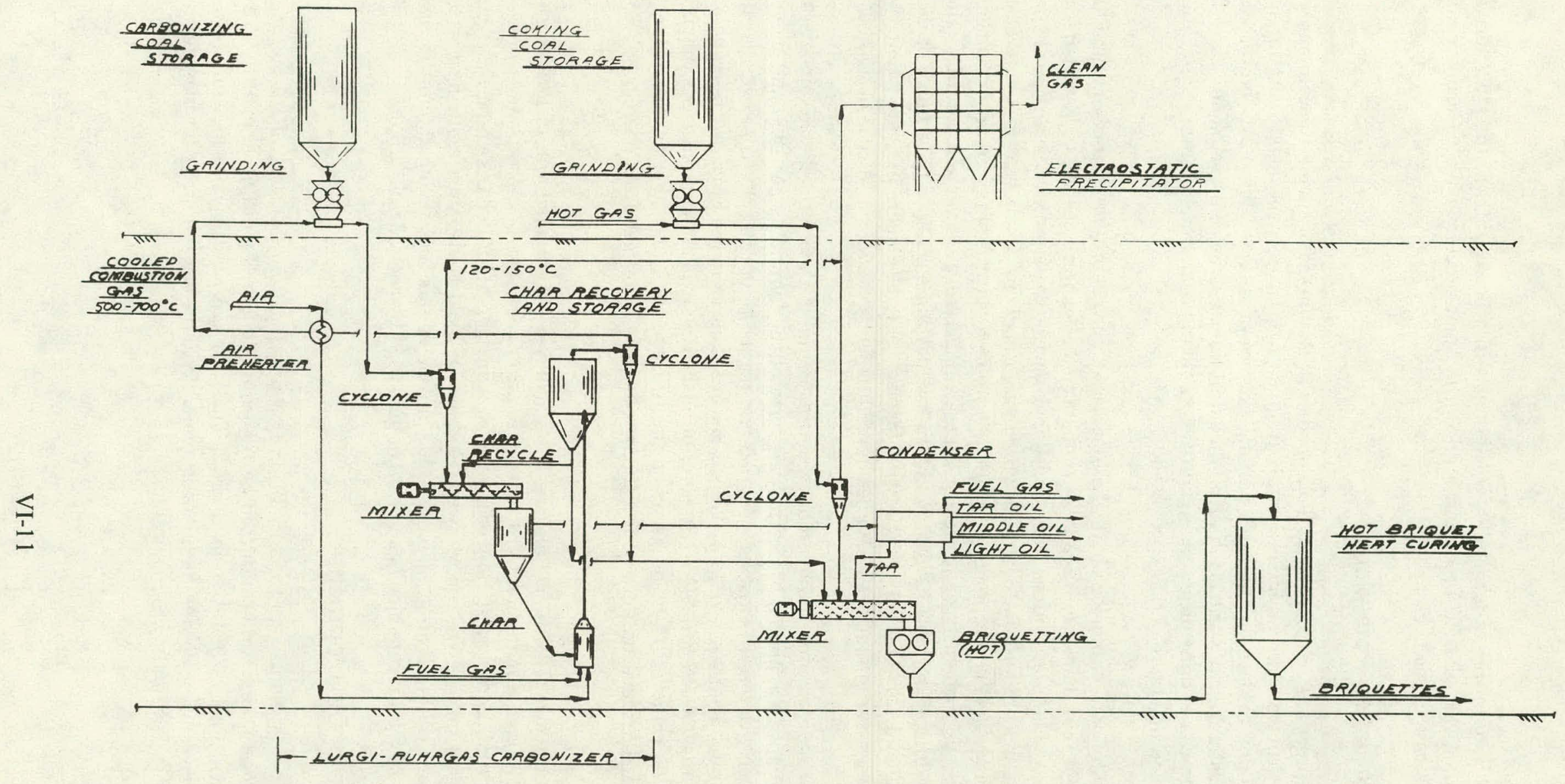

Source: P. Sehmalfeld and R. Rammler, "New Results of the Development and Present Stage of the BFL Hot Briquetting Process," presented at 13th Biennial Conference of the Institute for Briquetting and Agglomeration, August 1973. 
Other formed coke processes are under development in other countries: the DKS formed coke process in Japan, the HBNPC process in France, the Ancit process in West Germany, and the Sapozhnikov process in the U.S.S.R.

\section{Energy Conservation Potential}

Formed coke processes have not been developed with the intent of saving thermal energy, but rather of substituting more abundant non-coking coals for the conventional metallurgical coals. Those developed to date do this with varying degrees of success. The FMC process can reportedly use almost any coal without requiring the addition of coking coal to a blend. The BFL and Consol-BNR processes do require some quantities of coking coal, ranging from $5 \%$ to $25 \%$ of the total blend, depending on the other coals used.

The very sketchy data published about these processes and their byproduct output and fuel requirements suggest that the net fuel available from formed coke processes will be less than from conventional ovens. This is, of course, very dependent on the coal feed; if the coal is high in volatiles, it will produce proportionately more byproduct gas and oils. There is no inherent reason why formed coke processes cannot produce as much byproduct gas as is obtained in conventional practice. In fact, since formed coke processes generally operate at lower temperatures than conventional byproduct coke ovens, they should use less fuel while generating as much or more byproduct gas, oil, and tar. Direct contacts with formed coke developers indicated that they believe their processes can produce as much net byproduct as do conventional coke ovens.

The key question regarding the byproduct energy available from formed coke processes is not so much the quantity available but rather the form of the byproduct gas. It would be very difficult and expensive to retrofit existing steel plants designed to use 500-Btu coke oven gas to a new fuel gas with much lower Btu content. The off-gas available from the FMC process generally contains on an average of $150 \mathrm{Btu} / \mathrm{SCF}$. (Some unpublished pilot plant work suggests that 300$400 \mathrm{Btu} / \mathrm{SCF}$ may be achieved.) The off-gas from the BFL process is of higher heating value, as already mentioned. We have no data concerning the quality of off-gas from the Consol-BNR process.

Significant fuel conservation savings might be achieved by the adoption of formed coke processes, simply through a reduction in the energy required for coal transportation. At present, most of the coking coal used domestically originates in Appalachia; formed coke processes would

allow steel producers in the West or Midwest to draw on local coals, thus reducing the fuel required to transport coking coal to them. The magnitude of this fuel saving cannot he easily estimated because of the varying blends and coal origins used by each plant.

\section{Present State of Development}

FMC began to develop its process in 1956. The lirst blast furnace test of its Formcoke occurred in 1962, and others were conducted by Armco in 1967, by Inland Steel in 1970-71 and 1973, and by British Steel Corporation in 1971-72. The later tests were very successful. Formed colsc from FMC's Kcmmcrer, Wyoming, plant is available to the steel industry for blast furnace testing at a cost of approximately $\$ 120$ per ton. 
The Consol-BNR process is an improvement on Consolidation Coal's Disco Process, which was originally developed in the early 1930's. In 1964, 40 tons were produced for testing by the U.S. Bureau of Mines in the experimental blast furnace at Bruceton, Pennsylvania. A large demonstration plant was built in the early 1970's at Bethlehem Steel's Sparrows Point facility, but it was recently shut down without ever.achieving successful operation. The project has reportedly been temporarily abandoned by its sponsors for lack of funds.

Bergbau Forschung began studies on a continuous formed coke process in 1962. A 5-ton-perhour pilot plant began operation at Essen in 1965. Since that time, BF and Lurgi have jointly developed the process and produced over 25,000 tons of both green and coked briquettes. Blast furnace tests have been conducted fairly successfully by AIRBO, Hoesch, Rheinstahl, and British Steel Corporation (BSC). Two large plants were built for BSC and Ruhrcoal, but the latter was shut down in 1973 by an explosion and has not been successfully restarted. At last report, the BSC-operated facility was still not in operation.

\section{Discussion}

The economics of formed coke are uncertain, since few successful plants have been built. However, we would estimate that formed coke processes will cost as much as conventional byproduct ovens with associated pollution control technology. The cost of a modified FMC Formcoke demonstration plant of 500-tpd capacity was recently estimated at $\$ 30$ million, which is equivalent to the cost of a conventional replacement coke battery of equal capacity. The construction of such a plant is the logical next step in developing the technology; it would demonstrate the operational reliability of the process and allow long-term blast furnace tests under controlled production conditions to confirm the suitability of the product for this use. The environmental impact of a formed coke process could be determined by actual observation. The quality of byproducts could also be determined from this demonstration plant; byproduct quality and operational reliability will directly affect the overall economics of the demonstration plant.

The developers of formed coke processes have long claimed that their product can be produced more cheaply than conventional metallurgical coke. With capital investments on the order of conventional technology, steel producers thus should have a strong economic incentive to use formed coke, once it is demonstrated at a reasonable module size. Any formed coke produced by a new or updated process would need extensive blast furnace tests before being accepted by the steel industry.

The improvement of byproduct gas quality from formed coke processes is going on at the present time. Private efforts are being made to modify the successful FMC process in order to increase the byproduct fuel value to $400 \mathrm{Btu} / \mathrm{SCF}$. 


\section{IRON AND STEELMAKING}

\section{A. BLAST FURNACE}

\section{Coal Injection}

\section{a. Introduction}

Coke, which is used to reduce iron oxide and provide heat, is the most expensive form of energy consumed in the blast furnace. The average U.S. practice called for 1,230 pounds of coke per ton of hot metal in 1976, which represents 1.31 quads for a production of 87 million tons of hot metal. Iron and steelmakers have long devoted considerable time and effort toward reducing the "coke rate" or weight of coke necessary to produce one ton of hot metal.

The injection of auxiliary fuels through the tuyeres is one method for effectively reducing the coke rate. The first fuel to be widely accepted was natural gas, which was followed by oil when natural gas shortages began to occur. Depending on present specific blast furnace practice, coal injection can represent either of two possibilities:

a coke substitute, if no other fuel is presently being injected, or

- an oil or natural gas substitute, if either fuel is presently being injected.

Several plants use tar injection, but usually on a very limited scale for technical and economic reasons. Coal would displace tar as well.

\section{b. State of the Art}

Coal injection is presently practiced in this country by Armco Steel only. 'T'he first system was installed on the Bellefonte blast furnace of the Ashland Works in 1966, and a second system was installed on the Amanda blast furnace in 1973. Although numerous other systems have been proposed in the past, our discussion will be based primarily on this particular system. Other proposals do not present fundamentally different concepts. For a comprehensive list of such processes, see Ref. 1 .

Figures VII-1 and -2 depict the coal injection process. All the components shown are standard, from the pulverizers to the compressors. The innovation lies in the way the components are used.

The coal is dried with preheated air. It is then pulverized to the same extent required for pulverized coal combustion in steam boilers and is stored under inert atmosphere $\left(\mathrm{CO}_{2}+\mathrm{N}_{2}\right)$ in a buffer tank slightly above atmospheric pressure. The injection system operates under pressure. A series of standard compressors provides the necessary energy to move the coal through the circuit.

The problem of distributing the pulverized coal uniformly to each of the tuyeres is overcome by proper fluid flow and piping geometry. 


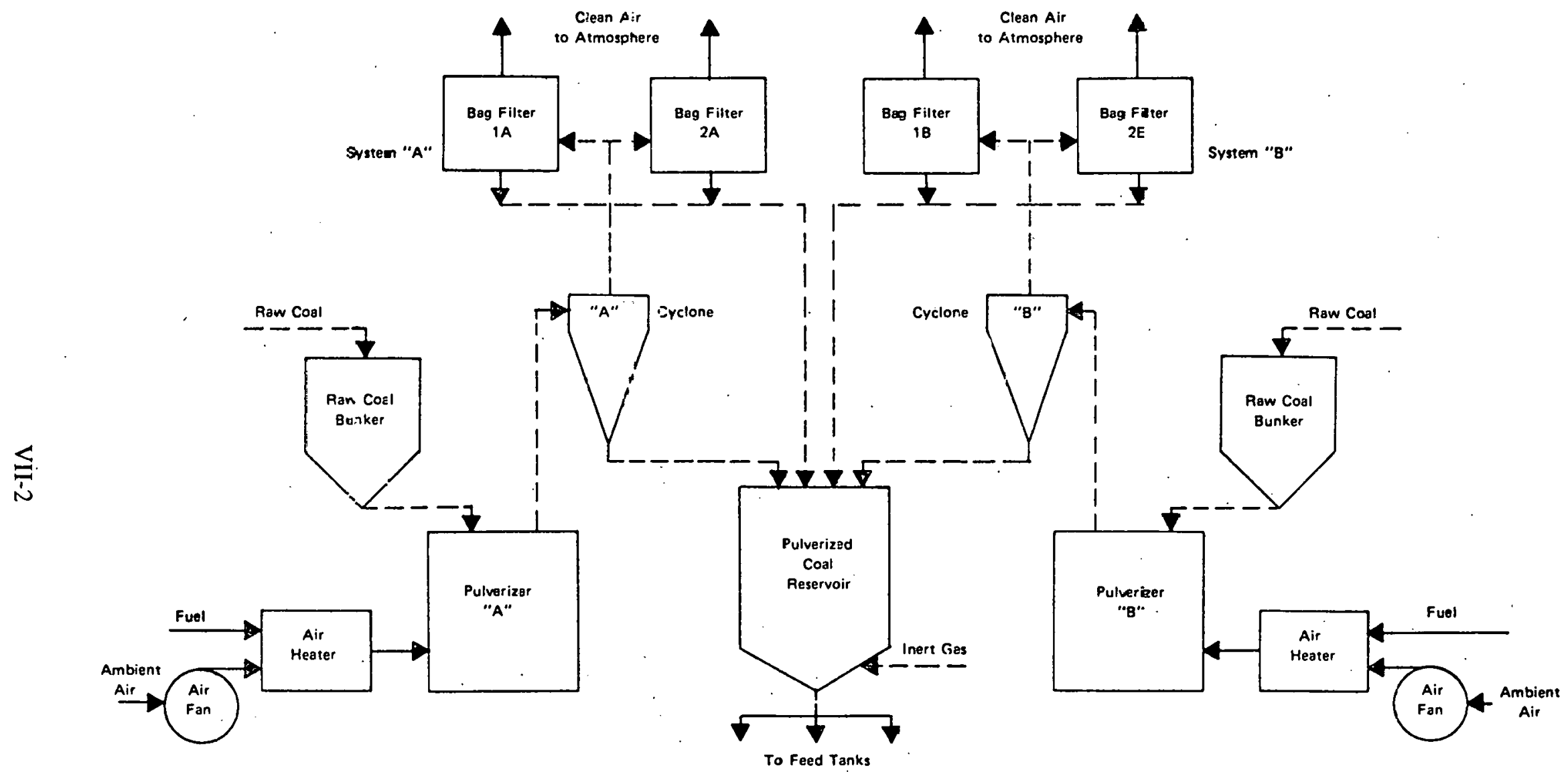

Sourco: Bul:, S.A., J.L. Pugt, J.R. Sexton, "Armco Coal Injection," for Presentation and Publication f.IME Ironmaking Conference ane Proseedings, private communication, 1976

FIGURE VII-1 AMANDA CCAL INJECTION--LOW PRESSURE AIR SYSTEM PLUS COAL PULVERIZING;COLLECTING 


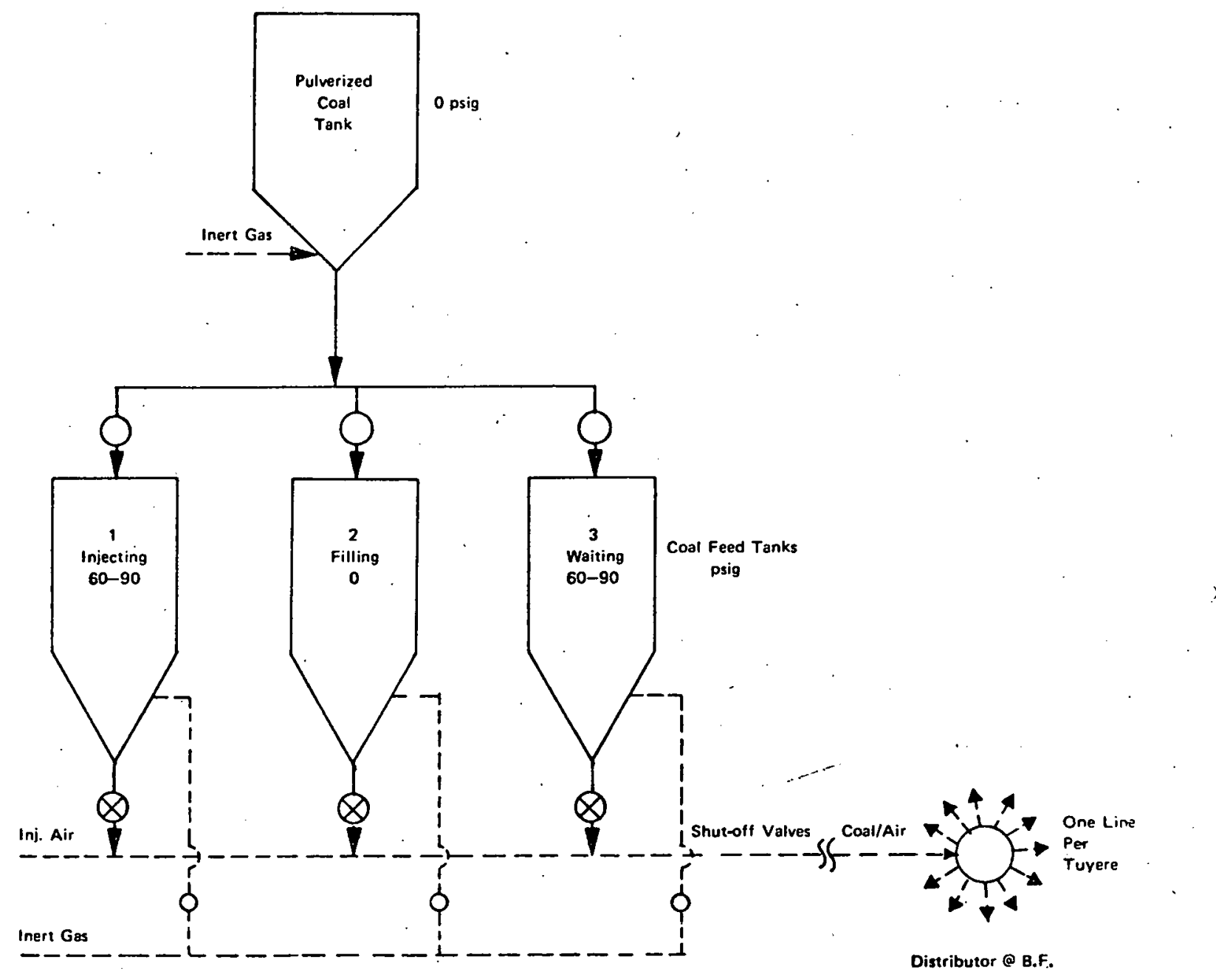

Source: Bull, S.A., J.L. Pugh, J.A. Sexton, "Armeo Coal Injection," for Presentation and Publication AIME Ironmaking Conference and Proceedings, private communication, 1976.

FIGURE VII-2 AMANDA PRESSURIZED COAL INJECTION SYSTEM 
The following limitations restrict the flexibility of coal injection:

- Like any other material charged to the furnace, the coal being injected must be of constant quality, in order to facilitate the control of the process. In particular, the amount and composition of the ash influences the hot metal chemistry.

- Up to $28 \%$ of the coke has been replaced by injected coal at Armco. Other experimental furnaces have been operated with even higher rates of substitution. However, incomplete coal combustion becomes a serious problem at such levels; $20 \%$ is considered a practical maximum. This clearly is an area for research.

- The thermal energy obtainable from injected coal varies with its ash content. For a given heat input to the furnace, the replacement of a ton of coke might require 0.91 ton of metallurgical coal but. 1,28 tons of higher-ash non-metallurgical coal. The following equation, which was devcloped by Armco engineers, quantifies this relationship:

Coke/coal replacement ratio $=1.48 \cdot 0.666(\% \mathrm{coal}$ ash $/ \%$ coke ash $)$

\section{c. Potential Energy Savings}

The following discussion assesses the potential energy impact of coal injection on the U.S. iron and steel industry. First, the following assumptions are made:

- Blast furnaces operate at the 1976 level of 87 million tons of hot metal production.

- 262 pounds of coal replace 233 pounds of coke per ton hot metal. This assumes no improvement of present technology.

- All blast furnaces switch to coal injection.

Under these assumptions, 11 million tons of steam coal replace 10 million tons of coke per year. On one hand, this lowers the national consumption of metallurgical coal by nearly 15 million tons. On the other hand, it deprives the steel plants of 0.082 quad of coke oven gas, which must be replaced by another fuel. Oil is the most likely candidate, which nullifies the energy saving from the process.

Second, one might take oil injection in all U.S. blast furnaces as a baseline. In this case, 11+ million tons of steam coal replace 66.4 million barrels of injected vil, or 0.398 quad.'

Third, one might take the following, more realistic approach: less than half the U.S. blast furnaces are presently operated with auxiliary fuel injection. It would probably be realistic to expect that this same fraction of the hot metal producing capacity would be amenable to coal injection. The total energy saving would then be of the order of 0.119 quad. We have used this figure for the purpose of this study.

1. Complete replacement would not be possible in practice, because oil can be injected in greater quantities than can powdered coal. 
TABLE VII-1

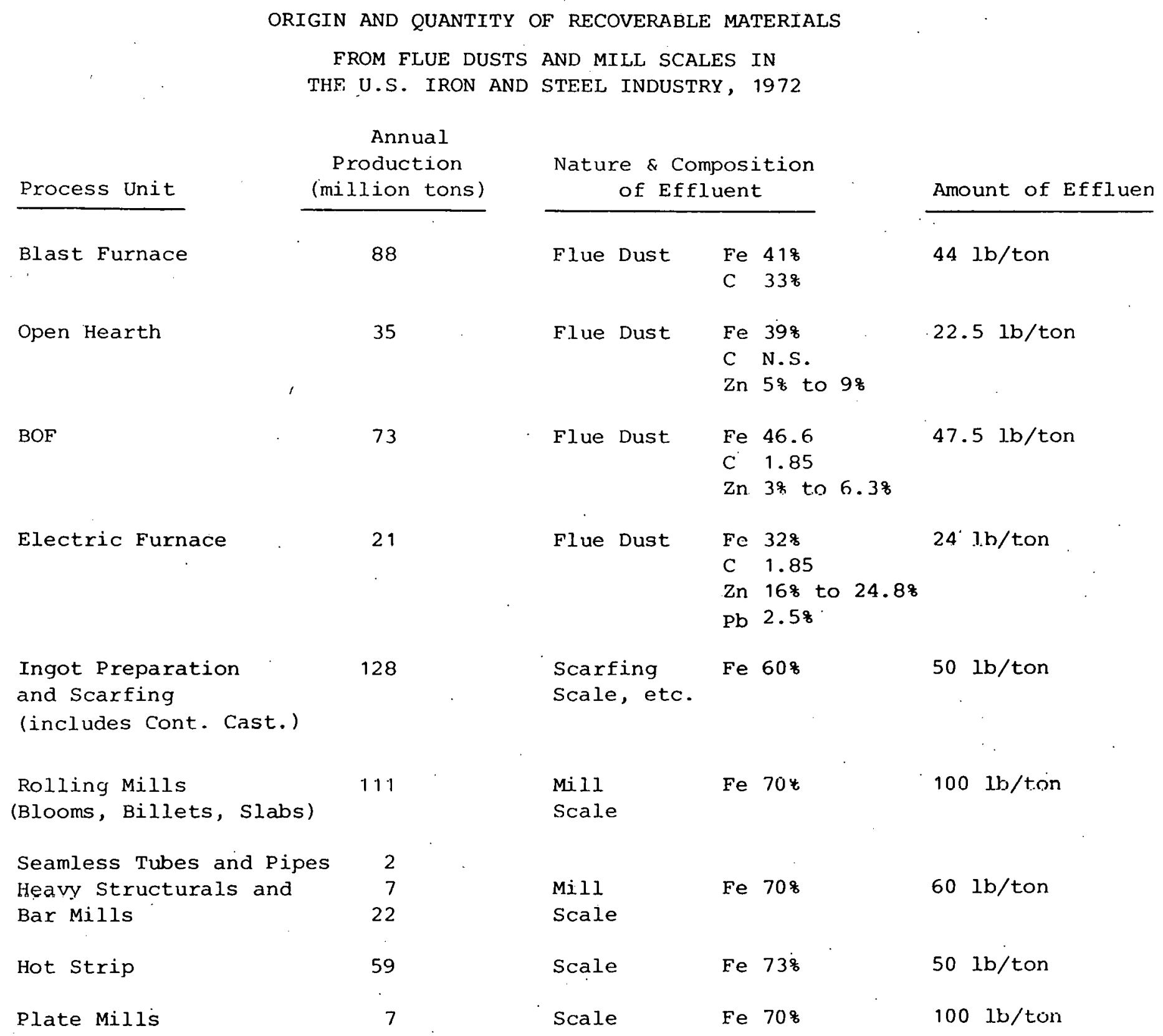

Source: Arthur D. Little, Inc., estimates. 


\section{d. Potential for Adoption}

(1) Costs and Risks. Coal injection is more costly than oil injection in terms of both capital and operating cost. The operating cost in a blast furnace has been estimated at $\$ 6$ per ton of injected coal, exclusive of coal cost. However, for a new facility having the choice of installing or not installing an injection system, an AISI study indicated that the payback period on a coal injection system would be 3.5 years.

From a technological standpoint, coal injection has been demonstrated only for a narrow range of conditions. In the steel industry's view, a systematic comparison between various grades of coal and with other auxiliary fuels if needed. Unfortunately, production blast furnaces are generally not available for test purposes.

(2) Environmental Fucturs. These are related to the mining of the coal being injccted.

(3) Possible Role of Government. The consensus among the steel companies we visited is that a demonstration program is needed to ascertain the advantages and disadvantages of coal injection. More specifically, a wider range of coal than in the past should be investigated, sn that interested companies could gather data on coals available to them. Although two furnaces are now operating with coal injection, these furnaces are not available for research and development purposes.

Should coal injection be found desirable, further research could be done in the field of coal combustion, in order to lift the present ceiling of $20 \%$ maximum coke replacement.

\section{Recycling Iron and Steelmaking Dusts}

\section{a. Introduction}

Flue dusts, mill scale, and other in-plant fines are generated in significant quantities at various stages of the iron and steelmaking sequence. In addition 10 iron, these materials contain such valuable constituents as carbon, zinc, and lead. Table VII-1 summarizes our estimates of the quantities and origins of emission of these materials in the United States, based on 1972 figures.

The proper approach to recovering metallic and carbon values from steelmaking dusts, scales, etc., involves two kinds of effort: meticulous housekeeping and sound recycling processes. In other words, the steelmaker should integrate proven processes into a comprehensive waste management program.

There are three points at which recycled materials can possibly re-enter the steeluaking sequence:

- $\Lambda t$ the agglomeration facility, e.g., the sinter strand,

- In the blast furnace, as pellets or briquettes, and

- In the steelınaking furnace, after proper preparation.

The sinter strand in many cases is ill-suited to process in-plant fines, as these increase the pollution load of this unit in an unacceptable manner. 
The blast furnace has severe limitations on the specifications of its feedstock; whereas carbon is an asset in any material added to the burden, zinc and lead must be carefully watched. Physical strength, reducibility, and softening behavior of the iron-bearing constituents of the burden must also meet high standards.

The steelmaking furnace can accept feed materials of much lesser physical strength than can the blast furnace. In this process, lead and zinc are readily volatilized, but carbon must be watched closely. Virtually no sulfur should be added. The amount of cold charge acceptable to the basic oxygen process is limited, especially when its oxide content is high.

\section{b. State of the Art}

The following three broad categories of recycling processes may be distinguished:

(1) Agglomeration at low or moderate temperalure (nondezincing processes). These do not change the chemical characteristics of the recycled materials. A binder, such as cement clinker, calcium carbonate, or polymerized asphalt, is intended to provide the physical strength needed during handling and subsequent furnace operation. These processes are comparatively cheap, and they produce briquettes or pellets containing all the carbon collected in the various fines, especially in blast furnace dusts. The blast furnace is the normal outlet for such products.

(2) High-temperature reduction and agglomeration (dezincing processes). If in-plant fines are heated to about $600^{\circ} \mathrm{C}$ under oxidizing conditions, followed by a reducing action around 950 $1050^{\circ} \mathrm{C}$, lead is volatilized as $\mathrm{PbO}$ in the first stage and zinc as metallic vapor in the second stage. An hour or two at the higher temperature is usually sufficient to volatilize $95 \%$ of the zinc present. The iron is partially reduced. The reducing effect of the carbon already present in the recycled materials must be supplemented by a sufficient quantity of coal, coke, or coke breeze. Prereduced pellets or briquettes with a low tramp-element content can be produced and fed to the blast furnace or, in some instances, to steelmaking furnaces.

(3) Hydrometallurgy. A number of patents have been granted on wet processes. Many schemes have been proposed whereby carbon and iron are recovered from in-plant fines by leaching, flotation, etc., but none has yet shown any promise of commercial success.

\section{c. Potential Energy Savings}

All the processes outlined above provide an outlet for coke breeze, which is often dumped. They also make use of the large amounts of carbon contained in blast furnace flue dusts. In this fashion, they combine natural resource recovery and fuel savings.

- Pre-reduced pellets made from steel mill dusts, sludges, etc., require about half the coke needed by oxide pellets in blast furnace smelting. These processes spare metallurgical coal, conserve natural resources, and save considerable amounts of energy if one uses level 2 accounting (mining, beneficiation, agglomeration, and transportation energy).

It is not unreasonable to expect the amount of waste materials recycled to the blast furnace to average $6 \because \because$ of the iron units contained in the burden. Such practice applied to pelletized prereduced materials would save about .037 quad in the form of coke. 
Asphalt bonding in essence substitutes asphalt for metallurgical coke. The overall energy balance on a straight Btu basis is about even: the energy expended in briquette preparation is practically offset by the energy saved in recycling carbon-bearing dusts.

Other cold bonding processes save energy only in a level 2 type of energy accounting, as they represent an on-site source of raw materials.

\section{d. Potential for Adoption}

The most advanced processes are the high-temperature dezincing processes. They have been proven under Japanese conditions, but not under U.S. conditions. Economic calculations show them to be increasingly attractive, but the steel industry is very reluctant to commit funds to such a pruject because of the financial and tochnological risks.

The financial risk is due to the fact that a 300,000 -ton-per-year plant (the typical size of industrial kilns) would cost upwards of $\$ 20$ million.

The technological risk is due to the fact that such processes are very difficult to operate properly, and that site-specific conditions may require major specific adaptations.

Due to its present capital shortage, the steel industry is not likely to make such an effort on its own. The lower temperature, cheaper processes have aroused enough interest to lead to industrial tests, but these tests have been unconvincing to date.

A level 2 energy accounting study (including the energy of materials consumed) should be made to determine whether energy can be conserved by such recycling. If the energy analysis is favorable, a government-industry joint demonstration program in this area would probably be very productive.

\section{Evaporative Stave Cooling}

\section{a. Introduction}

Effective cooling of various parts of the blast furnace is essential to minimize refractory wear and thereby reduce the time a furnace is out of service for replacement of its refractory lining. 'Traditional cooling systems are elther "unce though" or recirculating water eystems.

The main feature of the evaporative cooling system is the method of heat transfer from the conled unit to the coolant. Heated water, near its boiling point, is used as the coolant, and heat is abstracted from the furnace elements by evaporation of the water to form steam. In such a system, one pound of water removes approximately $1.100 \mathrm{Btu}$, in conlrast. to a conventlonal system where 18 to $40 \mathrm{Btu}$ arc removed. Thus, for a given heat load, a smaller coolant volume is: required in the evaporative system compared with conventional susterns.

The temperaturc risc of the water used in conventional cooling systems is small and does not lend itself to sensible heat recovery. Evaporative stave cooling, however, generates low-pressure steam, which has some potential for heat recovery. 


\section{b. State of the Art}

Evaporative stave cooling designs offered in the United States are based on Russian and Japanese technology. A diagram of an evaporative system is shown in Figure VII-3. Water is chemically conditioned to boiler feed quality. It then flows by gravity to the base of the furnace and ascends by natural convection. Steam is formed in the ascension pipe, and the water/steam mixture is separated in a drum.

Two modes of operation are possible: the steam is either used for heating purposes and the condensate returned to the system, or alternatively, when there is no demand, the steam is condensed without being used.

Evaporative stave cooling systems have been installed on or:contracted for several Japanese, Canadian, and domestic furnaces. The older installations are reported to be difficult to operate in the evaporative mode and are mostly operated in the simple recirculating mode. These staves require a very thin furnace lining and the establishment of an equilibrium between solidified slag and descending burden.

\section{c. Potential Energy Savings}

The major energy saving is that steam is generated by the system. For a furnace with a working volume of 100,000 to 150,000 cubic feet, steam generation is reported to be approximately 24,000 to 36,000 pounds per hour. If every U.S. blast furnace were fitted with an evaporative stave cooling system, the total energy generated in the form of low-pressure steam would be less than 0.007 quad per year (based on hot-metal production of 87 million tons).

Because the steam produced is saturated and low in pressure, it is a low form of energy and is difficult to utilize in the blast furnace area. It is suitable for space heating applications in the immediate vicinity of the furnace, but no plants are presently using it for this purpose.

A secondary, smaller energy saving is that no pumps are required to circulate the coolant through the system.

\section{d. Potential for Adoption}

An evaporative stave cooling system costs more to install than a conventional system. Retrofit is particularly expensive and costs over $\$ 6.5$ million (Ref. 2 ) for a furnace producing 5000 tons 'per day and yielding about $\$ 300,000$ worth of low-pressure steam per year if valued at $\$ 2$ per million Btu. This credit would not even cover 18-year depreciation, and the payback period (after tax) would be at least 18 years. Such an expenditure can be justified only if some other economic advantage is derived.

There are two possible benefits in using evaporative stave cooling:

- Energy conservation, if one can find a use for the steam produced.

- Longer production campaigns, if indeed the system provides more efficient cooling than conventional devices. 


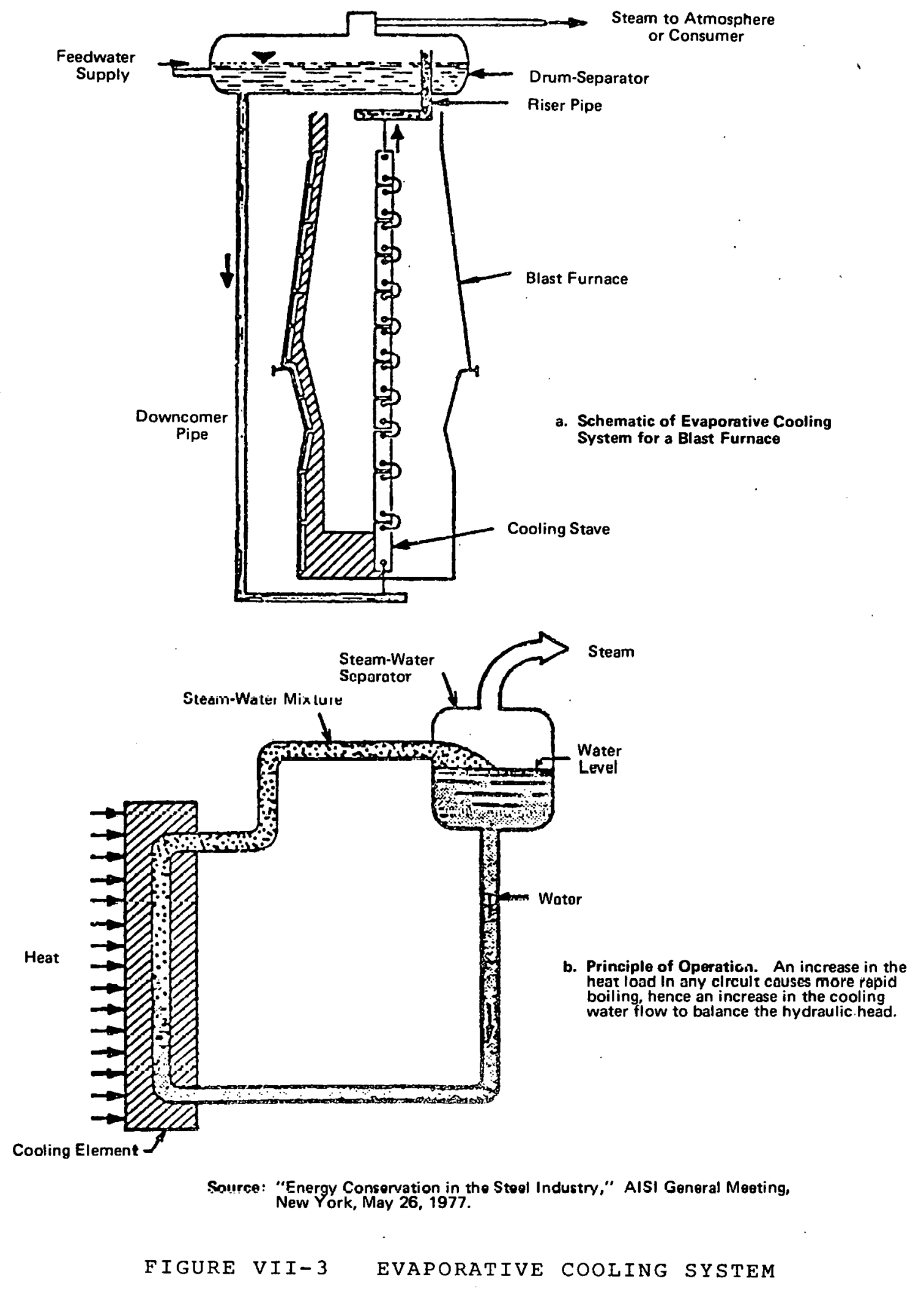

VII-10 


\section{$e$ : Role of Government Funding}

There are many potential sources of low-pressure steam in a steel plant; assessing the potential uses for such steam is a worthwhile research goal.

More specifically related to evaporative stave cooling is the technology associated with the concept. The ability of the system to operate as intended has yet to be demonstrated. The willingness of the industry to cooperate in this area of research should be investigated in more detail.

\section{Conversion of Top Pressure to Electricity}

\section{a. Introduction}

Modern blast furnaces operate under 30 to $45 \mathrm{psi}$ pressure. The gases leaving the top of the furnace must be cleaned, cooled, and reduced to the pressure of the blast furnace gas distribution system. This pressure drop can be used to drive an expansion turbine, which in turn can drive an electrical generator. In this fashion, part of the energy expended by the turbo-blowers in compressing the gas can be recuperated.

\section{b. State of the Art}

Figure VII-4 illustrates the gas flow through a blast furnace system with an expansion turbine and generator. The gas is collected in the uptake, a manifold located at the top of the furnace; it then flows down a large pipe called the downcomer. The coarser portion of the dust is collected in a dust catcher, where the velocity of the gas is reduced and its direction is changed. A wet scrubber is then used for secondary cleaning. Because of the very abrasive nature of blast furnace dust, expansion turbines must be located downstream of the wet scrubber.

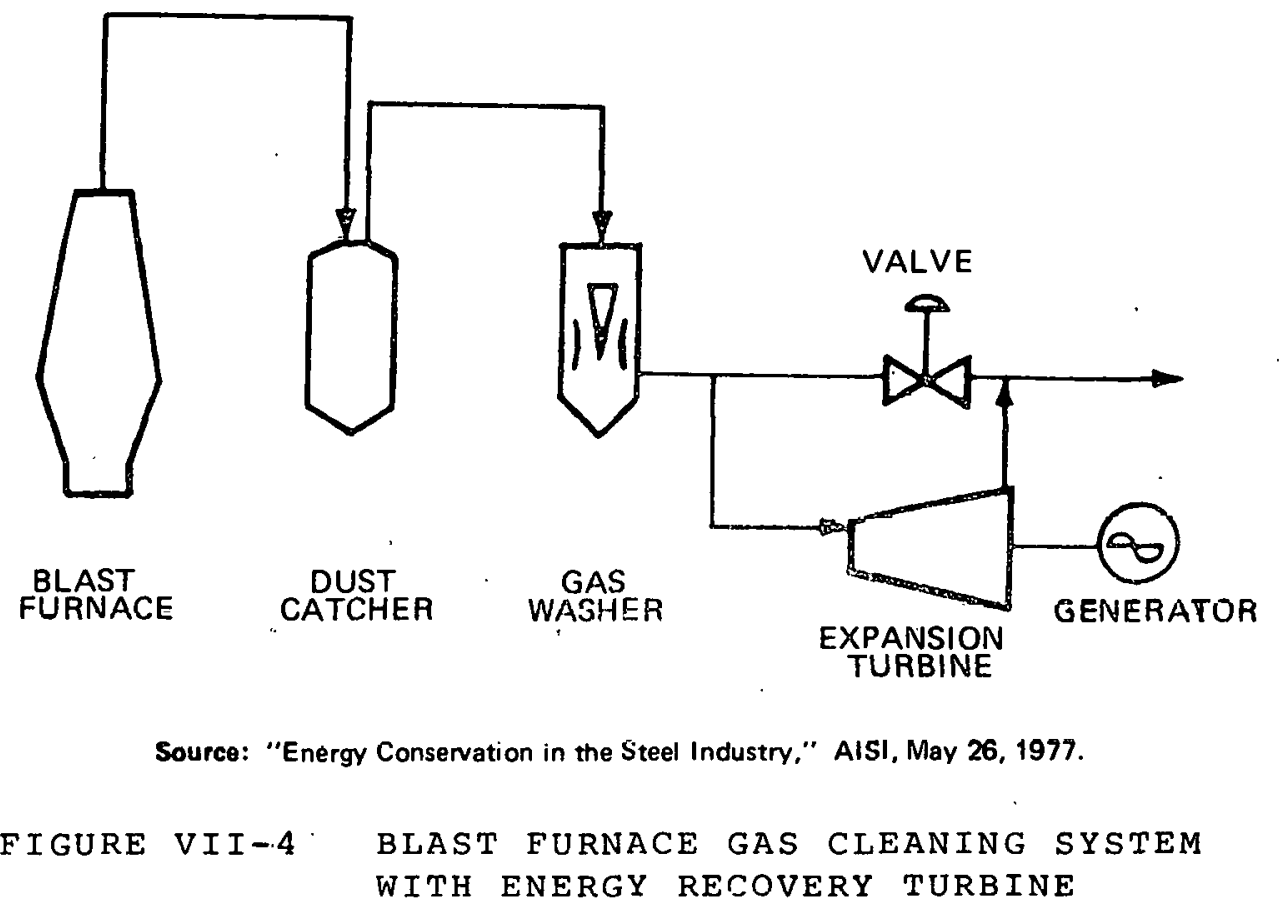


Both axial and radial turbines have been used for energy recovery systems in Europe and Japan. In axial turbines, the gas flow is parallel to the axis of the machine. To avoid damaging the turbine, the dust content of the gas must be less than .004 gram per SCF. The temperature must also be high enough to prevent condensation during expansion in the turbine. In some cases, this necessitates reheating the incoming gases, as they have been cooled in the scrubber. The overall efficiency of the energy recovery drops as a result of this reheating.

In radial turbines, the gas is admitted at the outer edge of the rotor and is directed toward the center. This design alleviates the problems of dust content and water condensation.

\section{c. Potential Energy Recovery}

All new blast furnaces will operate under high top pressure. However, it will be some time before all the atmospheric-pressure furnaces are replaced. Table VII-2 shows the potential energy recovery per ton of hot metal under various conditions.

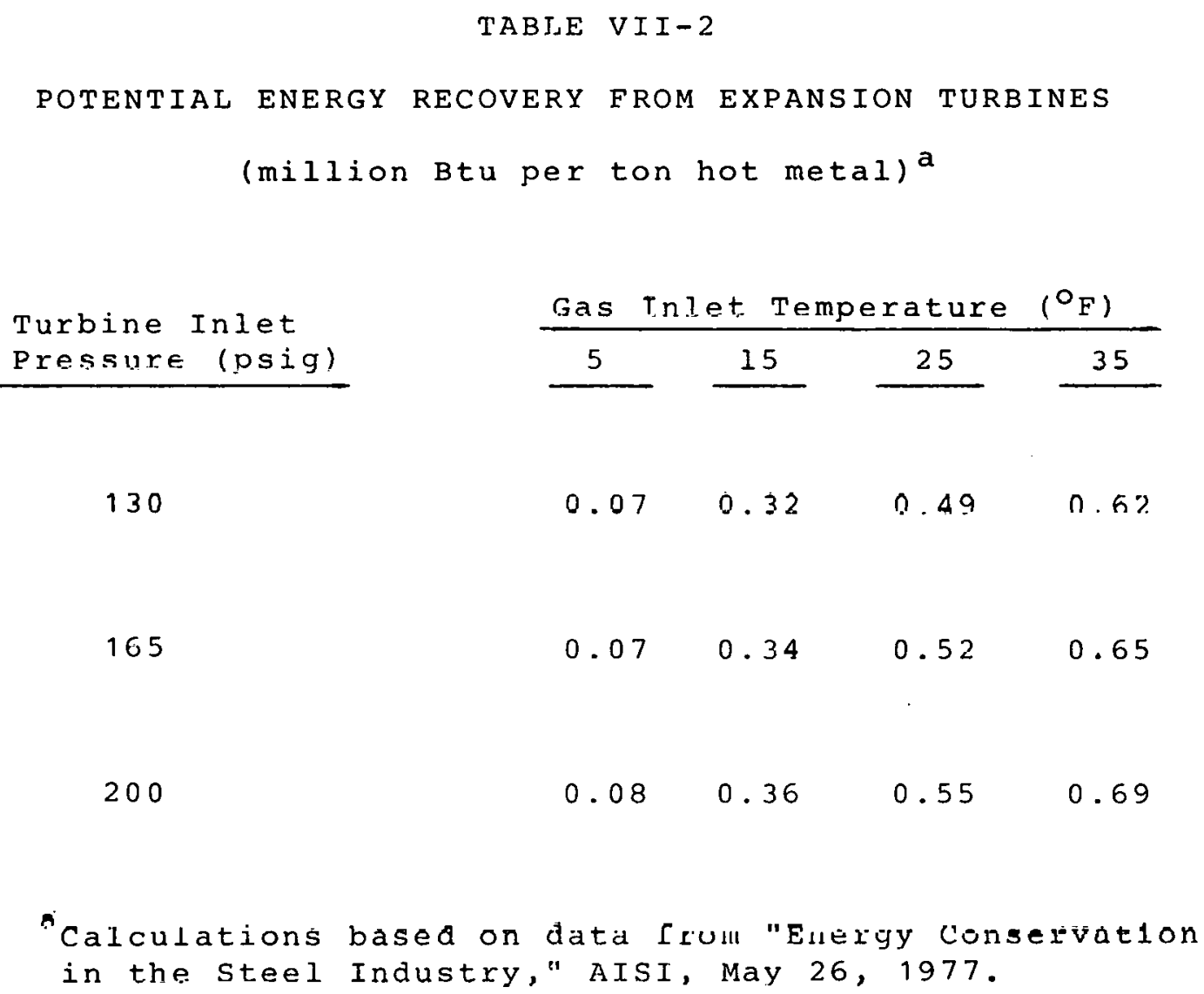

Assuming that about $20 \%$ of the U.S. blast furnaces will utilize high top pressure in the coming 5 to 10 years, expansion turbines could save the nation about 0.01 quad per year. 


\section{d. Potential for Adoption}

Only new blast furnaces will probably be equipped with expansion turbines; the return on investment for turbines mounted on new, large, high-top-pressure furnaces has been estimated at 14 to $18 \%$, while that for a small unit retrofitted on a blast furnace with only moderate pressure has been estimated at only 1 to $3 \%$ (Ref. 2). These calculations were based on a price of electricity of $3 \mathfrak{c}$ per $\mathrm{kWh}$. The large turbine would cost $\$ 600$ to $\$ 700$ per $\mathrm{kWh}$ of capacity, whereas the smaller, retrofitted one would cost twice as much. (Basis: 1976 dollars.)

\section{e. Role of Government Funding of $R \& D$}

Locating the turbine upstream from the wet scrubber would increase its efficiency. The problem is to select a material and turbine design that will minimize erosion of the blades. This problem may not warrant a special study by DOE, but if there were an opportunity to gain further insight into the problem as part of a more comprehensive program of blast furnace experimentation, its inclusion in the total scope of effort would be worthwhile.

\section{Injection of Hot Reducing Gases in the Stack}

\section{a. Introduction}

The endothermic reduction of higher iron oxides to $\mathrm{FeO}$ occurs in the stack of the blast furnace. Partial metallization to $\mathrm{Fe}$ also takes place and continues toward completion as the charge descends. The ascending gases generated by the combustion of coke in the tuyere zone are therefore cooled and oxidized in the stack. As a result, both their heating potential and reducing potential are depleted.

Injecting hot reducing gases $\left(1000^{\circ} \mathrm{C}\right.$ or higher) in the stack is a way to reduce the coke rate while providing sufficient heating and reducing potential to the gases working in the furnace. These injected gases can be generated externally from fuels other than coke. Gasified coal is a prime candidate; one of the proposals evaluated in this study includes a coal burner with a wide range of potential applications. (See section IX-A-3.)

\section{b. State of the Art}

A number of preliminary experiments on gas injection have been run over the years. All used oil or natural gas as the primary fuels from which hot reducing gases were derived.

Among the little published data are those disclosed by Professor Pierre Coheur of the Belgian CRM in 1971 (Ref. 3). Injection of hot reformed natural gas was found to decrease the coke rate of the experimental blast furnace at Ougrée. It was also found to be compatible with ordinary fuel injection through the main tuyeres.

The problem has always been to find an economical source of reducing gas at sufficient temperature. Either of two concepts discussed in this study - blast gasification and pulverized coal burners - might be the answer if they are developed and perform as experted. 


\section{c. Potential Energy Savings}

The hot reducing gas could be generated from coal, as noted above. The probable net effects would be:

- A shift from coke (metallurgical coal) to stean coal; and

- A slight increase in the total energy consumption on a straight Btu basis.

The impact of such a technology could be of the same order of magnitude as that of ordinary coal injection (see section VII-A-1).

\section{d. Potential for Adoption}

The potential for adoption cannot be assessed until the technology is proven from both technical and economic standpoints.

\section{P. Role of Gouernment Funding}

Good proposals showing the technical and economic feasibility of this concept should be considered for potential funding.

\section{External Desulfurization of Hot Metal}

The trend in blast furnace operation in the United States during the last 20 years has been to increase the degree of burden preparation in order to decrease coke consumption per ton of hot metal. As the production and consumption of highly beneficiated iron ore pellets has grown, slag volumes have declined. At the same time, the sulfur in coke has gradually increased, and the sulfur content of blast furnace hot metal has tended to do the same. The requirement to control sulfur at the blast furnace (i.e., in the hot metal) has increased for two reasons:

- The basic oxygen process, now coming into wider application, has a linited ability to remove sulfur.

- Simultaneously, the use of the open-hearth process, which has considerably more capacity to remove sulfur, is declining.

This combination of circumstances has encouraged the practice of external desulfurization of blast furnace hot metal. This is presently achieved by using calcium carbide or Mag-Coke as a desulfurizing reagent between the blast furnace and the BOF shop where the hot metal is consumed. More specifically, if calcium carbide is used, it is injected into the torpedo car that carries the hot metal from the blast furnace to the BOF shop; if Mag-Coke is used as the desulfurizing agent, it is encapsulated under a bell which is submerged into the hot metal contained in a ladle. However, desulfurization is presently done only when required; it is not done on every torpedo car or ladle of hot metal charged to the basic oxygen furnace. The practice is to desulfurize when necessitated by the sulfur content of the hot metal and the sulfur requirements of the steel to be produced from it. 
It would be advisable to fully develop and establish external desulfurization as a regular procedure for every ladle of hot metal produced, for the following reasons:

- To establish the extent of permissible sulfur content of metallurgical coke. Many high-sulfur coals have good coking qualities. With external desulfurization, some of these coals could be used to make metallurgical coke. If the sulfur specifications can be relaxed on good coking quality coals, the U.S. reserves of coking coal could be greatly extended.

- To reduce metallurgical coke consumption. Eventually, coal injection will probably replace natural gas and oil injection. This will increase the amount of sulfur introduced into the blast furnace and the extent of external desulfurization needed.

- To determine the best desulfurization practice and the preferred reagent for higher sulfur levels in the hot metal to be treated.

- To establish capital requirements, operating cost, and effect on energy consumption for production of low-sulfur hot metal. External desulfurization has been viewed as a means of correcting for the increasing sulfur content of fuels used in the blast furnace. The objective is to prevent the reduction in capacity and increase in energy impact that would be required if desulfurization were done in the blast furnace by introducing more lime. The latter would increase slag volume and basicity but would also increase coke and injected fuel consumption. Battelle estimated the potential energy saving attributable to external desulfurization from $.04 \%$ sulfur in hot metal to $.02 \%$ sulfur at 0.9 million Btu per ton of hot metal using either calcium carbide or Mag-Coke. However, others have estimated 0.82 million Btu per ton of hot metal for the same starting sulfur content and percentage removed using Mag-Coke.

In addition to the energy balance between fuel savings and desulfurizing reagent, there is approximately a $50^{\circ} \mathrm{F}$ temperature drop in the hot metal during desulfurization. This energy loss is small ( $1670 \mathrm{Btu} /$ ton of hot metal), but it must be accommodated in subsequent steelmaking operations. Some of the data on external desulfurization tend to confuse the picture, because when sulfur levels are higher, more reagents are required for the same blast furnace operating practice; thus, there is no comparison between the above and what the blast furnace energy consumption would have been at these higher sulfur levels if sulfur removal were done in the blast furnace. The indications are that the energy savings are about 0.86 million Btu per ton of hot metal.

The major long-range purposes of external desulfurization are 1) to extend the domestic resources of coking coal (which would mean high-sulfur coke and more sulfur in the blast furnaces) and 2) to prevent the increase in energy consumption that would occur if desulfurization were to be done in the blast furnace. As, a rough indication of the annual energy saving; the amount of hot metal produced in 1976 multiplied by 0.86 million Btu per ton gives 0.07 quad.

With respect to cost, it has been estimated recently (Ref. 2) that the capital cost for installing a desulfurizing station would range between $\$ 1.25$ and $\$ 1.40$ (say $\$ 1.33$ ) per annual ton 
of capacity. A station to treat one million tons of hot metal per year would therefore cost $\$ 1,330,000$. Depending on the reagent used, the operating costs of removing $.02 \%$ sulfur per ton of hot metal would be between $\$ 0.50$ and $\$ 1.00$ (say $\$ 0.75$ ) per ton. We understand that the cost of desulfurizing a ton of hot metal is equal to about two thirds of the savings obtained in the blast furnace, so the net saving is $\$ 0.34$ per ton of hot metal. We estimate that after-tax savings would pay back the investment in about four to eight years, depending on the sulfur content of the hot. metal.

The above is largely an oversimplified rule-of-thumb analysis. More extensive experience in the form of a large-scale industrial demonstration is needed to establish costs and energy-saving benefits. We believe that a large-scale demonstration of external desulfurization of higher sulfur hot metal has considerable merit for the purposes described above and should be favorably considered.

\section{Blast Gasifier}

\section{a. Blast Furnace Top-Gas Generation}

About $45 \%$ of the energy used by the steel industry is consumed in blast furnaces, primarily as metallurgical coke but also in the form of natural gas, oil, coke oven gas, and coke plant tar. The blast furnace is also a major source of a low-heating-value by-product fuel gas called blast furnace top gas. The volume produced is about 76,500 cubic feet per ton of pig iron. The fuel value of top gas is 6,507,500 Btu/ton of pig iron produced. During 1976, when 87 million tons of pig iron were produced, the heating value of the top gas amnunted to .566 quad of thermal energy. Typically, about $37 \%$ of this gas is consumed directly in the blast furnace plant, leaving .356 quad of thermal energy for other uses.

Thus, while the blast furnace is a major consumer of fuel, it is also a major producer of lowsulfur gaseous fuel. The major difficulty with top gas is that it has very low heating value (85 $\mathrm{Btu} / \mathrm{SCF}$ ) and is therefore more difficult to burn than coke oven gas. However, the blast furnace clearly has considerable potential as a gas producer, particularly if the blast air is oxygenenriched or blown with high-purity oxygen; this has been proposed in the so-called Blast Gasifier, which is an idle blast furnace converted to a medium-Btu gas producer.

\section{b. Blast Gasifier Concept}

As new, large blast furnaces are being built, smaller and older blast furnaces are left idle in many domestic steel plants. These furnaces can no longer be profitably operated as sources of hot metal for the steelmaking shops. Under the blast gasifier concept as proposed, these old furnaces and their attendant equipment (e.g., stock house, charging system, top-gas cleaning and dist.rihu. tion system) would be used primarily to produce gas. As much coal as possible would be injected, and the blast would be enriched with oxygen and stemu. The iron production would be consid. erably less than in an ordinary blast furnace. Some iron oxide derived from mill scale, slay, and other sources may be needed to control temperature.

The reducing gases produced in the furnace would undergo little oxidation. As a result, the top gas would be rich in $\mathrm{CO}$ and $\mathrm{H}_{2}$, and heating values of up to $300 \mathrm{Btu} / \mathrm{SCF}$ may be obtained. This gas could replace natural gas and oil in many steel plant applications. 


\section{c. State of the Art}

The idea of the blast gasifier as proposed is new, but it is based on established principles of ironmaking and coal gasification.

Present rates of coal injection in blast furnaces seldom exceed $20 \%$. To be economical, blast gasifiers should have a much higher ratio of coal to coke. One of the various possibilities is discussed in more detail in Appendix A.

\section{d. Potential Energy Savings}

The blast gasifier is one concept that has been proposed to replace oil and natural gas with a gaseous fuel derived from less critical steam coal and coke. It could be applied to such steel mill processes as firing soaking pits, firing reheat furnaces, and injection into blast furnaces. The energy content of gases from 17 to 40 blast gasifiers would range from 0.11 to 0.52 quad annually, depending on furnace size. An estimated 0.32 to 0.75 quad annually of solid fuels would be consumed in the gasifiers.

Blast gasifiers are also intended to produce some hot metal. Depending on the quality and quantity of iron produced, the blast gasifier should also be capable of demonstrating to some degree the amount of steam coal that can be substituted for coke. We suggest that this program of work be accompanied by extensive process modeling to optimize furnace performance.

\section{e. Potential for Adoption}

(1) Risk. The risk involved in developing the blast gasifier should be in the low to moderate range. Blast furnace technology itself is old and well developed, but there has been much less development on the pre-ignition of powdered coal using oxygen-enriched air (up to $100 \%$ oxygen) and steam additions.

One technology that has received some development for the type of combustion occurring in the pre-ignitor is the burner used in the Koppers-Totzek coal gasification system. Another pulverized coal burner that has received some development is the Pittsburgh Energy Research Center (PERC) burner. The operation and control of the pre-ignition system on a blast furnace is a new idea that needs development and demonstration.

The particular operating practices chosen will have an important effect on the economics. Having the gasifier produce iron from a scrap charge can help the economics, since credit can be taken for the hot metal produced.

Melting scrap is one way to use the reducing gases produced in the lower part of the furnace. The other alternative is to use endothermal reactions that contribute to the heating value of the top gas, such as steam decomposition or hydrocarbon cracking. The use of iron ore or scales should be minimized, since they could lower the Btu value of the gas.

Another operating parameter that will affect the economics is the ratio of steam coal to coke. Increasing the relative amounts of steam coal as much as possible will improve the economics and help to conserve the more critical coke. 
One caveat is that some of the older and smaller blast furnaces were not designed for the high pressures that the larger blast furnaces can withstand. Blast gasifiers based on old furnaces may have to take this pressure limitation into account, or some older blast furnaces may have to be reinforced.

(2) Environmental Considerations. Blast gasifiers transform a sulfur-containing solid fuel into a low-sulfur gaseous fuel. The sulfur compounds are removed from the gas by both the limestone flux and melting iron; at the lower temperatures near the top of the blast gasifier, iron is a more efficient collector of sulfur compounds than is lime. The blast gasifier will also trap most of the ash from the steam coal in the slag. Existing gas-cleaning equipment on blast furnaces could be used on the gasifiers.

Other environmental aspects are similar to those of the other blast furnaces present on the plant sitc and include:

- slag disposal,

- dust disposal, and

- particulate emissions due to materials handling and furnace operation.

(3) Costs. The cost of adapting a 17- to 20 -foot blast furnace will be in the $\$ 20$ million range. The economics of the process are very sensitive to gaseous fuel values. If the fuel price were $\$ 1$ per million Btu above the cost of product, the payback period could be as short as three years. A rapid payback is possible because a completely amortized blast furnace is a major part of the gasifier.

Similarly, the economics of the process are very sensitive to small decreases in the price of gaseous fuels, and the payback period could quickly increase markedly.

\section{t. Kole of Government t'unding $K \& U$ E'ffort}

Government funding is required; the technology needs demonstration before private industry will commit funds to a project that involves above-average risk in an industry that is short. of capital. The energy shortage is a sufficient threat to the steel industry to warrant immediate action. Also, an estimated 2000 to 4000 jobs would be dircetly involved with operating the 17 to 10 blast gasifiers.

\section{B. BASIC OXYGEN FURNACE}

\section{Conventional Technology}

In basic oxygen furnace steelmaking, oxygen is blown into the vessel containing hot metal and scrap. The reactions of the oxygen with silicon, manganese, carbon, and iron in the hot metal produce the heat required to melt the scrap. While reactions with the other elements produce solids that eventually enter the slag phase, the reaction with carbon produces carbon monoxide; about $10^{\prime \prime}$. of this gas is oxidized to carbon dioxide as it evolves from the BOF vessel and is at a temperature of about $2700^{\circ} \mathrm{F}$. The off-gas possesses both fuel value and sensible heat. 
In most BOF installations in the United States the exhaust gases are collected with open hoods over the vessels. Considerable air infiltration occurs, and the off-gas burns in the hoods. Flame temperatures of about $3000^{\circ} \mathrm{F}$ are obtained. The hoods are either steam-cooled or watercooled, causing the gas temperature to drop to about $1850^{\circ} \mathrm{F}$. In some plants a part of the heat from the burning off-gas is recovered as steam by heat transfer to the water-cooled hood or by radiant-heat transfer. After the gases have been further cooled and cleaned, they are released to the atmosphere.

Two major types of gas cleaning systems are used for dust removal from BOF off-gas: (a) electrostatic precipitators and (b) venturi scrubbers. In each case water is used to cool the gas to temperatures that can be handled by the gas cleaning system, i.e., for venturi scrubbers, $80^{\circ} \mathrm{C}$. $\left(177^{\circ} \mathrm{F}\right)$ and for electrostatic precipitators, $250^{\circ} \mathrm{C}\left(480^{\circ} \mathrm{F}\right)$.

Most of the sensible heat is removed from the combusted gases by injecting a water spray, which is rapidly vaporized by the hot gases. The heat removed by vaporization of the water spray is wasted. Typically, when steam is generated and utilized, the energy recovered from the off-gas is estimated at 150,000 to 250,000 Btu per ton of steel.

\section{Energy Conservation Through BOF Off-Gas Recovery}

The oxygen consumption in BOF steelmaking ranges from 1500 to 2400 SCF per ton of steel, Un the basis of a material balance (Ref. 4), about $60 \%$ of the usage, or 900 to $1440 \mathrm{SCF}$, is for the oxidation of carbon in the hot metal to carbon monoxide. Hence, the carbon monoxide generated ranges from 1800 to $2880 \mathrm{SCF}$. In practice about $10 \%$ of the carbon monoxide burns in the vessel. The carbon monoxide that could potentially be collected is in the range of 1620 to $2590 \mathrm{SCF}$ having a fuel value of 0.52 to 0.83 million Btu per ton of steel. In addition, the off-gas is at $2700^{\circ} \mathrm{F}$ and therefore possesses sensible heat ranging from 0.09 to 0.15 million Btu per ton steel. The gas volumes handled in suppressed-combustion systems are one third to one seventh of those handled in complete-combustion systems, resulting in an electrical energy saving of the order of $6 \mathrm{kWh}$ (0.06 million Btu) per ton of steel.

The potential for energy savings in BOF off-gas recovery is (a) production of by-product COrich fuel that could replace natural gas or oil of the order of 0.61 to 0.98 million Btu per ton steel and (b) electrical energy savings of the order of 0.06 million Btu per ton steel. If all plants were to adopt BOF off-gas recovery, a potential saving of $0.054-0.083$ quad is possible (based on the 1976 BOF production of 79.9 million tons).

\section{Schemes for Greater Energy Recovery from BOF Off-Gas}

\section{a. Collection of $\mathrm{CO}$ in Gas Holders}

(1) Status of Technology for Collectiom of Fuel Values. The schemes for the collection of basic oxygen furnace off-gas utilize a closed-hood system over the BOF vessel so that the combustion of $\mathrm{CO}$ is suppressed. As mentioned above, the gas volume that must be handled is about one third to one seventh of that handled by an open-hood system. As a result, the gas cleaning system is more compact. Figure VII-5 is a schematic of a BQF off-gas recovery system. 


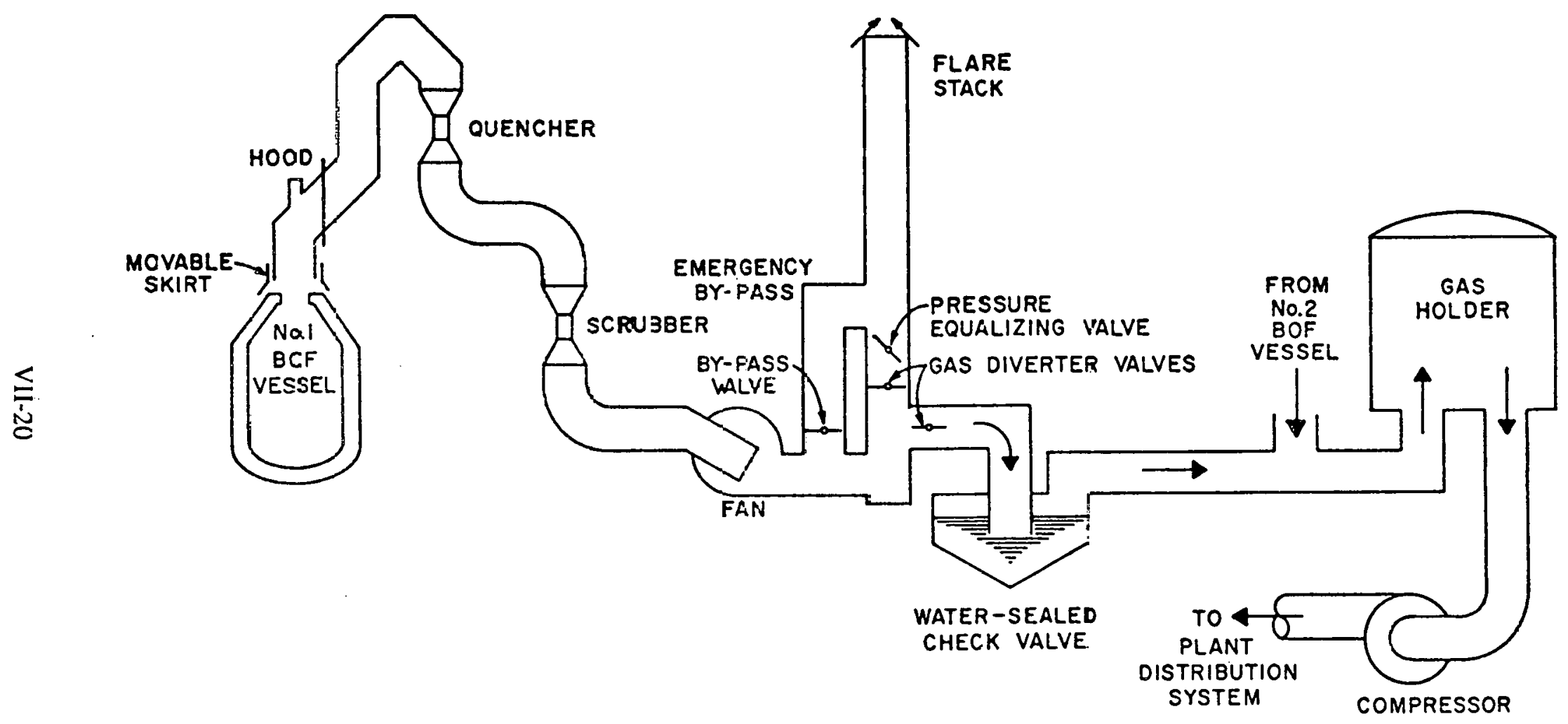

Source: Ref. 5

FIGURE VII-5 SCHEMATIC OF BOF OFF-GAS RECOVERY SYSTEM 
The technology for gas collection is fairly well established. More than 100 suppressedcombustion units are either in operation or being built in Japan, France, United States, U.K., Belgium, and the U.S.S.R. A number of Japanese and European plants have installed gas holders, controls, and compression equipment to recover gas from suppressed-combustion hood systems. By contrast, the United States has five BOF shops with suppressed-combustion hood systems, all of which flare the recovered $\mathrm{CO}$. Shops having suppressed-combustion hood systems represent an annual capacity of 10.8 million tons of steel (Ref. 6).

The collected gas is potentially valuable as a low-sulfur fuel which can be used to augment the gaseous fuel supply within the plant. At the beginning and the end of a blow in a partialcombustion system, the $\mathrm{CO}$ emitted from the vessel is burned; this is done to form a plug of inert combusted gas for flushing out the ductwork and preventing the formation of an explosive mixture of $\mathrm{CO}$ and air. For this reason it is practical to collect the off-gas for only a limited portion (usually half) of the blow. During the collection period, the $\mathrm{CO}$ content of the gas is relatively constant. About $60-90 \%$ of the gas volume is collected.

Approximately 1800-2000 SCF of gas can be recovered per ton of steel, with a fuel value of 210 to $250 \mathrm{Btu}$ per SCF. This represents an energy saving of about 0.45 to 0.5 million Btu per ton of steel. Further savings of energy can be realized if the sensible heat in the off-gas is recovered in the gas cooler and the cooling water is then fed to the waste heat boiler.

Other advantages claimed for the closed-hood system include (a) increase in steel yield of about a percent, due to lower slopping losses, and (b) easier dust collection, as dust particles in non-combusted off-gas are generally coarser and less oxidized.

(2) Likelihood of Implementation. The use of closed-hood systems is justified by easier gas collection and cleaning, and by increased steel yields, without taking credit for the fuel value of the recovered gas. However, if the off-gas is to be used as fuel, it must be collected and stored, compressed, and distributed to the point of use. In the United States, even with increasing fuel costs, gas storage and distribution is not now economically attractive.

Tables VII-3 and -4 present the cost structure for new complete-combustion and suppressed-combustion systems. These costs are for a three-vessel BOF shop with an annual raw steel capacity of 5.25 million tons. Both systems use high-energy wet scrubbers. Current designs of supprcsscd-combustion systems cull lor a separate gas-cleaning circuit for each vessel for safety reasons. Capital investment for suppressed-combustion systems is $\$ 4.4$ per annual ton vs. $\$ 2.7$ per annual ton for complete-combustion systems. If the recovered gas is used as a fuel and priced at $\$ 2 /$ million Btu, the total operating costs of the suppressed-combustion system are lower than those of the complete-combustion system (there is a saving of $\$ 0.81$ per ton of steel). If fuel is priced at $\$ 4.50$ per million Btu, the cost saving is $\$ 1.91$ per ton of steel.

Another important deterrent to installation of closed-hood systems on existing BOFs is the cost of retrofit. As discussed in Ref. 5, an existing BOF shop with dry gas cleaning (i.e., electrostatic precipitators) would require complete replacement of hoods, ductwork, and precipitators in order to handle the combustible gas. Even a shop equipped for wet gas cleaning would generally have to replace or modify hoods and ductwork due to differences in gas velocities and the need to provide a gas-tight system. An exception might be a shop with wet scrubbers that was planning to increase the oxygen blowing rate on its furnaces; in that case, the gas velocities in the 
hoods and ducts might remain high enough to prevent low-flow pockets where an explosive mixture could accumulate. It might be necessary to redesign the lower part of the hond to providr: means to regulate combustion beyond the mouth of the vessel. For plants with suppressedcombustion systems, additional equipment is needed for gas collection, storage, compression, andi distribution to the point of consumption.

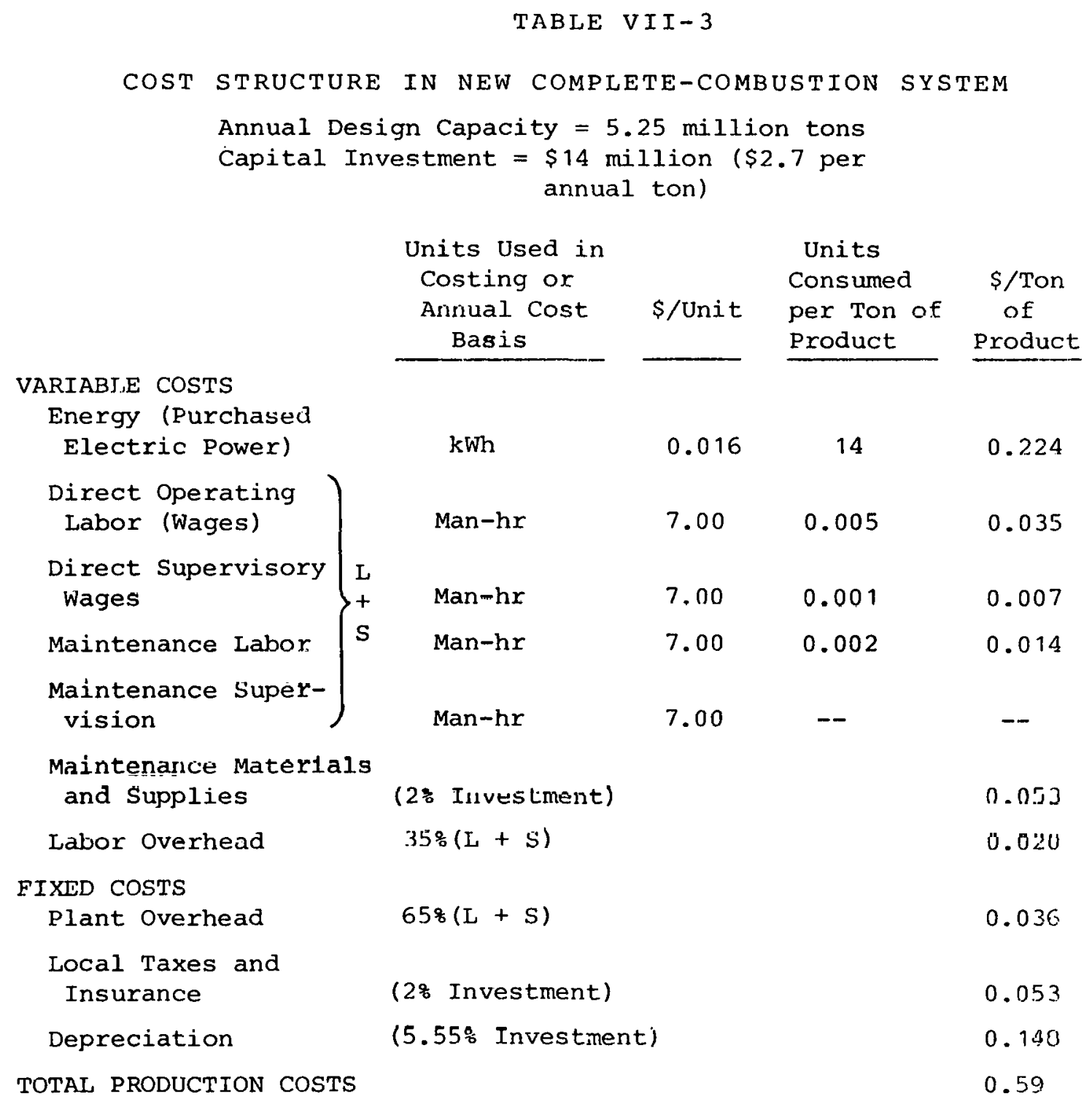

Source: Ref.7 
TABLE VII-4

COST STRUCTURE IN NEW SUPPRESSED-COMBUSTION SYSTEM

Annual Design Capacity:

Capital Investment:
5.25 million tons

$\$ 23$ milition ( $\$ 4.4$ per annual ton)

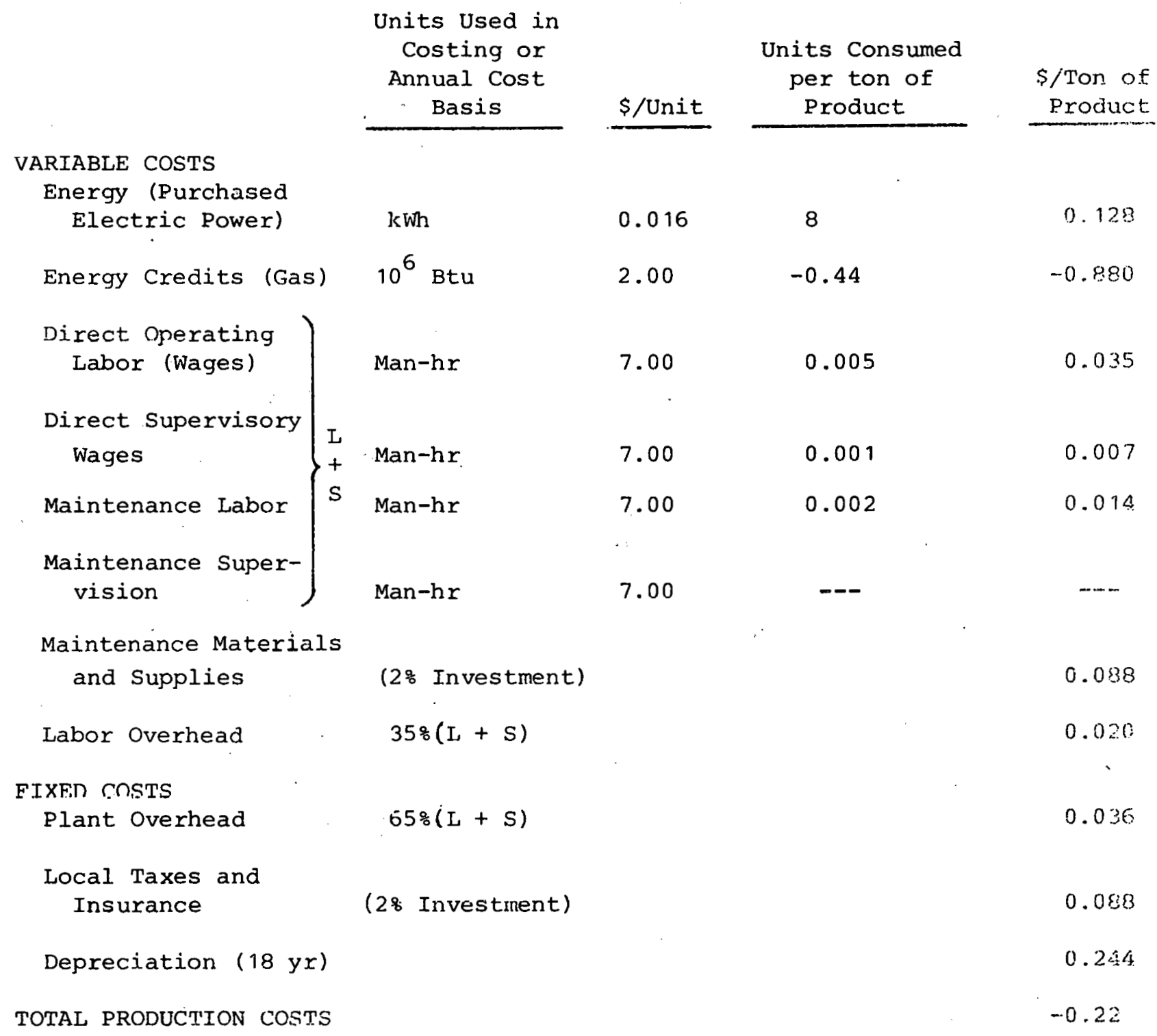

Source: Ref. 7 
Besides the cost of equipment needed for retrofit, another impediment is the downtime involved. The downtime is estimated to be several months, which is inordinately long for most steel plants. Normal shutdowns are for periods of one to two weeks.

An analysis has been made (Ref. 5) of the economic feasibility of retrofitting gas-holder and distribution equipment on an existing suppressed-combustion hood system and using the gas as; fuel for the soaking pits. The estimated capital, operating costs, and return on investment are presented in Table VII-5. At a fuel cost of $\$ 2.00$ per million Btu, the payback period would be 1.1 years and the internal rate of return less than $6 \%$. If fuel costs increased to $\$ 4.50$ per million Btu, the payback period would be reduced to 5.2 years.

The dust content in the $\mathrm{CO}$ collection system is less oxidized than in a total-combustion system, contains a smaller percenlage of submicron particles, and is easier to collect. Treatment. of the water used in scrubbing is facilitated by the more rapid settling that results. Solid waste? disposal methods are unattected.

A worldwide survey of steelmakers by Kaiser engineers (Ref. 6) indicated that the most widely used closed-hood system is the $\mathrm{O}$-G process, developed in Japan. Both IRSID-CAFI. (developed in France) and Baumco also have a significant number of installations.

(3) Time Frame for Implementation. We expect that suppressed-combustion systems will be used for BOF off-gas in new installations. In the near term it is likely that the systems will be built without provision for using the recovered gas. However, plans would probably include land and space provisions for a gasholder and compressors, so that they could be added in the future if required. Gas collection is not now economically attractive in the United States, even with rapidly increasing fuel costs, but in 10-15 years it will become more attractive if fuel prices continue to rise, the availability of natural gas and electricity diminishes, and construction costs rise less rapidly than fuel costs.

When retrofitting suppressed-combustion systems on existing open-hood BOF vessels, it is important to consider the facilities, fuel requirements, space, and downtime needed for retrotit. At present, there is not sufficient economic incentive, and it is unlikely that very many plants will he modified. Exceptions are where BOFs have to be shut down for other reasurs; in such cases, closed hoods could be installed during the downtime.

\section{b. Installation of Waste Heat Boilers}

Of the approximately 38 U.S. plants that have BOFs, 9 have boilers, and the steam is utilized in 7 of these. The 9 plants with boilers represent a capacity of 28.65 million tons, of which those with boilers and utilizing the steam represent a capacity of 21.95 million tons (Ref. 7 ). We have no information on the size of the brilers and the amount of heat recovered.

In Europe and Japan, large boilers have been installed over some BOF furnaces to produce steam more efficiently. Assuming boiler efficiencies of $80 \%$, it should be possible to recover 0.5 milliun Btu per ton of steel. The installation of such boilers is favored in locations where fuel prices are high and the steel plant generates much of its own electricity. The cyclic output of the waste heat boilers can be integrated into a larger steam system. 
TABLE VII-5

RETROFIT TO SHOP WITH EXISTING

SUPPRESSED-COMBUSTION HOOD SYSTEM

A. Capital Cost Estimate

- Ductwork, piping, valves, instrumentation controls, \& inert gas purge system at BOF shop and upstream of gas holder

$-2,000,000 \mathrm{ft} .^{3}$ gas holder installed

- Compressors, ductwork, piping, valves, instrumentation, \& controls to distribute gas from holdex to soaking pits

- Top Charges

- Total Est. Capital cost

$6,320,000$

$1,630,000$

$1,720,000$

$\$ 10,200,000$

B. Savings in operating costs

- Fuel cost savings $\$ 2.00 / 10^{6}$ Btu

$\$ 1,688,000 / \mathrm{yr}$

- System Operating cost $\$ .21 / \tan \times 2,000,000$ tons $/ y x$

$420,000 / y x$

Net Operating cost Savings

$\$ 1,268,000 / y x$

c. Return on Investment

- Depreciation $\left(\frac{10,200,000}{18}\right)$

S $\quad 567,000 / Y T$

- Taxable Income $(1,268,000-567,000)$

$701,000 / y x$

- Income raxes $(701,000 \times .50)$

$350,500 / y r$

- Cash Flow after Taxes $(1,268,000-350,000)$

$917,500 / \mathrm{yx}$

- Payback Period

$$
\frac{10,200,000}{917,500}
$$

11 years

Source: Ref. 2 
In the United States, there is currently little economic incentive to improve steam-generation efficiency from BOF off-gas over that already altainable with water-cooled or steam-cooled hoods. Some steel plants simply have no need for additional steam, particularly steam that is generated only intermittently. Even in plants where steam is needed, the capital and operating costs of installing large boilers over the BOF vessel would likely exceed the cost of operating conventional steam boilers. Only drastic increases in fuel prices above even the present high levels would make BOF boilers economically attractive in the United States.

\section{c. Use of Off-Gas to Increase Scrap Utilization in the BOF}

In the United States, the typical charge to the basic oxygen furnace is $72 \%$ hot metal and $28, r$ scrap. Increasing scrap utilization above this level in BOF steelmaking is advantageous from an energy standpoint, since every additional ton nf srrap results in an enorgy caving of 17 milliout Btu. An increase in scrap utilization from $28 \%$ to $38 \%$ of the BOF charge would translat.e ton an additional consumption of 8.8 million tons of scrap in the United States. 'I'his represents an annual energy saving of 0.15 quad.

It is generally considered that a BOF charge consisting of 28 scrap is close to being in thermal balance. To increase the scrap usage, additional heat would have to be provided. To the extent heat available in the BOF off-gas is utilized for this purpose, there is no increase in fuel demand.

One approach is to produce the additional heat by burning more carbon monoxide above the metal bath but in the BOF vessel. The heat is transferred from the burning $\mathrm{CO}$ to the molten bath and could be used to melt more scrap. However, the heat transfer to the bath is likely to be inefficient, and there are likely to be greater refractory-related problems because of the higher temperature.

Another approach to providing the additional heat is to preheat the scrap. This techuique has been shown to allow increased use of scrap, and steel companies have experimented with methods of doing this both inside and outside the BOF vessel.

One concept would be to use the collected BOF off-yas as fuel in a separate scrap preheater vessel. However, as discussed above, there are barriers to the adoption of off-gas collection in gas holders. It is unlikely that this method will be utilized, at least in the near term.

In another concept, described in a French patent (No. 1312160) issued to Calderon Automation Inc., two vessels are used - one for refining and another for preheating. The carbon monoxide evolving from the refining vessel is ducted and burned in the vessel containing the scrap to be preheated.

We feel that some problems may arise with such a concept, especially in a two furnucc shop, in scheduling the furnaces - i.e., in synchronizing preheating and refining. (Most BOF shops in the United States are two-furnacc shops.) Synchronized preheating and refining introduces one more link in the system and could potentially lower its reliạbility.

In scrap preheating, the high-temperature limit has been $1200-1300^{\circ} \mathrm{F}$ in order to avoid excessive oxidation and melting. A violent reaction is possible when hot metal is added to oxidized scrap. This limit on temperature may restict the extent to which scrap in the charge can be increased. 
Another method of preheating scrap is to use an open-hood system (Figure VII-6) and burn the $\mathrm{CO}$-rich gas with infiltrated air in the hood. The hot gases are passed through the scrap charge contained in a preheating vessel close to the BOF vessel. This concept was tested by the U.S. Bureau of Mines (Ref. 8) in a quarter-ton pilot plant BOF. For tests in which the charge contained $33 \%, 36 \%$, or $40 \%$ scrap, scrap temperatures were in the range of $1050-1150^{\circ} \mathrm{F}$, and the heat stored in the scrap provided $23-26 \%$ of the energy required for melting. The heat recovered in the preheated scrap ranged from about 20,000 to 120,000 Btu per ton.

The Bureau of Mines tests are being extended to study heat transfer efficiency, effect of scrap density, and dust removal. We feel that testing would be needed to detormine if there is scrap oxidation and whether dust removal is adequate before this operation is scaled up.

\section{Role of Governmental Funding of R\&D Effort}

The technology for BOF off-gas collection and storage has been well demonstrated. The constraints to its adoption are mainly economic, and the appropriate role of the government may be to provide financial incentives. An area for research is to develop ways of better utilization of the sensible heat in the off-gas. This research could probably be done by equipment manufacturers supported by the steel companies and would be encouraged by DOE support. Benefits from such research would be realized in the longer term.

In the area of scrap utilization, research is needed to develop preheating concepts and systems that would allow more scrap to be charged to the BOF. Concepts that utilize in-plant generated fuel, such as CO-rich gas collected from the BOF off-gas, deserve special attention; these would allow utilization of a gas that at present is not being used for its fuel value. The use of such gas may also permit the attainment of suitable preheat temperatures without oxidation of the scrap. To the steel companies, the greater utilization of scrap is attractive only when it is cheaper than hot metal. We feel that steel companies do not have sufficient incentive to pursue this area of research on their own. However, the export of scrap has a significant effect on the U.S. economy, since it is equivalent to exporting energy, and we feel that research on greater scrap utilization is an area that the DOE could usefully support.

\section{SCRAP-BASED PROCESSES}

\section{Electric Arc Furnace}

\section{a. Mathematical Modeling}

(1) Introduction. Electric arc furnace production is expected to grow from a present level of approximately 28 million tons of raw steel per year to approximately 45 million tons by the late 1980 's. This growth rate is higher than the $2.5 \%$ per year production increase projected by Arthur D. Little, Inc., for the domestic steel industry because of the continued decline of the scrapconsuming open hearth furnaces. Since the BOF does not have the scrap melting capacity of the open hearth, electric arc furnaces will take over part of the scrap melting function of the open hearths that presently remain.

Electric furnaces consume a reported average of $480 \mathrm{kWh}$ per ton of raw steel. 'This translates into 0.14 quad for 28 million tons and 0.23 quad for 45 million tons. 


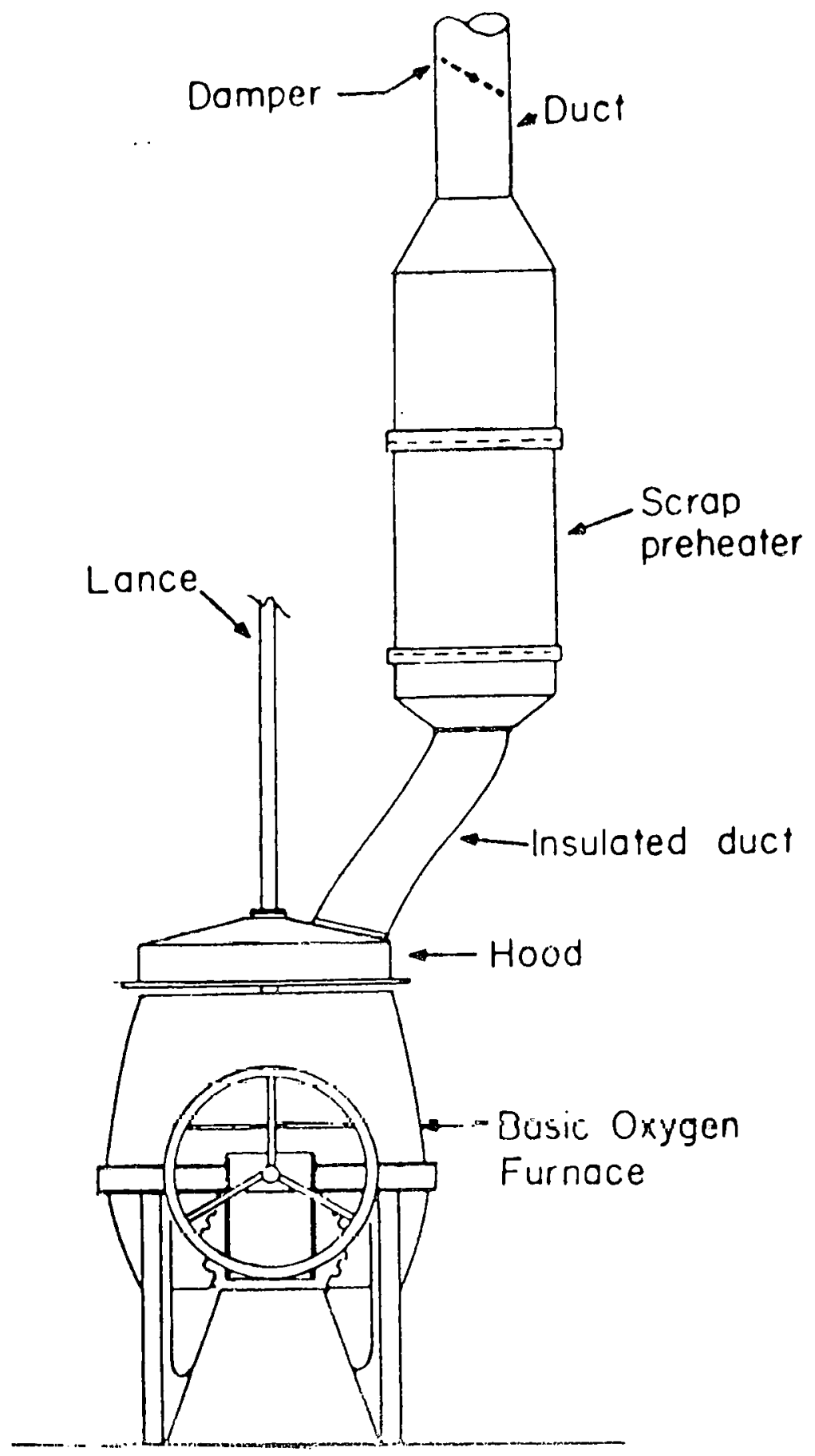

Source: Rict. 8

FIGURE VII-6 BOF-PREHEATER SYSTEM 
(2) State of the Art: The general configuration of the electric arc furnace for steelmaking is a shallow-depth, large-diameter cylindrical shell with a dished bottom. The shell is covered with a removable roof through which are inserted three graphite electrodes. The entire shell and roof are lined with high-performance refractories.

Steel scrap is the principal raw material for electric furnace steelmaking. Sponge iron from direct reduction has also been found to be practical for up to $50 \%$ of the charge; if this raw material is available, it is expected to have increased importance in the future.

The capacity of electric arc furnaces has increased from the 4 tons per heat of the original 1906 U.S. furnace to 400 tons per heat in what is believed to be the world's largest electric arc steelmaking furnace. Operating practice has been improved with the installation of high-powercapacity transformers ranging from $30,000 \mathrm{kVA}$ for small furnaces to $60,000 \mathrm{kVA}$ for large furnaces. With the higher power, melting is more rapid, and the furnace heat schedules have been decreased to periods of three to four hours for a complete cycle for carbon steel.

A fiurnace heat cycle begins with the loading of a partial charge into the top of the furnace. The roof is then closed, and the electrodes are lowered so that an arc is formed between the electrodes and the charge. After the initial charge is melted, the balance of the charge is put into the furnace, and melting and refining proceed to completion of the heat. When larget chemistry is attained, the heat is tapped into a transfer or teeming ladle, and the remaining slag is dumped from the furnace into a slag pit. The refractory is then patched to make the furnace ready for the next heat.

The process is characterized by flexibility of operation and close control of heat chemistry. Therefore, it may be used to produce the full range of carbon and medium-alloy structural steels and specialty alloys, stainless steels, tool steels, and superalloys.

The principal heat lusses arise from the following:

- air draft into the furnace and from there into the pollution control system;

- Losses from the furnace shell to the environment;

- cooling during charging;

- resistance losses in the electrical system.

An optional design should therefore include :

- Minimum draft;

- Fast and efficient melting, requiring a modern ultra-high-power supply and possibly preheated scrap;

- An efficient heat transfer for fast melting and minimum shock to the refractories;

- Fast charging procedures. 
(3) Potential Energy Savings. The thermal efficiency of electric furnaces is of the order of $75 \%$ at present. A $5 \%$ improvement would represent $24 \mathrm{kWh} /$ ton, or 0.007 quad in 1978 and 0.011 quad in 1990. Such savings would be reflected in the amount of fuel used by power generating stations.

A specific proposal to investigate the possibility of such savings has been prepared by Professor Szekely of M.I.T. and is discussed in Appendix B.

\section{b. Scrap Preheating}

(1) Introduction. Only a few scrap preheaters are used in the steel industry, primarily because of numerous difficulties with the process: scrap oxidation, welding of the scrap in the preheating bucket, inability to obtain uniform temperatures in the scrap (i.e., it is hot and possibly oxidized on one end of the preheater and cold on the other), gas by-passing, logistical problems in moving scrap to the steelmaking furnace, and scheduling problems, especially when several back-charges of scrap are needed.

(2) Energy Conservation Potential. If all electric furnace steel were made from scrap heated to $1200^{\circ} \mathrm{F}$, these furnaces could save up to $100 \mathrm{kWh}$ per ton of steel, and a national energy saving equivalent of $29 \times 10^{12}$ Btu per year would be realized. This would be in the form of electrical energy not needed in the furnaces for melting the charge materials. The total energy saved by scrap preheating would undoubtedly be considerably smaller, since:

- Average scrap preheat temperatures may be well below $1200^{\circ} \mathrm{F}$;

- Many shops may not be able to incorporate a preheater because of shop layout; and

- The fuel used to preheat scrap, such as natural gas or fuel oil, may reduce the total calculated energy saving.

Finergy savings might also be realized if heat could be recovered from hot ingots or billets to preheat scrap. A concept for using heat from ingots or billets that are normally alluwed to cool to ambient temperature has been proposed by Mr. Harrison Woolworth. A preliminary evaluation indicated that the application of this concept to smaller electric furnace shops has a potential for annual savings or $5.7 \times 10^{12} \mathrm{Btu}$ in the form of electric power (using $10,500 \mathrm{Btu}$ per $\mathrm{kWh}$ ).

\section{Hot Blast Cupola-BOF for Melting Steel Scrap}

In this concept, steelmaking scrap is melted in a hot blast cupola to produce iron hot metal, which is then converted to steel in a BOF shop. There are two possible variations:

- Using a cupola metallic charge consisting of a high percentage of steel scrap (up to about $80 \%$ ) and a small percentage of iron scrap (pig iron or gray iron). The cupola hot metal is then converted to steel in a BOF.

- Using a cupola metallic charge consisting of $100 \%$ steel scrap. The cupola hot metal is then converted to steel in a BOF. 
In a number of operations in the United States and abroad, steel has been made by melting up to $80 \%$ steel scrap in a cupola and then blowing the hot metal in a BOF. In early 1958 , Gusstahlwerk Witten A.G. in Germany installed a 30-ton detachable-bottom oxygen converter that was fed with hot metal from a scrap-melting hot blast cupola. In the following year, Acme Steel Company began a similar operation (described in Refs. 9-11) which consumed approximately $75 \%$ steel scrap.

The hot blast cupola-BOF scheme is presently being practiced by Allegheny Ludlum and Bethlehem Steel Company. Up to about $80 \%$ steel scrap is used; the rest is iron scrap or pig iron. We understand that the cupola-BOF scheme requires control and/or adjustment of the silicon content of the hot metal from the cupola and/or adjustment of the amount of scrap melted in the BOF.

According to industry sources, it is possible to operate the cupola-BOF scheme with 100 . steel scrap into the cupola (i.e., no iron scrap or pig iron) by adjustment of coke rate, air preheat temperature, and BOF operating practice. As far as we know, this concept has not been tested by the U.S. steel industry.

\section{DIRECT REDUCTION}

\section{Conventional Technology}

One of the newer technologies being considered and implemented in many parts of the world today is direct reduction. This process has been used successfully to provide a substitute for scrap in electric arc furnaces, which are largely based on scrap steel and iron. From a technical viewpoint, a directly reduced product can also be used in place of scrap in oxygen furnaces and open-hearth operations, or as a partial substitute for iron ore in blast furnaces; however, none of these practices are in large-scale use, primarily for economic reasons.

The three commercially demonstrated direct reduction processes in the United States use hydrocarbon fuels (e.g., natural gas or naphtha) in vertical shaft furnaces. The total capacity of these plants is estimated at 1.1 million short tons of product per year. The exhaust gas from the furnaces has a maximum fuel value of $70 \mathrm{Btu}$ per SCF and is presently flared. (Typical gas volumes are 57,000 SCF per minute at a temperature of $1200^{\circ} \mathrm{F}$ for a furnace with a capacity of $400,000 \mathrm{cons} /$ year production.) We expect this technology to be implemented only where excess amounts of natural gas are available.

Steam-coal-based processes such as the SL/RN process (Stelco Lurgi, Republic Steel, and National Lead), the Kawasaki process, and the Krupp-Renn process have had technical demonstrations. However, coal-based direct reduction processes need more commercial demonstrations and testing before they are accepted for use by the steel industry. Therefore, we do not expect a large amount of directly reduced iron to be produced in the United States in the next decade. Scrap will continue to be the main source of "cold metal" charged to steelmaking furnaces.

\section{Energy Conservation Potential}

The existing direct reduction plants could be operated on gasified coal fuels instead of the critical hydrocarbon fuels now used. An estimated $12 \times 10^{12} \mathrm{Btu} / \mathrm{year}$ of critical fuels could be 
saved by this fuel change. However, since this process is very sensitive to fuel costs, the direct, reduction plants now operating in the United States may be shut down as uneconomical within five years. We believe that the present relatively high cost of gasified coal fuel would not change the economic picture for gasified fuel direct reduction processes. Since these plants may close, it is unlikely that money will be invested to recover the heat in the low-Btu gas that they produce, with or without a government-funded demonstration.

The steam-coal-fired process would save metallurgical coke normally used in the blast furnace process but would consume more total energy. Table VII-6 shows that the likely direct reduction-electric arc furnace route to steel consumes $56 \%$ more energy than the coke oven-blast furnace-BOF route. The only advantage of the direct reduction route is in replacing a given number of Btu's from metallurgical coke with a larger number of Btu's from less critical steam coke and clectricity.

\section{Comparison of Energy Savings from Steam Coal Injection into Blast Furnaces with Coal-Fired Direct Reduction}

The injection of powdered steam coal into the tuyeres of the blast furnace appears to be a preferable method for reducing the consumption of metallurgical coke in steelmaking, since it would not increase the overall energy used in producing steel. Another advantage is that the large investment in the existing blast furnaces would not be lost. Implementation of steam coal direct reduction processes is a long-term development, while steam coal injection into blast furnaces could save metallurgical coke within five years.

\section{Role of Government Funding of Direct Reduction Projects}

Funding of direct reduction demonstrations should be done only after careful consideration, because it appears that alternatives such as coal injection into blast furnaces have more immediate potential benefits. 
ENERGY REQUIREMENTS OF THE CONVENTIONAL AND DIRECT REDUCTION STEELMAKING ROUTES

(million Btu per ton of steel)

A. Direct Reduction

Kiln

Coal

Electric Power ${ }^{a}$

10.96

0.41

Electric Arc Furnace

Electric Power ${ }^{a}$

6.30

Total Production

17.67

Pollution Controls

Air: Kiln (electric power)

0.036

EAF (electric power)

0.487

Water: Kiln (electric power)

0.065

Kiln (fuel)

0.187

Total Pollution

Total:

0.78

18.45

B. Base Line

Coke Oven

1.85

Blast Furnace

9.45

Basic Oxygen Process ${ }^{b}$

$(0.13)$

Total Production

11.17

Pollution Controls

$$
\begin{aligned}
& \text { Air (electric power) }{ }^{a} \\
& \text { Water (electric power) } \\
& \text { Water (fuel) } \\
& \text { Totàl Pollution }
\end{aligned}
$$

Total:
0.34

0.08

0.25

a. $1 \mathrm{kWh}=10,500 \mathrm{Btu}$ fuel equivalent at power source.

b. Includes $0.44 \times 10^{6}$ Btu credit for Co recovery.

Source: Ref. 7, p. 79. 


\section{REFERENCES FOR CHAPTER VII}

1. Bell, S.A., et al., "Armco Coal Injection," (private communication) for presentation and publication in AIME Ironmaking Conference and Proceedings, 1976.

2. "Energy Conservation in the Steel Industry," 84th General Meeting of American Iron and Steel Institute, May 1976.

3. Coheur, P., "Direct Reduction in the Blast Furnace," conference at ILAFA Meeting in Mexico City, October 5, 1971.

4. Healy, G.W., The Basic Oxygen Process, The Pennsylvania State Universily, 1966, pp: 32-333.

5. "Energy Conservation in the Steeel Inductry: Utilizatiun uf BOF Ott-lias," 84th (ieneral Meeting of American Iron and Steel Institute, May 1976, pp. 69-74.

6. Stone, J.K., "Worldwide Roundup of Rasic Oxygen Steelmaking," Iron and Steelmuker, April 1976, pp. 31-35.

7. Iron and Steel Industry, Vol. III of Environmental Considerations of Selected Energy Conserving Manufacturing Options, EPA Contract No. 68-03-2198, December 1976, pp. 18-28.

8. Mahan, W.M., and Daellenbach, C.B., "Thermal Energy Recovery by Basic Oxygen Furnace Off-Gas Preheating of Scrap," in Efficient Use of Fuels in the Metallurgical Industries, Institute of Gas Technology, December 1974, pp. 457-465.

9. Ess, T.J., "Acme Steel Company," AISE Proceedings, 1960, p. 197.

10. Kimberly, R.L., and Tatousek, R., "Cupola Oxygen Steelmaking at Acme Steel," J. Metals, August 1963.

11. Shaw, R.B., "Basic Hot Blast Cupola - BOF Steelmaking," Iron and Steel Engineer, lanuary 1968. 


\section{STEEL CASTING - INGOTS, BILLETS, BLOOMS, AND SLABS}

\section{A. CONVENTIIONAL TECHNOLOGY}

The conventional method of casting steel, not only in the United States but largely throughout the world, is by the original method of pouring the molten steel from the various steelmaking processes into cast iron molds of various designs and dimensions. The resulting ingots can be subsequently hot-rolled into various semifinished steel forms - slabs, blooms, and billets.

In this process, molten steel produced in the steelmaking furnaces is poured into receiving ladles, which are transferred by crane and positioned over a line of ingot molds that stand on small rail cars. The molten steel is discharged (teemed) from the bottom of the ladle through a control valve into the molds.

After solidification, the filled ingot molds are transferred by rail to a stripping building, where the molds are removed from the ingots. The latter are then reheated in soaking pits to $2200^{\circ}-2400^{\circ} \mathrm{F}$ and rolled into slahs, blooms, and billets on the primary breakdown mill.

\section{B. CONTINUOUS CASTING}

In continuous casting, a newer technology, molten steel is directly converted to semifinished forms. This eliminates the soaking pits and the primary breakdown mill, thereby reducing energy consumption by half; the reheating of ingots in the soaking pits in particular consumes large amounts of thermal energy. In addition, the yield from molten steel to slabs and blooms is improved from about $82 \%$ with conventional ingot casting and rolling to $96 \%$ with continuous casting, which in itself represents an energy saving.

Thus, in considering the potential energy savings to be gained by continuous casting, one must compare the effect at the slab, bloom, and billet stage in the steelmaking process, because continuous casting will affect the energy saved due to yield improvements in soaking pits and primary breakdown mills.

At the present time, only about $11-12 \%$ of the steel produced in the United States is continuously cast; the remainder is cast as ingots in the conventional way. This compares unfavorably with such countries as Germany and Japan; as long ago as 1973, more than 17\% of Germany's molten steel was continuously cast, and the corresponding figure for Japan was over $21 \%$

It is estimated that 2.54 million Btu per ton of liquid steel is consumed in conventional ingot casting, reheating the ingots in soaking pits, and the primary breakdown to blooms and slabs. The rolling of blooms into billets adds another 0.5 million Btu per ton, giving a weighted average energy consumption of 2.65 million Btu per ton of rolled semifinished products (billets, blooms, and slabs). The remelting of scrap reduces the yield in the respective steelmaking process from which it originated; this adds another 3.17 million Btu per ton of rolled semifinished billets, blooms, and slabs, making a total energy input of 5.82 million Btu per ton of conventionally produced semifinished steel. 
The weighted average energy requirement for continuous casting of billets, blooms, and slabs is 1.01 million Btu per ton. Provisions for yield loss (i.e., remelting scrap in the respective steelmaking processes from which it originated) would add 0.71 million Btu per ton to make a total of 1.72 million Btu per ton.

With only $11-12 \%$ of the liquid steel being continuously cast, the total energy consumed in producing semifinished blooms, billets, and slabs largely by conventional casting would amount to 0.68 quad per year.

Not all grades of steel can be continuously cast. However, it is estimated that the technology is presently available to permit continuous casting of $50 \%$ or more of the steel presently produced in the United States. If this were to be accomplished, the effects would be significant. On the basis of the 1976 production rate, if $50 \%$ of the billets, blooms, and slabs were made by continuous casting, the energy consumption would be 0.48 quad per year, or 0.2 quad less per year than at present.

The steel industry is well aware of the benefits of continuous casting in terms of yield improvement and energy savings. The industry claims, however, that progress in applying continuous casting is impeded by a lack of capital funds to make the required major investments. Increasing the amount of steel continuously cast is part of most companies' long-range plans.

The economics are highly favorable for new installations, but justifying the replacement of existing facilities for conventional ingot casting and primary breakdown mills is more difficult. This conclusion is based upon information provided by the American Iron and Steel Institute in a compendium of identified opportunities. In its report, "Energy Conservation in the Steel Industry," the chapter on continuous casting provides a brief analysis of the economics of the process. Capital costs for new continuous casting facilities amount to $\$ 50-\$ 60 /$ annual ton of capacity; this compares favorably with new facilities for conventional ingot casting, reheating, and primary breakdown operations, which cost $\$ 60-\$ 65 /$ annual ton of capacity. Production costs for continuous casting are as much as $\$ 15 /$ ton of product less than for the conventional method of producing semifinished steel. (The energy saving alone is about $\$ 8 /$ ton of product.) Such savings would provide a 4.5-year payout, based upon energy costs of $\$ 2.00$ per million Btu. At $\$ 4.50$ per million Btu, the payback period based on savings alone would be 3 years.

The above is, of course, greatly oversimplified, since it does not include taxes, depreciation of the new facilities, and the remaining investment in the facilities that would be replaced. Also, the conventional method of ingot casting and primary breakdown does provide more flexibility than does continuous casting.

What is needed to increase the use of this process in the American steel industry? Certainly, continuous casting technology has been demmstrated for many of the grades, and new applications are found each year. As the cost of energy increases, the economic justification for continuous casting improves. To increase the present rate of application, however, incentives of some kind will probably be required. 


\section{STEELFORMING}

\section{A. SOAKING PITS AND REHEAT FURANACES}

\section{Conventional Technology.}

Steel is reheated for hot working to make it plastic enough for economic reduction by rolling or forging to the desired shape.

Figure IX-1 shows the product flow in the production of steel products and the stages at which reheating is done. Table IX-1 shows the estimated capacities of reheating furnaces in the United States. Table IX-2 shows the reheating temperature and energy consumption for the primary and intermediate heating operations in a steel plant.

The heating furnaces used in the steel industry are of three principal kinds:

- Soaking pits (for primary heating)

- Slab/bloom reheaters

- Billet reheaters

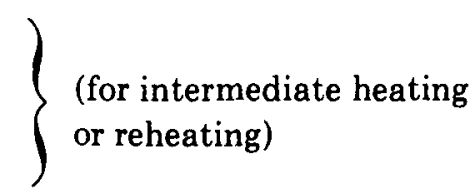

A soaking pit is a heating furnace in which as-cast ingots are preheated to a temperature of $2150-2450^{\circ} \mathrm{F}$ prior to hot rolling on a slabbing/blooming mill. The temperature in the soaking pit varies with the grade of steel, size of ingot, and rolling mill characteristics. Various designs of soaking pits are used, depending on the requirements of ingot shape, reheat temperature, furnace atmosphere, etc. Details are available in, published literature (Ref. 1).

The United States has over 2500 soaking pits with an estimated total reheat capacity of approximutely 185 million tons. The capacity utilization factor is about $60-70 \%$.

We estimate that the amount of fuel consumed per ton of steel heated in the soaking pit varies from approximately $500,000 \mathrm{Btu}$ to $3,000,000 \mathrm{Btu}$. This variation is related to factors such as the temperature at which the ingot is charged into the soaking pit, pit design, waste gas losses, condition of furnace insulation, pit capacity utilization, heat recovery system, furnace curitruls, ingot size, ingot shape, type of steel, and combustion conditions. A typical soaking pit in the United States consumes about 1.5 to 2.0 million Btu per ton of steel ingot reheated.

Slab/bloom reheat furnaces are used for the reheating of slabs and blooms for further conversion by hot rolling into hot-rolled mill products. Their temperature is generally in the 2200 $2400^{\circ} \mathrm{F}$ range. Two principal types of slab/bloom reheating furnaces are used in the U.S. steel industry - the pusher type and the walking-beam type. About $90 \%$ are of the pusher type.

In a pusher-type slab reheat furnace, the inspected slab (which is usually at ambient temperature) is moved by a mechanical pusher through the furnace on longitudinal pipes or "skids" at a controlled rate. Normally, this furnace has several combustion zones, each with separate temperature controllers and burners. 


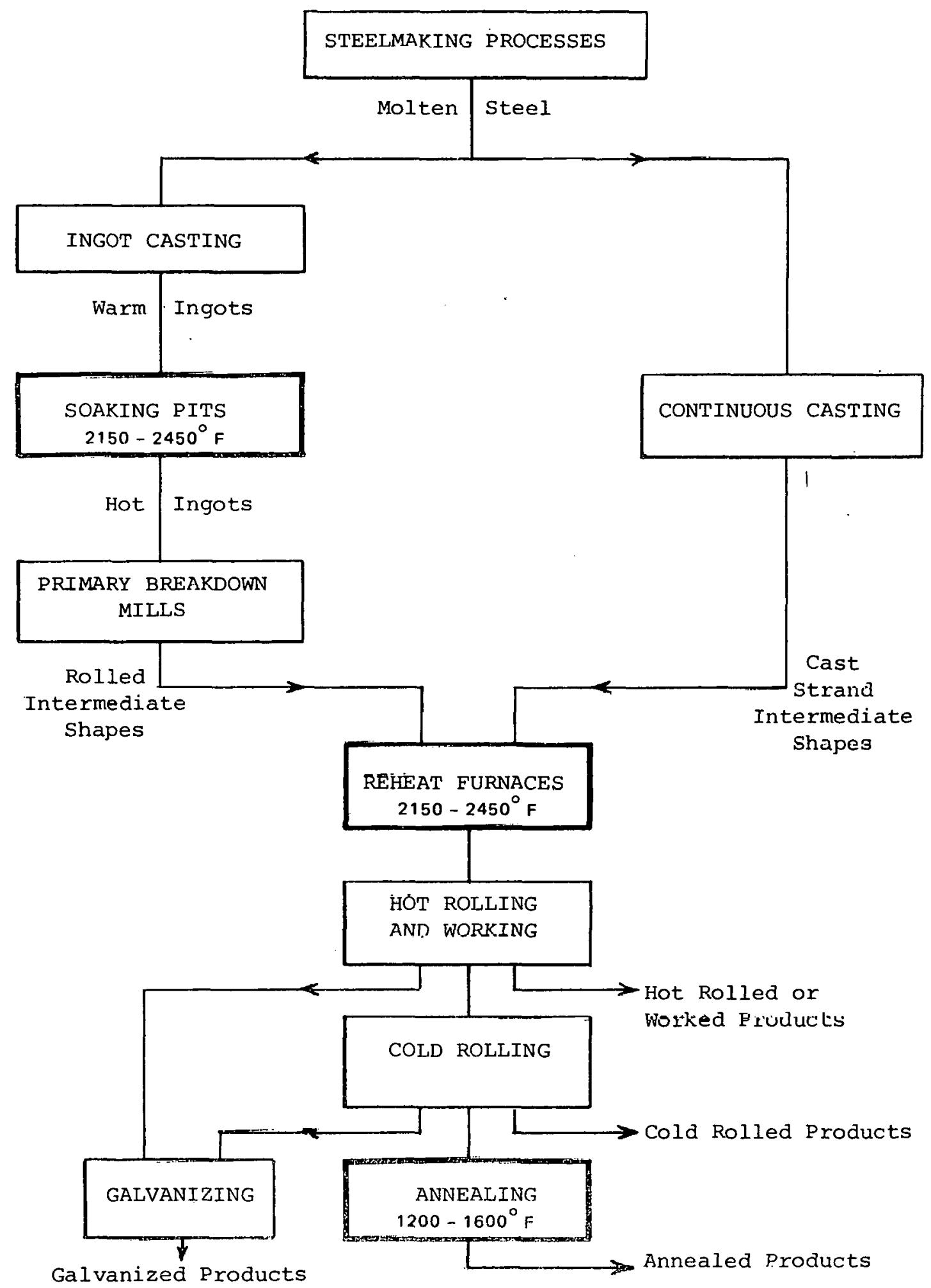

FIGURE IX-1 STAGES AT WHICH SOAKING PITS, REHEAT FURNACES, AND ANNEALING FURNACES ARE USED IN A STEEL MILL 
TABLE IX-1

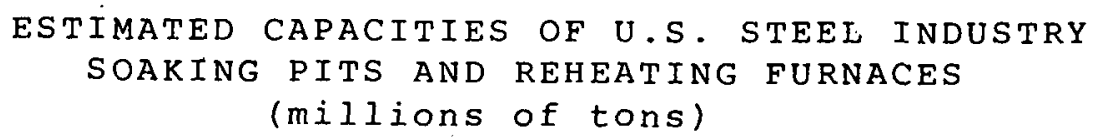

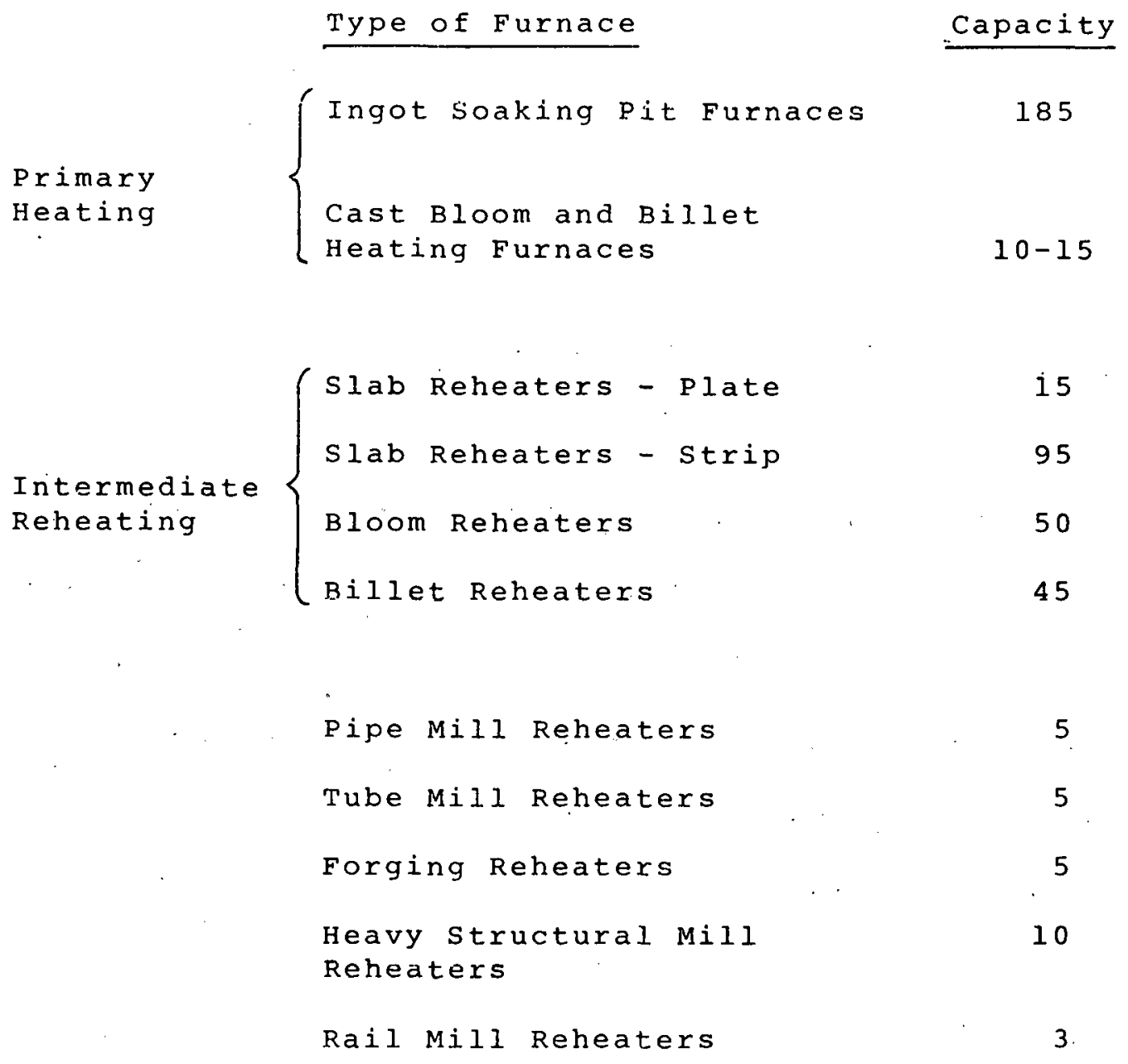

Source: Arthur D. Little, Inc. estimates 
TABLE IX-2

HEATING TEMPERATURES AND ENERGY CONSUMPTION

IN SOAKING PITS, REHEATING FURNACES, AND ANNEALING FURNACES

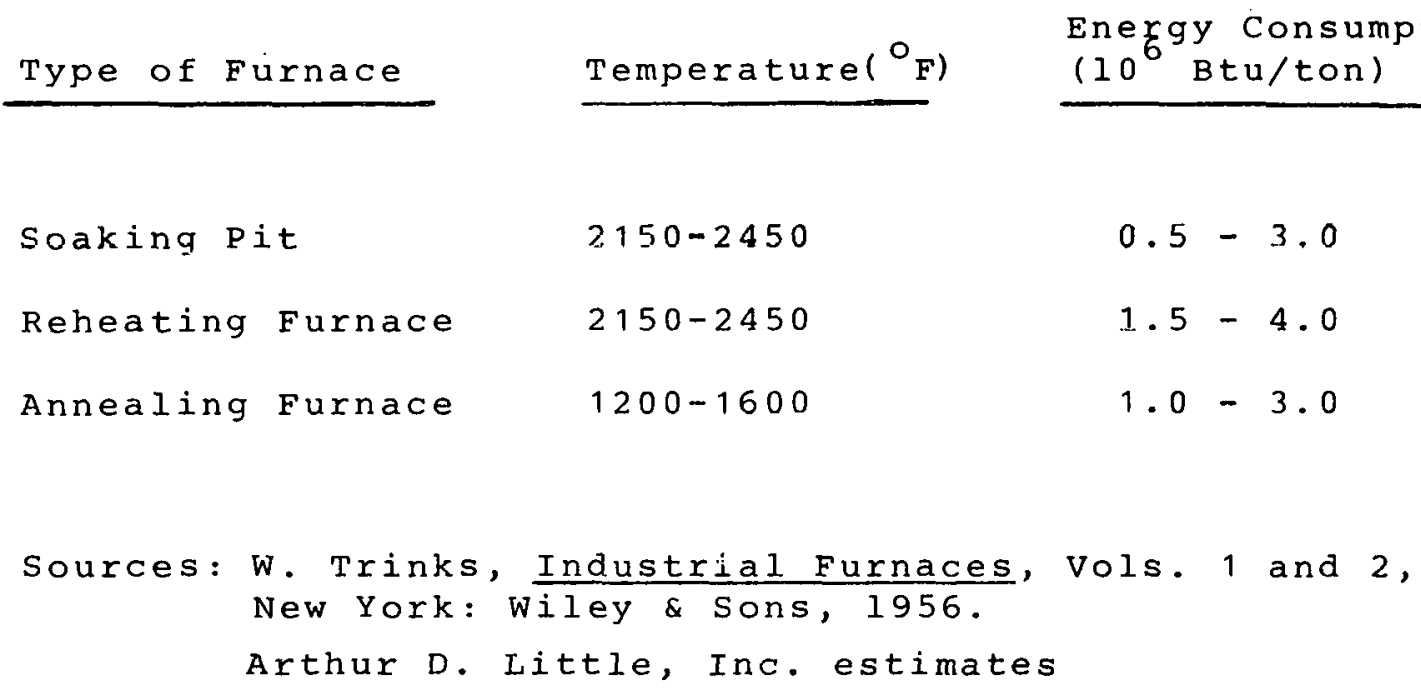

Walking-beam furnaces, of which there are only about ten in the United States, were introduced to overcome some of the limitations and drawbacks of the pusher type. They have a set of stationary water-cooled skids similar to those used in a pusher-type furnace and a set of movable water-cooled skids. 'I'he slabs are lifted hy the movable skids, advanced a few feet loward the discharge end, and lowered back on the stationary skids. The movable skids then return to their starting point and begin a new cycle. The walking-beam furnace provides a higher reheating capacity per unit hearth area and a more uniformly reheated slab than does a pushertype furnace, but it has a higher capital cost and lower energy efficiency. The typicul energy requirement for reheating slabs ranges between 2 and 3 million Btu per ton.

The billet reheating furnace is used to reheat steel billets to $2100-2300^{\circ} \mathrm{F}$ fur rolling in a rod or bar mill. Practically all are of the pusher type. Typical energy requirements for these furnaces range between 1.5 and 4.0 million Btu per ton of billets.

The energy efficiency of reheating furnares is dependent not only nn their desigu but also un their age, condition of insulation, type of heat recovery system, burner design and operation, and general housekeeping and operating practices. Estimates of the energy efficiency of soaking pits and of the principal types of reheating furnaces are given in Table IX-3.

Soaking pits and reheat furnaces in the U.S. steel industry consume approximately 0.5 quad of energy and are thus among the highest consumers of energy in the industry. Table IX-4 is an estimated breakdown of the consumption of various types of energy for the soaking pits, reheat furnaces, and annealing furnaces. 
TABLE IX -3

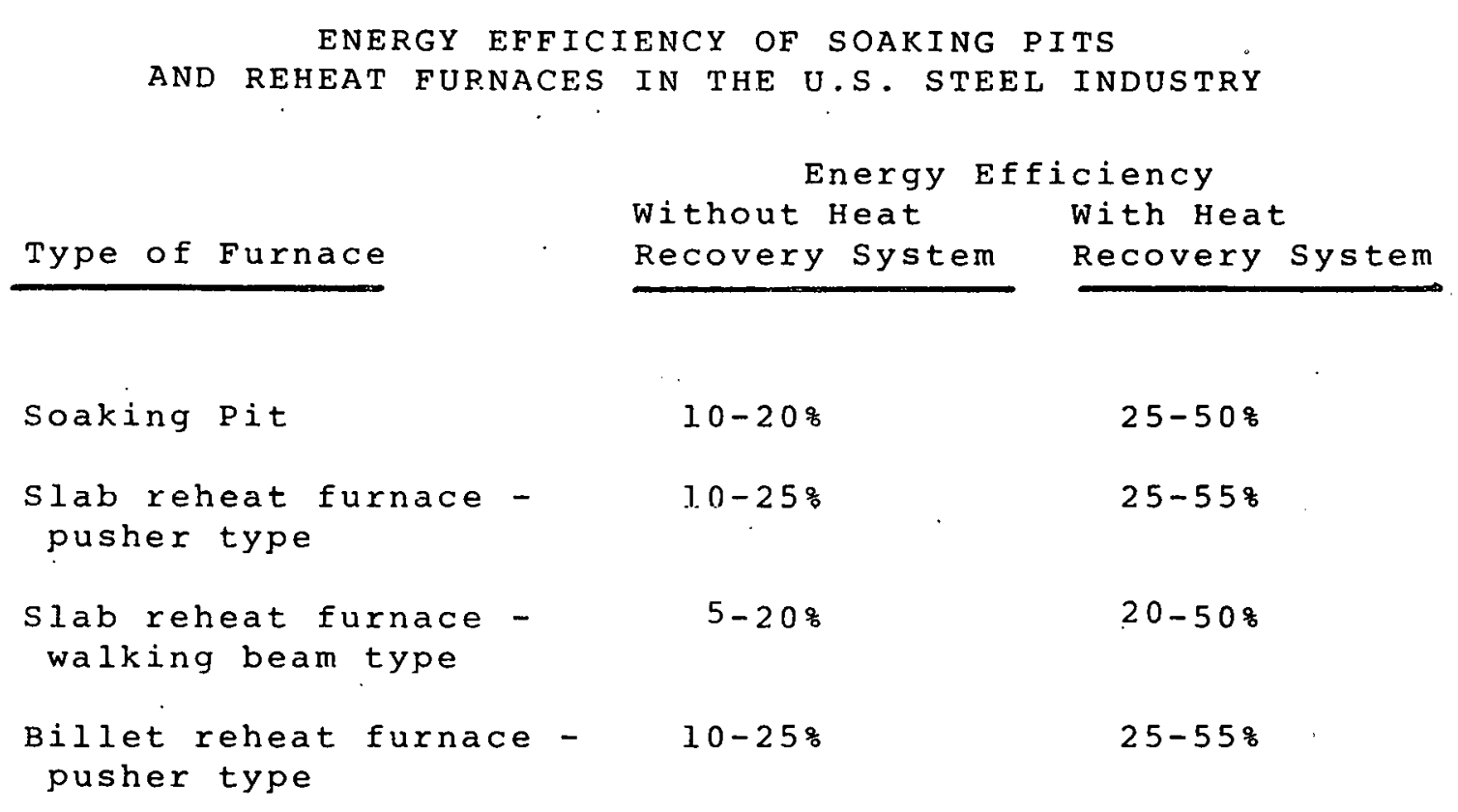

Source: Arthur D. Little, Inc. estimates

TABLE IX -4

ENERGY CONSUMPTION IN REHEAT AND ANNEALING FURNACES IN THE UNITED STATES, 1976

Type of Fuel

Consumption

$\underline{B t u \quad \times 10^{12}}$

Fuel oil

$591.9 \times 10^{6} \mathrm{gal}$

88.79

Natural Gas

$334,517 \times 10^{6} \mathrm{cu}$ ft 334.52

Coke Oven Gas

$248,811 \times 10^{6} \mathrm{cu}$ ft 124.41

Blast Furnare Gas

$121,509 \times 10^{6} \mathrm{cu}$ ft 11.54

Total

559.26

Source: AISI statistics, 1976. 
Approximately $70 \%$ of the soaking pits in the United States have a heat recovery system, usually of the recuperative or regenerative type. Similarly, over $80 \%$ of slab/bloom reheat furnaces have some form of waste heat recovery system, usually a metallic recuperator. Air reheat temperatures in the $600-1000^{\circ} \mathrm{F}$ range are common among soaking pits and reheat furnaces, and some recent ceramic recuperators have been designed to preheat air up to $1600-1800^{\circ} \mathrm{F}$.

According to one published source (Ref. 2), over $90 \%$ of ingots are hot when charged to the soaking pits. Practically all of the slabs, blooms, and billets, on the other hand, are reheated from ambient temperatures.

Energy is lost in soaking pits and reheat furnaces primarily because of the following:

- Waste gas losses

- Skid pipe water losses (water-cooled skids only)

- Furnace openings (doors, cracks, etc.)

- Wall and roof losses

- Idle firing

- Underutilization of furnace capacity

- Poor combustion conditions

Soaking pits and reheat furnaces consume a very significant amount of fuel oil and natural gas, as shown in Table IX-4. Although this table includes the energy consumption in annealing furnaces, most of the energy is consumed by the soaking pits and reheat furnaces.

In subsections 2 through 9 which follow, we shall discuss varinus developmente relatcd to these types of furnaces and their potential for energy saving.

\section{Monobeam Slab Reheating Furnace}

\section{a. Concept}

Of the three types of reheating furnaces, slab reheaters are the most important; they process the greatest quantity of steel, so their fuel firing rates and heat losses are much greater. The fuel efficiency of the pusher and walking-beam types is about the same - typically $33 \%$ and $32 \%$ respectively. Fuel input with off-gas heat resnvery is approximatcly 2.36 million Btu per ton for the pusher type and 2.40 million Btu per ton for the walking-beam type.

The monobeam furnace, proposed by Loftus Engineering, is essentially a walking-beam furnace with the walking-beam mechanism entirely inside the furnace. It retains all the advantages of the walking bcam furnace uver the older pusher turnace, namely, higher capacity, elimination of skid marks, and more uniform slab temperature.

The five-zone pusher-type furnace, the industry standard, has reached maximum practical length because of the force required to overcome the friction of the slabs on the skids and the suak hearth. If they are pushed harder and fired faster to increase output, the result is poor slab temperature uniformity and, worse, skid marks. The walking-beam concept permits lengthening of the furnace to provide a sixth firing zone and, thus, greater capacity. 
The walking-beam mechanism not only eliminates skid marks and gouges but also makes possible the use of refractory materials on the supporting surfaces; the insulating properties of these materials allow the temperature of the slabs to be more uniform.

One disadvantage of the walking-beam furnace is that it has slightly lower fuel efficiency than the pusher-type, primarily because heat is lost through the slots in the furnace floor and their attendant water seal troughs. However, in the monobeam design, the water-cooled skid losses and slot losses are largely eliminated. Another claimed advantage is that heat is transferred more rapidly and evenly to the slabs when firing with oil.

The monobeam slab reheating furnace is expected to have a $35 \%$ efficiency and a fuel input requirement of 2.25 million Btu per ton.

\section{b. Energy Savings Potential}

We estimate that the 1976 thermal energy requirements for reheating slabs in the United States was about 0.19 quad. If all the water-cooled slab reheating furnaces in the United States were converted to the monobeam design, approximately 0.007 quad of energy would be saved.

\section{c. Discussion}

The monobeam slab reheating furnace is primarily a new concept that has been studied and analyzed by Loftus Engineering and Armco. Since its potential is considered significant, these companies (with DOE assistance) have begun testing the monobeam concept in one zone of an existing walking-beam slab reheating furnace at Middletown. The results apparently offer sufficient promise that Armco and Loftus are proposing a cost-sharing program to build and operate a large monobeam furnace at Middletown.

Armco has estimated the capital cost of retrofitting an existing slab reheating furnace with a typical capacity of 1.5 million tons per year at $\$ 2.6$ million. The annual savings were estimated at $\$ 330,000$ for $\$ .30$ per gallon fuel oil (about $\$ 2$ per million $B t u$ ), which was equivalent to a payback period of 7.9 years. Thus, they concluded that energy savings alone could not justify the investment; however, they did indicate that the additional heating capacity and flexibility combined with the energy savings could justify this concept.

If vil were $\$ 4.50$ per million Rt.1, the savings would be greater and the payback period would be 3.5 years. On this basis, we expect that the combined savings and other advantages wuuld justify extensive conversion of slab reheating furnaces to the monobeam concept. This suggests that proposals to further demonstrate the monobeam slab reheating furnace concept should be favorably considered if tests of the concept are successful. It is claimed (Ref. 3) that most of the existing pusher-type furnaces, which are predominant in the industry, can be retrofitted. Moreover, this concept might also be applied to the smaller bloom and billet reheating furnaces.

\section{Coal-Fired Soaking Pit and Reheat Furnace}

\section{a. Concept}

Presently all soaking pits and reheat furnaces in the United States are fired with natural gas, coke oven gas, blast furnace gas, oil, or a combination of these fuels. Coal is not used because it is much more convenient to fire gas and/or oil. Coal also introduces problems of ash and sulfur content. If reheal furnaces could be fired with conl, however, it would permit a switch from highpriority fuels to a low-priority fuel. 


\section{b. Energy Sávings Potential}

It is unlikely that any energy will be saved by switching from gaseous fuels and fuel oil to coal in soaking pits and reheat furnaces. However, the switchover would offer an opportunity to reduce dependence on natural gas and fuel oil, a central point in the U.S. energy policy. From estimates of the various types of fuels used in 1976 in the soaking pits and reheating furnaces (Table IX-4), it is estimated that the firing of reheat furnaces with coal could save an estimated 0.09 quad of fuel oil energy and 0.33 quad of natural gas energy. Though savings of approximately 0.14 quad will also occur in coke oven gas and blast furnace gas energy, we do not regard this as a savings, because in most plants a part of these fuels will have to be accounted for within the steel plant to keep the plant energy in balance.

\section{c. Discussion}

There are three conceptual methods for firing coal in reheat furnaces:

- Firing coal directly into the furnace working area through a burner;

- Firing coal through the experimental burner developed by PERC (Pittsburgh Energy Research Center);

- Firing coal in a combustion area which is separated from the furnace working area;

- Firing low-sulfur, low-ash coal.

According to industry sources, coal firing is not practiced anywhere in the world. It is understood, however, that if coal could be liquefied or gasified, it could be fired into the reheating furnace as a liquid or gaseous fuel.

Firing coal directly into the furnace working area, as employed in the ceramic industry, may deposit ash on the reheated steel and thereby produce a poorer rolled product if it does not come off with the scale during initial rolling. Ash could also interfere with the normal operation of the relieat furnace hy forming slag, and hy corroding and eroding furnace components and refractories. Because of ash and sulfur in the coal, it would be necessary to install pollution control devices to meet EPA regulations on particulates and sulfur oxide emissions.

The Pittsburgh Energy Research Center is prcsently testing a special cyclone burner called a first-stage cyclone gasifier, which fires coal into the burner along with below-stoichiometric oxygen requirements. The gas emanating from the burner raceway is prnjerted to contain $\mathrm{CO}, \mathrm{H}_{2}$, $\mathrm{N}_{2}$, and small amounts of $\mathrm{CO}_{2}$ and $\mathrm{H}_{2} \mathrm{O}$. Industry sources speculate that PERC's cyclone burner tests are oriented toward reducing the ash content of the coal and sulfur uxides exiting from the burner raceway by as much as 75 to $80 \%$. If the objectives of these tests are met, the PERC burner opens great opportunities for firing coal into reheating furnaces.

'I'he third option - firing coal in a separate combustion chamber and then transporting the combustion gases to the reheat furnace - will reduce the amount of ash entering the reheat furnace and thereby alleviate (to a limited extent only) the associated ash problems. However, this system will have a lower energy efficiency than a direct coal-fired reheat furnace and will not completely eliminate the ash problems. Further, to meet EPA regulations, it will also be necessary to install a pollution control system for the particulates and sulfur oxide emitted from the reheat furnace. 
The fourth option is to fire the reheat furnace with low-sulfur, low-ash coal. 'This option is: very limited in that it requires an expensive and not easily available variety of coal. Further, it is not expected to eliminate ash deposition on steel, refractory wear and corrosion, or sulfur oxides and particulate emissions. Because of the particulate and sulfur oxide emission problems associated with coal firing, the PERC cyclone burner system is the prime option if coal is to be used for soaking pits and reheating furnaces.

Retrofitting a gas- or oil-fired 275-300 tph slab reheat furnace will involve a cost of about $\$ 5$ 6 million, including pollution control system. At these costs there is no incentive for a company to replace gas or oil firing with coal firing on reheating furnaces, because there is practically no payback. Instead, coal firing will add to capital cost, operating costs, and maintenance costs. It will add to air pollution, water pollution and product quality problems. However, from the energy conservation viewpoint, potential replacement of oil or gas firing with coal firing is important. Therefore, the government must do two things to provide an incentive for the industry to ardopt coal firing on soaking pits and reheat furnaces:

- Test and prove that coal can be fired in soaking pits and reheating furnaces without impairing product quality or violating air and water pollution control regulations.

- Prove through industrial tests and detailed study that coal firing is equal to or better than oil/gas firing in terms of economics.

Considering the time involved in testing and proving coal firing in reheating furnaces and the time involved in installation, we believe it is likely that reheat furnaces can be coal-fired within 5 years; therefore, the process has a significant energy savings potential for the $5-15$ year time frame.

Coal firing can be installed on new soaking pits and reheat furnaces. It can also be retrofitted on existing soaking pits and reheat furnaces, if the necessary space is available. This is a site-specific problem and can only be addressed for each site individually.

\section{High-Temperature Skid Material}

\section{a. Concept}

Most high-production steel reheat furnaces are continuous pusher-type furnaces, in which the work to be heated rests on water-cooled pipe skids and is pushed through the furnace. Depending upon its grade, the steel is heated to temperatures up to $2400^{\circ} \mathrm{F}$ for charging to the hot rolling mills. This theoretically requires about 0.75 million Btu per ton for heating the steel from ambient temperature.

Since the theurelical energy requirement averages about $25 \%$ to $30 \%$ of the actual fue! consumption, energy losses are about 2 million Btu/ton. The major sources of these losses are the heat content of the hot exhaust gases (as much as $45 \%$ of the heat input) and the cooling water in the skid pipe (in the range of $10-30 \%$ of the heat input, or up to about 0.8 million Btu/ton). The principal method of decreasing the heat loss to the cooling water is by insulating the skid, but the movement of the steel through the furnace causes rapid deterioration of the insulation and its effectiveness. 
This energy-saving concept proposes that the energy losses to the water-cooled skid pipe could be substantially reduced if the skids were made of high-temperature ceramics that could retain their mechanical integrity at the furnace working temperature without the need for water cooling.

In this concept, the ceramic skids would be embedded in the furnace hearth in place of the water-cooled skid pipes. The steel workpieces would rest on the ceramic skids, which would essentially be at furnace temperature. Since the high-temperature skid would present the steel with a comparatively hot contact essentially at the same temperature as the adjacent furnace hearth, the skid marks which are currently encountered would be avoided. With this approach, there is no need to water-cool the ceramic skid, so no energy is lost to a cooling system.

\section{b. Energy Savings Potential}

The potential energy saving which might accrue is essentially the energy now lost to the skid-pipe cooling water. It has been shown (Refs. $3,4,5$ ) that the energy loss to the couling water ranges from $10 \%$ to $30 \%$ of the energy consumed, depending upon the presence and integrity of any thermal insulation on the skid pipe. If the effective rate of energy loss is estimated to be about the average of the above range, the energy lost to the cooling water would amount to $20 \%$ of 2.75 million Btu per ton, or about 0.55 million Btu per ton. The elimination of the cooling water would stop this loss.

The quantity of intermediate shapes heated in the overall industry amounted to approximately 110 million tons in 1976. An energy loss rate of $20 \%$ would result in an industry-wide loss of 0.04 quad, assuming about $70 \%$ of the furnaces have water-cooled skids. Thus, if all the reheating furnaces with water-cooled skid pipes were converted to ceramic skids, the resulting energy saving would amount to 0.04 quad.

\section{c. Discussion}

One of the merits of the high-temperature material skid sytem is that it has the potential for retrofit installation in existing furnaces.

Designers of high-production-rate reheat furnaces look to the walking beam as a first alternative to the pusher type. Walking-beam furnaces also employ water-cooled skid pipes, but the work load in the furnace is walked through by the skid beams rather than pushed along the tops of the fixed skids. Although walking-beam motion substantially reduces wear on the skid pipe insulation, the thermal energy losses to the cooling water gradually increase as the insulation is degraded and eventually approach the energy loss rate of the pusher furnace skids.

Moreover, the installation of the reheat furnace witli a walking-bcam skid system entails a capital cust substantially grealer than for one with pusher ekids. A further limitation of the walking-beam system is that it is not readily retrofitted to an existing pusher furnace; it must be installed as an integral part of a new furnace.

The high-temperature material skid system could avoid both of these limitations. The ceramic would be subject to degradation in time, due to abrasion from the motion of the sleel, but its abrasion would not be accompanied by any increase in thermal losses from the furnace. The skid material itself maintains its characteristic thermal conductivity and is, in turn, set onto the furnace hearth so that the integrity of the hearth insulation is maintained. 
Another advantage of the high-temperature material skid system is its potential to replace the traditional water-cooled pipe skid by retrofitting the skids into existing furnaces. This could be accomplished when a furnace is either down for repairs or scheduled for a major overhaul.

Historically, the availability of high-temperature ceramic material with thermo-mechanical properties suitable for application as skids in pusher reheating furnaces has been restricted. The working conditions in the furnaces are severe - a combination of high temperatures, heavy loads of steel, abrasion and vibration from the movement of the steel, and possible thermal shock when cool steel is placed onto the heated skids. Recent developments in ceramic materials have substantially improved their strength and shock resistance, so materials with suitable properties should be attainable with moderate efforts in R\&D.

It should be possible to make candidate ceramic materials in shapes suitable for furnace skids for under $\$ 1$ per pound. The resulting skids with nominal cross sections 4 to 6 inches square should thus have a cost on the order of $\$ 100$ to $\$ 150$ per foot. Allowing for four skids across the hearth to support long slabs or billets in reheating furnaces with nominal hearth lengths up to 1.10 feet, a cost ranging from $\$ 25,000$ to $\$ 40,000$ is estimated. If removal of the old pipe skids and installation of the proposed ceramic skids costs about an equal amount, the total system cost. would range from $\$ 50,000$ to possibly $\$ 100,000$ for larger furnaces.

Furnaces with the above dimensions should have heating rates of 100 to 300 tons per hour. At a fuel credit of $\$ 2$ per million Btu for the elimination of the energy loss of 0.55 million Btu per ton, the prospective savings are on the order of $\$ 1$ per ton or $\$ 1.00$ to $\$ 300$ per hour, depending, upon furnace capacity. At these potential savings, a service life for the ceramic skids of 500 hours would be cost effective; any longer service life would be cost advantageous. Therefore, a formal program to test and evaluate the candidate ceramic materials in several alternative shapes should be undertaken to measure their expected longevity.

The time frame for implementation of this program would depend upon the results of the materials development and evaluation program. Extrapolation from known properties of existing ceramics should result in completion of the $R \& D$ program within two years. Favorable results and sufficient production capacity to produce the skids in the requisite quantities could allow implementation within the near term.

A principal alternative to the high-temperature ceramic skid system is the evaporative cooling skid system; this offers the potential for recovering the energy lost to the skid pipe water cooling system, as discussed below.

\section{Evaporative Cooling of Furnace Skid System}

\section{a. Concept}

The skids in conventional reheat furnaces are water-cooled, as described in the preceding section. 'The heat absorbed by this cooling water represents abnut a $10-30 \%$ heat loss in the furnace, as the heat input to this cooling water is either dissipated in a cooling tower or the water is discarded in a once-through operation. This heat might be reclaimed if it were possible to essentially use these skids as a boiler to generate saturated steam; the steam might then be used to supply a part of the plant needs. 
In an evaporative or hot cooling system, water at boiling temperature and pressure ( $400 \mathrm{psig}$ and $442^{\circ} \mathrm{F}$ ) is supplied from the steam drum to the skid system. This water is circulated through pumps, which insure that the velocity of flow in all pipes is sufficiently high to prevent steam pockets within the system. The heat absorbed as the hot water passes through the skid system produces saturated steam bubbles, which flow back with the water to the steam drum through riser pipes. The saturated steam is then separated from the water in the steam drum.

\section{b. Energy Savings Potential}

If we assume that a $20 \%$ heat loss accompanies water cooling of the skids in pusher and walking-beam reheat furnaces, this would represent about a half million Btu per ton. An evaporative cooling system might reclaim $70 \%$ of this loss. If such systems were installed on all furnaces with water-comled skids in the U.S. steel industry (i.e., on about ' $7 \%$ \% of all pusher and walking-beam reheat furnaces), a yearly energy saving of about 0.029 quad would be achieved.

\section{c. Discussion}

No evaporative cooling skid systems are now used in the United States. The system described above is conceptual, and no specific proposal has yet been submitted to DOE. Thus, its reliability and its associated risks cannot be quantified. However, from a materials standpoint, it would appear that the concept should be feasible. Thus, proposals demonstrating technical and economic feasibility should be considered for potential funding.

The only directly competitive process to evaporative cooling would be the use of ceramic skids. Also, it should be noted that retrofitting to this type of system dues not pose any additional environmental effects. The time required for commercialization of this scheme is expected to be in the order of 5.10 years.

\section{Direct Rolling and Hot Inspection}

\section{a. Concept}

Direct rolling (Ref.3) reters to the processing of intermediate shapes of slabs, blooms, or billets that are still hot as they leave the primary breakdown (roughing) mill. In direct rolling, these hot semifinished products are not cooled to ambient temperature in slab, bloom, or billet. yards but are charged directly to the hot rolling mills. This procedure avoids the conventional requirement for reheating the intermediate shape to hot-rolling temperulures between the form ing step and the rolling step, thereby conserving the reheating energy.

Two potential routes are claimed for direct rolling: (1) taking conventionally cast ingots hot from the primary breakdown mill and charging them directly to the downstream hot rolling mill; and (2) taking continuous-cast strands from the casting machine, heating them to rolling temperature, and charging them to the downstream hot rolling mill. In either of these potential routes, the sensible heat in the workpiece is conserved so that the expenditure for energy to bring the workpiece to rolling temperature can he mininized.

Two heating steps are common practice for conventional cast ingots: heating the ingot in a soaking pit for primary breakdown to intermediate shape, followed by reheating the worked ingot to rolling temperature for conversion by the hot rolling mill. By eliminating the production of ingots, continuous casting avoids primary heating in the soaking pit. Thus, these are two alternate routes for direct rolling, and they have independent considerations. 


\section{b. Energy Savings Potential}

The potential energy savings which might accrue for direct rolling arises from the elimination of the reheating step for hot rolling. Comparisons with conventional rolling indicate energy savings of about 2.2 million Btu per ton of hot strip mill product. An additional 0.1 million Btu per ton is conserved at the soaking pits by careful management of charging and holding pracitice. The combined energy savings amount to 2.3 million Btu per ton of strip mill producc for conventionally cast ingot practice.

The application of direct rolling to continuous-cast strand augments the above energy saving with that gained by avoiding the primary soaking pit heating. For direct rolling of continuous-cast strand, the combined thermal energy savings have been reported at 2.8 million Btu per ton (Ref. 6). This energy corservation is partly obtained from elimination of primary heating ( 1.53 million Btu per ton) and ingot breakdown (0.07 million Btu per ton); the remaining saving of 1.2 million Btu per ton is attributed to the energy reduction achieved by charging the hot strand stock directly to the reheat furnace.

In general, the rates of energy conservation that could be expected for corresponding process schedules for treating of slabs, blooms, and billets would be similar to those indicated above for two independent operations for converting slab to hot-rolled strip.

On the basis of the above estimates, the potential energy savings for direct rolling in 1976 would have amounted to about $225 \times 10^{12} \mathrm{Btu}$ for intermediate shapes rolled from ingots and about $42 \times 10^{12}$ Btu for intermediate shapes from continuous casting. These two quantities total $267 \times 10^{12} \mathrm{Btu}$, or approximately 0.27 quad.

\section{c. Discussion}

Direct rolling has long been recognized as a potential method of conserving energy. The process incorporates practices which are based on mature technology. However, it imposes restrictions on the extent of surface conditioning that can be done prior to the hot rolling mill and thereby limits the surface quality attainable on the rolled product.

Another consideration is that most steel plants produce a variety of grades of steel in heat sizes from a few tons up to several hundred tons, and each grade must generally be heated $t o$ the proper rolling temperature for that grade. To accommodate the range of grades in production, extensive supporting facilities are required to maintain inventory control and supply stock for rolling. Thus, the incorporation of direct rolling into existing steel plant operations would cause a major disruption of the present production practice.

To adapt existing plants to direct rolling for production of material with high surface quality, provision must be made for high-speed removal of surface defects on the intermediate shapes before rolling. One approach is total hot-skin scarfing, which would remove the entire external surface layer including any surface flaws; however, this approach could incur unaccep. table yield losses. A second procedure would be to use an on-line hot inspection system to identify and locate surface flaws to be removed by selected spot hot scarfing. With this procedure, existing plants could be retrofitted with appropriate material control systems adapted for direct rolling.

It has been estimated that a strip rolling capacity of 4 million tons based on direct rolling from ingots would require a capital investment of $\$ 515$ million for the combination of soaking pits 
and slabbing-strip mill. The comparable capacity based on conventional reheating practice would entail an investment of $\$ 580$ million. Thus, direct rolling could offer a capital cost saving of 11 '" for these facilities in a new plant.

Available information indicates that the only greenfield steel plant currently under consideration in this country is a multi-million-ton plant being proposed by United States Stetel Corporation for installation at Conneaut, Ohio. The announced product mix planned for this plant indicates that direct rolling should be a viable process for incorporation in the plant operations. In this case, hot slabs cut from continuous strand casting will be rapidly transferred directly to heating furnaces to bring them to proper temperatures for rolling. The proposed plant could be operational within the next five years. Some additional information indicates that within the same time frame, one or two mini-mill-size bar and rod mill steel plants might be installed which could also take advantage of direct rolling.

As other steel plants are planned and designcd for installation in the longur lerm, convid eration on a plant-by-plant basis would be given to direct rolling to determine whether it would be compatible with the product mix.

Whether direct rolling will be widely accepted and utilized at existing steel plants will depend upon the development of a high-speed, on-line hot inspection system for the moving steel surface. This system would identify surface flaws which require skin conditioning treatments before being charged to the rolling mills. 'The output signal of the on-line hot inspection system will be needed as a positioning control for an automated on-line hot spot scarfing system to remove the flaws and to condition the surface to the desired quality for subsequent hot-rolled product specifications.

Direct rolling would alsu uffer potential benefits of decreased environmental impact by elıminatıng one heating operation and advantageous process economics by decreasing capital investment costs and requirements for in-process material handling. As was noted earlier, these benefits are now being obtained at some sacrifice of product surface quality, which could bo overcome by the development of an effective on-line hot inspection system. The potential savings: w energy even in the near term, coupled with the recognized maturity of the technology, warrant undertaking an $R \& D$ program for further development of direct rolling and on-linc hot inspection.

\section{Induction Heating}

\section{a. Concept}

Induction heating basically consists of inducing an electric current to flow in the piece to be heated. To accomplish this, a water-cooled coil is made to surround the workpiece. An alternating current is passed through the coil, which in turn induces a current in the workpiece, causing it to heat. To minimize electrical lusses, the furnace coil is made to conform to the same shape as the piece to be heated and only slightly larger. This coil is backed up by a refractory insulation to minimize radiation losses from the workpiece.

A broad frequency range (60 to 10,000 Hert.7) is available in today's technology, thercby virtually eliminating any size and/or shape restrictions in the material to be heated. The production rate determines the power requirements for the generator. Presently systems are being 
used in the United States which inductively heat charges to reheating temperatures for work loads up to 70 tons. Induction heating of soaking pits is practiced in steel mills in Europe.

\section{b. Energy Savings Potential.}

Typical conversion efficiencies at the induction generator from the line are about $90 \%$. However, as further losses are associated with coupling efficiencies to the workpiece, radiation losses, etc., an overall efficiency of $40-45 \%$ is usually attained. Furthermore, one must recognize that this $40-45, n$ efficiency figure at the steel plant does not include the losses at the electrical generating plant, which could have up to a $33 \%$ efficiency; when one is determining net energy savings, these losses must also be included. Thus, overall induction heating of slabs has an efficiency of only about $13-15 \%$. This efficiency is significantly lower than the industry average of about $35 \%$ being attained in the newer fossil-fuel-fired reheating furnaces (including recuperation) described elsewhere in this report. Therefore, no energy saving is achieved by using induction heating in reheat furnaces.

It must be noted, however, that induction heating does provide for fuel switching from natural gas and/or oil to coal, as coal may be used to generate the electric energy used for induction heating, thereby providing a clean fuel to the workplace. In this context, induction heating could permit the replacement of all the natural gas and fuel oil used, but at the expense of lower overall energy efficiency.

\section{c. Discussion}

Induction heating of slabs is presently being practiced in the United States. The state of the art is quite mature, so further DOE expenditure for research in this area should be minimal at best. After-tax payout periods have been estimated at 5.4 years (Ref. 3). The makers of induction equipment, who used motor generators in the past, have been proposing the use of their new solid. state generators, which have extremely high line conversion efficiencies and low maintenance costs. Other advantages of induction heating are its high reliability and flexibility, zero pollutiom at the plant, and quick heatup times. Its chief competition comes from fossil-fuel-fired furnaces, which are traditional in the industry.

In view of the fact that induction heating is not a net energy saver when one considers power generation efficiencies and that the concept is already commercialized, it is questionable whether further $R \& D$ efluil is needed here.

\section{Waste Heat Recovery}

\section{a. Concept}

The major cause of the poor efficiency of reheating furnaces is the loss of heat in the flue gases. The problem is that when one wishes to reheat semifinished steel to a given temperature, the flue gases must be at a higher temperature to transfer heat to the steel. The heat loss in the nue gas can be reduccd by countercurrent: firing, i,e., by causing the combustion gases to flow countercurrent to the flow of steel so that the hottest gases at the firing end transmit heat to the hottest steel near the furnace discharge end and the coldest gases transmit heat to the coldest steel at the feed end. The flue gases will discharge at a temperature well below that of the steel discharged. While this concept is practiced in reheat furnaces wherever possible, the heat in the discharged flue gas is still the major cause of fuel inefficiency. 
There are two ways to recover the heat that is now wasted in the discharging flue gas primary and secondary recovery. Primary recovery includes recovery of heat in recuperators or regenerators, which transmit the heat to preheat combustion air and cause a direct improvement in efficiency by reducing the fuel requirements. Secondary recovery implies the use of devices such as waste heat boilers; these recover heat for other uses such as producing steam or space heating and do not affect the fuel efficiency of the furnace from which the gases are discharged. Secondary waste heat recovery is practical where there are other uses for the heat, but it is more often impractical or uneconomical. At any rate, we are chiefly interested in primary recovery which results directly in fuel savings by using the heat from the flue gases to preheat combustion air.

A steel reheating furnace that is discharging $2000^{\circ} \mathrm{F}$ flue gas has a potential of $50^{\prime \prime} \%$ relative fuel savings. This would require preheating the combustion air to about $1800^{\circ} \mathrm{F}$. Unfortunately, basic limitations, primarily materials of construrtion, rostriot the operation of the heat recovery device and the hurner system to air preheat temperatures well below $1800^{\circ} \mathrm{F}$ and, therclore, reduce relative fuel savings below $50 \%$.

For example, large burners, as used in soaking pits, are limited to about $1200^{\circ} \mathrm{F}$ air preheat. temperature, which limits the potential for relative fuel savings to 35-40', as are used in reheat furnaces, are limited to $1000^{\circ} \mathrm{F}$ air preheat temperature and rclative fuel savings of $30-35 \%$.

Actually, the temperature limit for the preheat air is generally the maximum that most commercial recuperators can deliver. However, this is not the problem with regenerators, which are capable of delivering high air preheat temperatures. Unfortunately, except for blast furnace stoves, coke ovens, and the few remaining open hearths, recuperators have ruplaced regenerator's in mudern steel plant furnace systems. The difficulty with regenesalurs is that they cannot be operated at the pressures required for high turndown and intensive mixing burners. Also, they have considerable space requirements.

It is apparent that the key to improving waste heat renovery lieg in the muterials if cusstruction of recuperators and burners.

\section{b. Energy Savings Potential}

The total thermal energy consumed in heating and anncaling operations in 1976 a mounted to 0.56 quad. A majur purtion of this thermal energy was consumed in reheating furnaces and soaking pits, and a minor portion in annęaling.

It is virtually impossible to determine the potential encrgy savings that might be accomplished through the use of improved materials of ronstruction and bet.ter designed heut recuperators and burners.

We estimate that neer $85^{\circ} \circ$ of the thermal energy consumed in heating and annealing is used in soaking pits and reheating furnaces. This means that approximately 0.48 quad is consumed in the soaking pits and reheating furnaces.

Figure IX-2 shows the energy savings possible with various levels of air preheating. If a better designed recuperator could increase preheat temperatures by $300-500^{\circ} \mathrm{F}$, it would be 
possible to obtain approximately 5-10\% energy savings in the furnace. If as little as a 5 “ saving in fuel consumption could be obtained by improved recuperation, it would save 0.02 quad of thermal energy. A $10 ;$ improvement would save 0.04 quad.

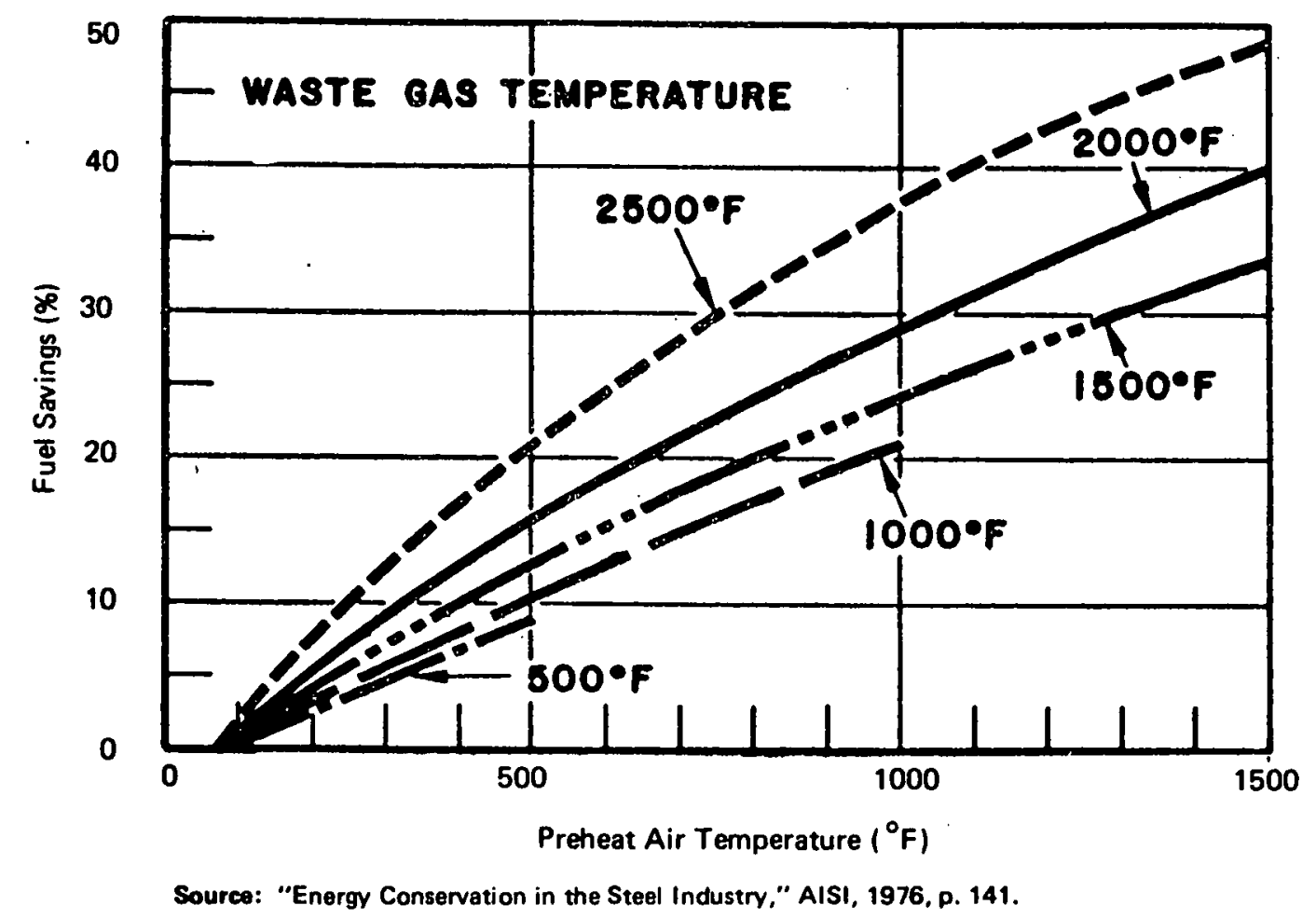

FIGURE IX-2 ENERGY RECOVERED BY AIR PREHEATING, EXPRESSED AS RELATIVE SAVINGS OF NO. 6 FUEL OIL

\section{c. Discussion}

Many types of recuperators are available, and some newer ones are under development. This is a highly competitive business where the needs for heat recuperation are well known and understood. The materials of construction of the recuperator and burner appear to be the chief consideration. In addition to meeting strength requirements, the material must be able to withstand temperatures up to $2000^{\circ} \mathrm{F}$ and oxidizing conditions, at moderate pressures.

Most recuperators in place are made of high-temperature metals and alloys. To improve the heat recovery potential, consideration might also be given to ceramic materials for recuperators and also burners. Past experience has shown that because of mortar failure, cracking, plugging, and leakage problems, ceramic recuperators have not worked out as well as expected.

It is difficult to suggest specific projects, but those that relate to improved materials of construction for recuperators and burners should be given favorable consideration. 


\section{Improved Efficiency Forge Furnace}

\section{a. Concept}

A slot forge furnace is basically a 10-foot-wide furnace with an opening 4-6 inches high for forgings. Since this opening usually has no door or enclosure, there is quite a significant radiation loss from the door opening. Hague International of South Portland, Maine indicates that it has improved the energy efficiency of the slot forge furnace quite significantly by incorporating an 8 . inch-high slot with an enclosure or door. The Hague furnace also has a recuperator which is capable of preheating combustion air to $1500-1800^{\circ} \mathrm{F}$; to date, however, a maximum air preheat temperature of $1300^{\circ} \mathrm{F}$ has been achieved, and more typically air is preheated to the $1000-1100^{\circ} \mathrm{F}$ range. Presently, it is using two recirculating-type burners fueled with No. 2 oil. The two burners are typical for this type of furnace.

The possibility of using a coal-oil slurry for firing the furnace is also bcing considered by I Iague International. A 20'n coal-No. 6 oil slurry would likely bc used. At this time no tests have been run, but no significant combustion problems are expected with the firing of this slurry. On the other hand, the fly ash and sulfur generated from the coal in the slurry could have adverse effects upon the steel and most likely would reduce refractory life. The degree to which these would be affected remains to be seen. However, much of the know-how on coal/oil slurry firing for slot forging furnaces, if available, could be transferred to other reheating furnaces in the steel industry.

\section{b. Energy Savings Potential}

Slot forging furnaces typically operate in the $2200^{\circ} \mathrm{F}$ range and consume about $3000-4000$ Btu of energy per pound of steel, or about 6-8 million Btu per ton. By incorporating a recuperator and an enclusure in this type of furnace, a significant reduction (about 4 million Btu per ton) may be achieved. There are about 8000 such furnaces in the United States, each having a capacity of about 2500 pounds per hour; assuming eight-hour days, this amounts to 20 million tons per year. If one assumes a production output of only $10 \%$ of capacity and an energy saving of 4 million $\mathrm{Btu} / \mathrm{ton}$, the net energy saving would be $8 \times 10^{12}$ Btu per year.

\section{c. Discussion}

Hague international is presently testing an improved-efficiency slot forge furnace which it has developed with the help of government funding. This furnace, as mentioned, requires only about one-third as much energy for heating as does a conventional-type slot furnace. The risk associated with implementation is low, since it would add only about $\$ 65,000$ to the cost of a new furnace. Using a saving of 2000 Btu per pound and a fuel cost of $\$ 2.00$ per million Btu, this results in an after-tax saving of about $\$ 16,000$ per year for a single facility forging 10 tons ner day, or a payback period of slightly more than 4 years. At a fuel cost of $\$ 4.50$ per million Btu, the payback perind is slightly over 2 years.

Basically, this improved technology has no competitive te.chnologies, nor does it impose any new environmental restrictions on the process. 


\section{B. HEAT TREATING FURNACES}

\section{Conventional Technology}

Heat treatment is a process of controlled heating and cooling of steel workpieces or components through a specified heating/cooling cycle designed to cause changes in microstructure within the steel so that desirable physical and/or mechanical properties are attained. Various heat treatment methods are used in the steel industry - annealing, normalizing, tempering, spheroidizing, cyanidizing, carburizing, and others.

Estimates of the energy consumed in the various categories of heat treatment furnaces indicate that annealing is the only heat treatment that is done on a large enough scale within the U.S. steel industry to be relevant to this study.

Figure IX-1 shows the flow of material in a typical steel mill and the point at which annealing is used. Its principal use is in treating cold-rolled flat product.

Annealing furnaces are classified as either batch or continuous. In batch annealing, the material to be heat-treated remains stationary; in continuous annealing, the charge moves during heat treatment.

The most common types of batch annealing furnaces are:

- Box type

- Car-bottom type

- Bell type

- Pit type

Each of these is described in published literature (e.g., Ref. 1).

The simplest annealing furnaces are the direct-fired batch type with manual control. The more elaborate installations used for large production lines are continuous-strip furnaces with automatic program control. Approximately $60 \%$ of all annealing furnaces are direct-fired, but in . situations where furnace atmosphere control is critical, muffle furnaces and radiant-tube-fired furnaces are among the available choices.

Table IX-5 lists the capacities of the various types of heat treating furnaces in the United States. The capacity utilization factors are generally very low.

Table IX-6 shows the annealing temperatures and the energy used in three typical annealing operations. In general, annealing temperatures range between 1200 and $1600^{\circ} \mathrm{F}$ and consume approximately 1 to 3 million Btu per lun of product anncaled.

Because of the nature and purpose of the annealing operation, the heating cycle must be closely controlled, not only during heating and soaking but also during cooling. Therefore, the energy efficiency of the process is only $5 \%$ to $25 \%$. 
TABLE IX -5

\section{ESTIMATED CAPACITIES OF U.S. HEAT TREATING FURNACES (millions of tons)}

$\begin{array}{r}\text { Type of } \\ \text { Heat Treating Furnace } \\ \hline\end{array}$

Sheet Annealing

Coil Annealing - Bell

Coil Annealing - Strip

Plate Normalizing

Bar Annealing

Wire Annealing

Forging Heat Treatment

Casting Heat Treatment

Forging Temperiny

Bar 'l'empering

Source: Arthur D. Little, Inc. estimates
Annual Capacity
5

70

10

5

5

5

5

1

1

1 


\section{TABLE IX-6}

\section{ANNEALING TEMPERATURES AND ENERGY \\ CONSUMPTION}

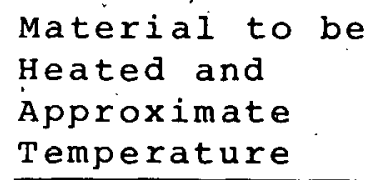

Steel sheets $-1300^{\circ} \mathrm{F}$

Box Annealing

\section{2}

Steel sheets--1500 $\mathrm{F}$

Continuous

1.9

Coils-- $1300^{\circ} \mathrm{F}$

Box Annealing

1.3

Source: Arthur D. Little, Inc. estimates

\section{Energy Conservation}

The principal sources of heat losses in an annealing furnace (batch or continuous) are:

Waste gases

Furnace openings (doors, cracks, etc.)

Improper combustion

Idle firing

Underutilization of furnace capacity

Since all of these losses also occur in soaking pits and reheat furnaces, most concepts of energy conservation applicable to annealing furnaces are similar to those described in Section A of this chapter. However, some of those concepts (e.g., the monobeam slab reheat furnace, coal firing, evaporative cooling, ceramic skids, direct rolling, and more efficient forge furnaces) are either not applicable or have a very limited application to annealing furnaces. Two of the most important concepts in annealing furnaces are waste heat recovery and direct firing; these are discussed below.

\section{a. Waste Heat Recovery}

(1) Concept. The concept of waste heat recovery in annealing furnaces is similar to that discussed under soaking pits and reheat furnaces. In general, very few annealing furnaces in steel plants have heat recovery systems. 
(2) Energy Savings Potential. A typical high-production annealing furnace consumes about 1.3 to 1.7 million Btu per ton of steel annealed; the total for all annealing furnaces is about 0.05 quad of energy per year. If all were retrofitted with recuperative waste heat recovery systems, we estimate that about 0.004 quad could be saved.

(3) Discussion. Cold-rolled sheet and strip are the principal materials that are annealed in the steel industry. Most annealing is done on a batch basis at $1200-1600^{\circ} \mathrm{F}$. Because of the low temperature of the off-gases $\left(1400-1500^{\circ} \mathrm{F}\right)$, their heat savings potential is much lower than with the high-temperature soaking pits and reheat furnaces. According to a recently published economic analysis (Ref. 3), it is uneconomical to install a recuperator on a radiant-tube furnace. Even if fuel is assigned a value of $\$ 4.50$ per million Btu, the recuperator is difficult to justify economically, because annealing furnaces are relatively minor consumers of energy among steelheating furnaces. Therefore, funds would be better spent in energy sonservation programs in the soaking pits and reheat furnace sections, where the potential savings are much larger.

\section{b. Direct-Fired Annealing Furnaces}

(1) Concept. Essentially all flat-rolled sheet and strip is annealed, either in continuous or batch operations. We are primarily concerned here with batch annealing and the application of direct firing to replace the present practice of indirect heating (i.e., radiant-tube annealing) because of the potential for energy savings. In radiant-tube heating, a burner discharges into a loop of alloy tubing; the flame and products of combustion heat the tube, which radiates heat to the product to be annealed. We estimate that 15 million tons per year of cold-rolled coils are batch-annealed in furnaces heated by radiant tubes.

(2) Energy Savings Potential. Direct firing is not applicable to continuous annealing, only to batch annealing. If all the batch-annealing furnaces were converted to direct firing. the total energy consumed in batch plus continuous annealing would be .05 quad. This conversion would effect an energy saving of .01 quad for annealing.

The fuel used would have to be coke oven gas, atomized fuel oil, or, if available, natural gas. Of the 1.68 million Btu consumed in annealing a ton of coils in a radiant-tube hatch furnace, 1.4 million Btu is fuel; the remainder is power and inert atmosphere. The energy saving with direct firing is $15 n-30 \%$. If we use the mean of this range, the saving per tone of coils annealed is 0.315 million Btu per ton, which means the total energy for batch annealing with direct firing is 1.36 million Btu per ton.

(3) Discussion. A few batch-annealing installations have been converted from radiant-tube heating to direct firing. For a four-stack, four-coil installation, direct firing would permit an average annual saving in fuel cost of about $\$ 220,000$ with fuel at $\$ 2.00$ per million Btu. This is after-tax savings, assuming a $22 \%$ reduction in fuel consumption; pre-tax savings would be double this amount. If the cost of fuel were $\$ 4.50$ per million Btu, the annual after-tax savings would be $\$ 495,000$, or nearly $\$ 1$ million pre-tax. The cost of retrofitting existing batch-annealing furnaces for direct firing varies so much from one installation to another that it is not possible to evaluate the economic incentive with any degree of accuracy.

Since the prices of natural gas, coke oven gas, and oil are expected to continue to rise, all new batch-annealing furnaces are likely to be designed for direct firing. This price escalation will 
also encourage more conversions of batch-annealing furnaces from radiant-tube heating to direct firing. Fortunately, the direct firing of batch-annealing furnaces is a fully developed technique and does not require additional investigation or development.

Development of the "flat-fiame" burner has improved flame control in direct-fired batchannealing furnaces. These burners provide excellent radiation heat transfer characteristics to the inner cover. In multistack annealing furnaces, the long-flame burner would be used to direct tlames between the stacks, where impingement on the inner cover is less likely. Flat-flame burners reduce fuel consumption in batch-annealing furnaces. They are not applicable to continuous annealers.

\section{ROLE OF GOVERNMENT FUNDING OF R,D\&D}

Table IX-7 summarizes the maximum potential energy savings which could be gained with the various concepts described in this chapter. Although no energy saving is associated with coal firing, it dues uffer the possibility of replacing significant quantitics of natural gas and fuel oil. The table also indicates whether existing furnaces could be adapted to use the new concepts. Considering the potential savings of natural gas and fuel oil energy resources, and the probabilities of success, we believe that research, development and demonstration (R,D\&D) work should be initiated in the following areas:

- Monobeam slab reheat furnace

- Coal-fired reheat furnaces and, to a lesser extent, soaking pits

- High-temperature recuperative system

- Low-heat-loss skid system.

In general, most of the energy-conserving and fuel-switching concepts cannot be justified purely on the basis of economics. This, plus the fact that the development work is expensive, gives steel companies little or no incentive to push their development. Therefore, it will be necessary for the government to provide leadership in developing the concepts that have significant potential for the total U.S. energy conservation effort instead of waiting for individual companies to take the initiative.

As an example, steel companies have practically no incentive to develop a coal-fired reheat furnace except to protect themselves against gas and/or oil shortages. However, from the viewpoint of U.S. energy policy, a switch from oil or gas to coal firing in reheat furnaces would offer a significant saving of critical fuels. Therefore, the government may wish to encourage the development of this concept.

Another example is the use of water-cooled skids in slab reheating furnaces. According to private communications with industry sources, energy losses in the United States from watercooled skids in slab reheat furnaces total approximately 0.04 quad of energy. However, an individual steel company has little economic incentive to develop and install an energy-saving skid system because of the high development costs and the loss of the production capacity of its furnaces while they are being retrofitted. In such instances, incentives are necessary to initiate and stimulate development work. 
TABLE IX -7

SUMMARY OF ENERGY SFVINGS, PROBABILITY OF SUCCESS, RETROFITTING POTENTIAL, AND TIME REQUIRED FOR COMMERCIALIZATION OF CONCEPT

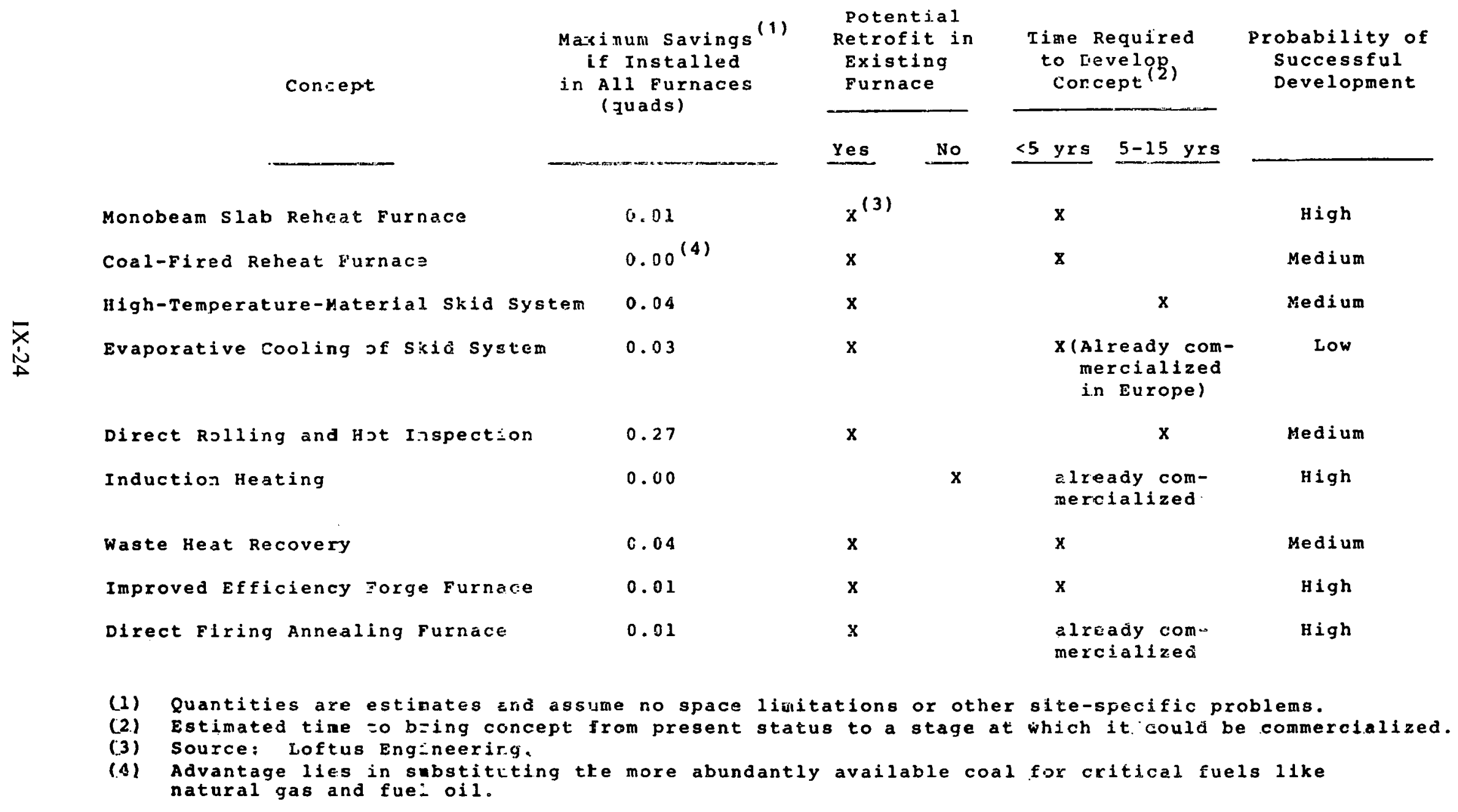


The preceding statements can be generally extended to other potential approaches for energy conservation. Technical development efforts undertaken by industry are generally directed to resolving problems of immediate urgency in current production, process engineering improvements for cost reduction, and market-oriented process and product developments. Since many of the energy-saving concepts discussed in this review appear to be economically marginal at present, they would be treated as subordinate projects by the industry. Therefore, it is even less likely that they would be undertaken and pursued to completion within the near term without government incentives. However, the industry does have the resources and facilities to conduct these programs should they be stimulated by direct program support and indirect incentives for implementation.

If the concepts suggested by this review were supported by government funding, the time frame for their accomplishment should be substantially decreased. Table IV-7 shows the expected time frame, starting from the initiation of development work to the stage where the concepts would be developed and ready to be commercialized. This schedule depends upon the assurance of the availability of government funding. It is seen that many of the concepts could be commercialized and their implementation initiated within five years and that, therefore, they fall within the 5-15 year time frame for industry-wide implementation potential.

\section{REFERENCES FOR CHAPTER IX}

1. Making, Shaping, and Treating of Steel, U.S. Steel Corporation, 9th ed., 1971.

2. Battelle Institute, "Potential for Energy Conservation in the Steel Industry," report to Federal Energy Administration, Contract CO-04-51874-00, 1975.

3. "Energy Conservation in the Steel Industry," AISI, 84th General Meeting, New York, 1976.

4. Fontana, P., et al., Iron and Steel Engineer, July 1977, pp. 40-51.

5. National Steel Company, Pittsburgh, Pa. (private communication).

6. Korey, W.J., ISI Special Report 127, 1973. 


\section{X: OTHER ENERGY CONSERVATION OPPORTUNITIES}

In addition to the energy-conserving technologies within the steelmaking processes that have been described in the preceding chapters, other opportunities for energy conservation have been proposed and are discussed here. Some of these are general concepts whose application could have considerable potential in many parts of a steel mill; others are quite speculative and would need research, development, and testing to establish their practicality.

\section{A. BETTER SENSORS, INSTRUMENTATION, AND CONTROLS}

Steelmakers have an incomplete knowledge of what is taking place inside a blast furnace with regard to channeling, reduction efficiency at various levels, etc. The most reliable sensors are in-wall thermocouples; on the basis of their measurements and certain assumptions about heat and mass transfer, iterative calculations are made to simulate the conditions in a given region of the furnace. However, the means to verify these predictions by accurate measurement of gas temperature and gas composition are inadequate except for certain regions. The development of continuous sensors for measuring temperature and gas composition is desirable.

In BOF steelmaking, more research is needed in the area of on-line probes to measure oxygen, sulfur, and temperature.

Another area where better instrumentation is needed is in estimating the temperature at the center of the slab in a reheating furnace. Furnace operators need a temperature sensor that will actuate a burner control circuit. This development could improve yields in the hot rolling of slabs.

\section{B. IMPROVED BURNERS}

Burners designed with a large turndown ratio would find application in balancing an intermittent source of fuel, such as basic oxygen furnace off-gas.

\section{GAS STORAGE}

Because of the intensive development of coal gasification, a gas holder is needed to store low- to medium-Btu gas. It would be desirable to separate carbon dioxide, carbon monoxide, and/or nitrogen from the low-Btu gases, since (in addition to enriching the gas) it would decrease the volume that had to be stored. Some available concepts include removal of $\mathrm{CO}_{2}$ by acid gas scrubbing and recovery of $\mathrm{CO}$ by the COSORB Process, which was developed for petrochemical applications.

\section{POWDER ROLLED STRIP}

Among the uncommon technological processes for production of steel mill products is the direct formation of steel strip by roll-compacting metal powders. This concept offers potential for energy savings by avoiding the multiple steps involved in forming and heating thick steel intermediate sections for conversion to thin strips. 
The roll-compacting of powder to strip consumes energy in the preparation of the powder, the compaction of the powder, and the heating of the compacted powder to sinter the individual particles into a coherent structure. Several processing methods have been developed for producing powder with properties suitable for rolling to steel strip - gaseous reduction of steel metal scale, hydrometallurgical reduction of ferrous fluoride, and spray atomization of molten steel. Of these, the latter is the least energy-intensive, consuming about $600 \mathrm{kWh} /$ ton for large-scale production. The energy consumed in rolling the powder could be comparable to that consumed in hot-rolling strips by conventional practice. The sintering process should be done at a temperature of $2300^{\circ} \mathrm{F}$ for an extended soaking time, which is comparable to the reheating of thick intermediate shapes. The heating energy for the continuous strip furnace will depend on the rate of throughput and cannot be predicted without experimental investigation. In analyzing the energy required for these steps, one must compare it with the energy used in producing strip by conventional practice at an integrated steel mill. including the amounts consumed in the coke oven, blast furnace, steelmaking, ingot casting, soaking pits, ingot breakdown mills or continuous casting to intermediate shapes, and reheating and rolling to the final strip product.

\section{E. RECOVERY OF SENSIBLE HEAT IN COKE OVEN GAS}

\section{Description}

When raw coke oven gas leaves the conventional coke oven, it is typically quenched to 100 $200^{\circ} \mathrm{C}$ by water sprays in the coke oven gas main. It is further cooled in the by-product plant: either by direct contact with water or by indirect heat exchange with cooling water. A significant quantity of thermal energy could be recovered if the gas were available from the coke oven gas main at a higher temperature, something nearer the typical $600^{\circ} \mathrm{C}$ oven exit temperature. It could then be used to generate steam or hot air by indirect heat exchange.

\section{Energy Conservation Potential}

If the coke oven gas were available at $600^{\circ} \mathrm{C}\left(1100^{\circ} \mathrm{F}\right)$ and were dropped in temperature by indirect heat exchange to $175^{\circ} \mathrm{C}\left(350^{\circ} \mathrm{F}\right)$, thermal energy equivalent to $3 \times 10^{\circ}$ Btu per ton of coke produced could be recovered. If this recovery technology were applied nationally to all coke ovens, a total of $16 \times 10^{12}$ Btu per year could be conserved; this is almost as much thermal energy as could be saved by preheating the coal to coking ovens.

\section{Present State of Development}

This form of energy conservation has not been demonstrated anywhere. No work that we know of is now being done on the concept. Significant engineering problems would have to be resolved before it could be implemented, including identification of suitable materials of construction and drastic modification of the mechanical design of the coke oven gas mains. Before these engineering questions are resolved, the potential economic benefit of this sensible heat recovery cannot be realistically evaluated.

\section{Discussion}

The technical feasibility of recovering the sensible heat in raw coke oven gas must yet be demonstrated. The materials of construction and the mechanical design of new coke oven gas 
mains must be investigated to determine if high-temperature gas can be reliably conveyed from the ovens to an indirect heat exchanger in the by-product plant. Questions relating to condensation of tars and pitch in the heat exchanger would have to be resolved, but these would be similar to problems already addressed in such operations as quenching of the high-temperature gaseous effluent from ethylene production facilities.

This technology could probably be demonstrated and implemented within ten years. The incremental cost for its adoption at new coke oven batteries would probably be quite low; however, it will be strongly influenced by the sophistication of materials and construction required. The first step in this development effort will be the funding of preliminary engineering studies. Since no private interest in this concept is evident, government intervention seems advisable.

\section{F. OXYGEN ENRICHMENT FOR LIME PRODUCTION}

The manufacture of lime $(\mathrm{CaO})$ involves the calcination of limestone (basically $\left.\mathrm{CaCO}^{3}\right)$ to drive off $\mathrm{CO}_{2}$ gas. Most lime in the United States is produced by rotary kilns, but there are still a number of shaft kiln operations.

The average rotary lime kiln, without elaborate heat-recovery devices, requires about 7 million Btu per ton of product. In lime plants, the auxiliary equipment is not elaborate. Thus; there would appear to be a good possibility of obtaining increased capacity from a lime kiln by use of enriched air.

The basic advantage of oxygen enrichment is a higher flame temperature, which, in turn, increases the rate of heat transfer to the limestone. The smaller proportion of nitrogen in the combination gases also frees more heat for useful consumption. As a result, the throughput of material can be increased or the fuel consumption can be decreased.

The possible effect of increased temperature on the limestone and calcined lime introduces a degree of caution in lime burning. Some investigations have shown that calcination of limestone. at a temperature high enough to induce molecular mobility and crystal growth causes impurities contained in the stone to migrate to the grain boundaries of the crystals. Extensive surficial concentration of impurities can have a detrimental effect on the reactivity of the lime.

If a highly active lime is desired, overheating may have a detrimental effect even on very pure lime. The process of calcination produces a lime with a porosity of about $57 \%$, as a result of the escape of $\mathrm{CO}_{2}$ molecules from the structure. Excessively high temperatures will tend to close these voids, through recrystallization and consolidations, and reduce the activity of the material.

These considerations point to the fact that lime manufacturers do not desire high calcination temperatures but, rather, greater uniformity of temperature and atmosphere composition in the calcining furnace. Hence, the effective application of enriched air to lime-burning will entail a development program designed to minimize the possible adverse effects of the hotter flame.

It is conservatively estimated that with $26 \% \mathrm{O}_{2}$ contained in enriched air, there would be a $10 \%$ fuel reduction with a $30 \%$ increase in production. This results in a fuel saving of 1.8 million Btu per ton of lime produced. Since the U.S. steel industry consumed over 7 million tons of lime ii 1976 , an energy saving of 0.012 quad is a possibility. 
It is clearly evident that commercialization of oxygen enrichment in lime manufacture cannot occur until development work has proven the technical and economic advantages. Basic research or pilot plant research is not required; commercial plant testing for a reasonable period of time is the necessary step to develop this technique for commercialization. 


\section{APPENDIX A \\ COMMENTARY ON A PROPOSAL FOR WORK ON A BLAST GASIFIER}

We understand that Arthur D. McKee, in association with a consortium of steel companies, has proposed the blast gasification concept for production of large volumes of medium-Btu gas in idle, obsolete blast furnaces in U.S. iron and steel plants. (See discussion in Section VII-7 of this report.) They claim that "upwards of 40 idle blast furnaces exist in the United States." Presumably, these furnaces could be converted to blast gasifiers. This number is entirely reasonable, since out of 195 furnaces in the U.S. industry, only 119 were "on blast" in 1976. This would leave 76 idle. During a high-production steel year, many of these would be returned to operation; however, there could reasonably be 40 that would be considered small and therefore uncconomical as pig iron producers but would represent sizable gas generators, i.e., blast gasifiers. Until a survey is made of the practicality of converting these blast furnaces into gasifiers, the real potential of this concept cannot be completely evaluated.

Large commercial gasifiers produce 12,000-16,000 SCFM of medium-Btu gas. The projected volume of medium-Btu gas from a single $17-\mathrm{ft} 3-\mathrm{in}$. hearth diameter blast furnace converted to a blast gasifier would be 48,000 SCFM of 300-Btu gas plus 169 tons per day of by-product molten pig iron, according to an analysis made by Republic Steel. Republic also estimated that the cost of converting an existing blast furnace would be less than $25 \%$ of the cost of an equivalentcapacity, medium-Btu commercial gas generator installation.

One suggestion is to produce gas at an elevated pressure (40-60 psig). We question the ability of these old blast furnaces to withstand such high top pressure and the ability of the existing blowing equipment to provide the blast.

With these reservations, we believe that the proposal has considerable merit and deserves favorable consideration for the following reasons:

1. It has the potential for producing large volumes of medium-heating-value gas, 1.e., about $300 \mathrm{Btu} / \mathrm{SCF}$. If appled to 40 old furnaces, the annual output would be about .29 quad of thermal energy in the form of low-sulfur gas that could be used in a variety of applications in the steel industry - e.g., for fuel injection into blast furnaces, underfiring coke ovens, and firing soaking pits and other reheating furnaces. The annual thermal energy output of thése 40 blast gasifiers would be slightly greater than the heating value of the net blast furnace top gas produced from 119 blast furnaces operating in 1976 . These furnaces produced $86,870,000$ tons of pig iron and 0.282 quad of net thermal energy in the form of top gas (i.e., gas that was not consumed directly at the blast furnaces).

2. An investigation into the blast gasifier will provide further insight into the practical limits of oxygen enrichment of the air blast used in pig iron blast furnaces. In present Japanese blast furnace practice, the average blast enrichment is $1.8 \%$; i.e., 
the average blast contains $22.8 \%$ oxygen. The range is frem no enrichment up to $3.5^{\prime}$ " enrichment. It is conceivable that some degree of intermediate oxygen enrichment between the extremes of $3.5 \%$ (present practice) and high-purity oxygen (blast gasifier) will be found that can be justified by increased iron production and higher-heating-value, more useful top gas. 


\section{APPENDIX B \\ COMMENTARY ON A PROPOSAL FOR DEVELOPING A MATHEMATICAL MODEL OF THE ELECTRIC ARC FURNACE STEELMAKING PROCESS}

Prof. Szekely of MIT proposes to develop a mathematical representation of heat transfer, fluid flow, and melting phenomena in the electric arc furnace, with the specific objective of providing guidelines for increasing the thermal efficiency of the process. '

In a first phase, Prof. Szekely proposes to examine the feasibility of developing the mathematical model and obtaining the substantial industrial cooperation that will be needed if the results of the work are to gain widespread practical application.

In a second phase, he proposes to assemble an interdisciplinary team for the actual development of a comprehensive mathematical model of the arc furnace and the implementation of the improved operational guidelines. This second phase would be proposed only if the results of the first phase warrant it.

In spite of numerous past investigations, there is no satisfactory theoretical account of heat transfer, fluid flow, and melting phenomena in the electric arc furnace. A better understanding of such phenomena could lead to improvements in thermal efficiency - perhaps $5 \%$ would be a reasonable goal over the coming decade. The steel industry has already shown interest in the study and would certainly be receptive to better operating ideas; implementation would then be a question of overall economics.

This work is of a theoretical nature and would certainly be expertly handled by Prof. Szekely. It could potentially result in a more energy-efficient practice for all electric arc furnace operators, including those who could never afford that type of research. Thus, modest funding by the DOE may play a meaningful role in this potential energy-conserving project.

1. A more detailed description of the proposed effort is given in an unsolicited proposal to the U.S. Energy Research and Development Administration. 


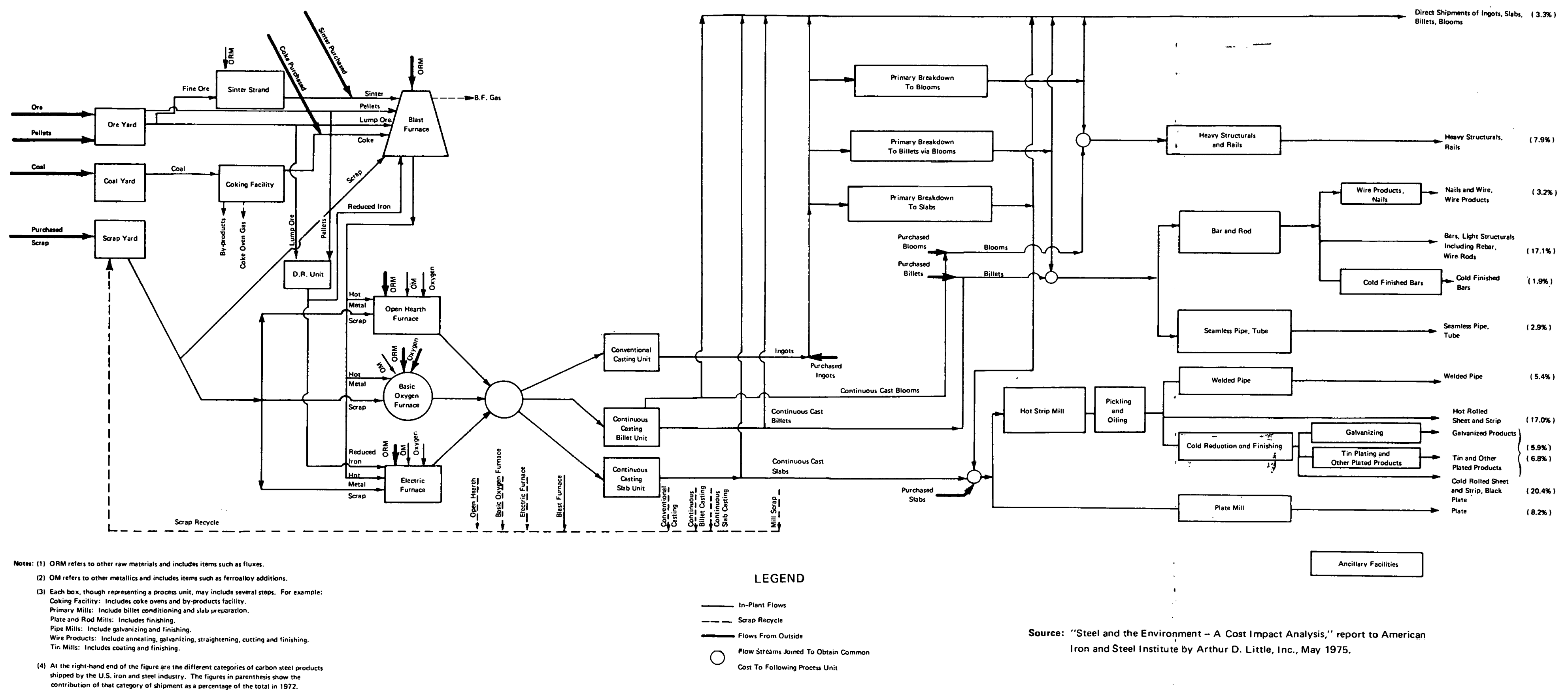

FIGURE II-3 PROCESS UNIT INTERRELATIONSHTPS 